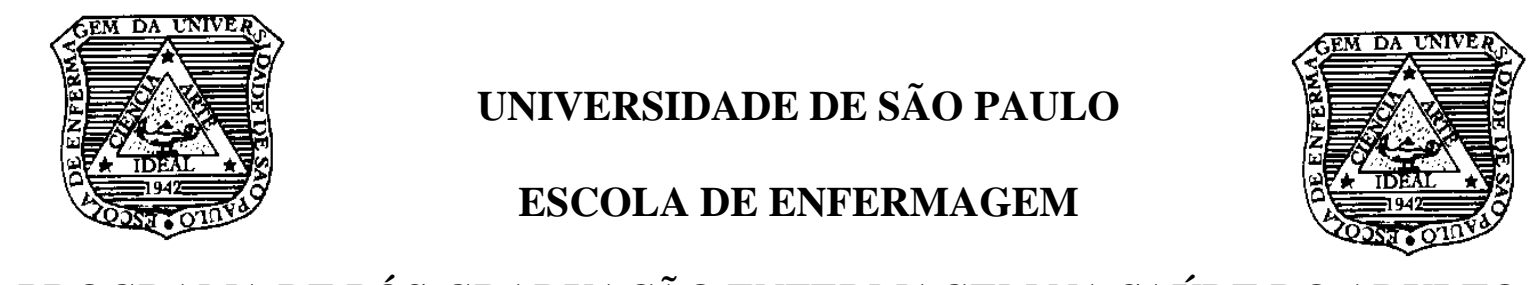

PROGRAMA DE PÓS-GRADUAÇÃO ENFERMAGEM NA SAÚDE DO ADULTO

CAMILA CRISTINE ANTONIETTI

Percepção de estresse e estilo de coping dos pacientes no período pré-procedimento colonoscópico

Orientadora:

Profa. Dra. Ana Lucia Siqueira Costa

São Paulo

2012 
UNIVERSIDADE DE SÃO PAULO

ESCOLA DE ENFERMAGEM

PROGRAMA DE PÓS-GRADUAÇÃO ENFERMAGEM NA SAÚDE DO ADULTO

CAMILA CRISTINE ANTONIETTI

\title{
Percepção de estresse e estilo de coping dos pacientes no período pré-procedimento colonoscópico
}

\author{
Dissertação apresentada à Escola de \\ Enfermagem da Universidade de São Paulo para \\ a obtenção do título de Mestre em Enfermagem \\ Área de concentração: \\ Programa de Pós-Graduação em Enfermagem na \\ Saúde do Adulto (PROESA). \\ Orientadora: \\ Profa. Dra. Ana Lucia Siqueira Costa
}

São Paulo

2012 
AUTORIZO A REPRODUÇÃO E DIVULGAÇÃO TOTAL OU PARCIAL DESTE TRABALHO, POR QUALQUER MEIO CONVENCIONAL OU ELETRÔNICO, PARA FINS DE ESTUDO E PESQUISA, DESDE QUE CITADA A FONTE.

Assinatura:

Data:

\section{Catalogação na Publicação (CIP)}

Biblioteca "Wanda de Aguiar Horta"

Escola de Enfermagem da Universidade de São Paulo

Antonietti, Camila Cristine

Percepção de estresse e estilo de coping dos pacientes no período pré-procedimento colonoscópico. / Camila Cristine Antonietti. -- São Paulo, 2012.

$134 \mathrm{p}$.

Dissertação (Mestrado) - Escola de Enfermagem da Universidade de São Paulo.

Orientadora: Prof ${ }^{a}$ Dr $^{\mathrm{a}}$ Ana Lucia Siqueira Costa

1. Estresse psicológico 2. Adaptação psicológica 3. Colonoscopia 4. Exames endoscópicos. I. Título. 
“O valor das coisas não está no tempo que elas duram, mas na intensidade com que acontecem. Por isso, existem momentos inesquecíveis, coisas inexplicáveis e pessoas incomparáveis...” Fernando Pessoa 


\section{DEDICATÓRIA}

A Deus, por nunca me deixar desistir, ensinar-me a perseverar e acreditar que não há nada nesse mundo que eu não possa alcançar, desde que mereça tal conquista. A Ele, dedico minha vida.

A meus pais, Mário José Antonietti e Hilda Silva Antonietti, por serem meus exemplos de vida e amor eterno, pela dedicação, paciência, carinho e por me ensinarem que a educação é o melhor caminho. A vocês, dedico todas as minhas conquistas, vitórias e caminhos.

A meu irmão, Gustavo Henrique Antonietti, pelo companheirismo, amizade e pelas longas conversas pelo telefone.

A meu namorado, Luiz Duarte Júnior, por me ensinar a amar, pelo companheirismo, compreensão, amor, amizade, presença, carinho, atenção e pelas longas noites fazendo-me companhia.

A meus avós, in Memoriam, por me ensinarem a amar e persistir na conquista de meus sonhos mesmo que pareçam impossíveis.

À Profa. Dra. Ana Lucia Siqueira Costa, a quem serei eternamente grata por me permitir adentrar no mundo da docência, pela amizade confiada e por toda a dedicação e paciência. Pelas idéias, críticas, sugestões e por me fazer acreditar que este fazer era possível. 


\section{AGRADECIMENTOS}

Às minhas amigas, queridas e amadas, que acompanharam nesta trajetória desde o início e apoiaram-me mesmo ficando meses sem comparecer ou responder e-mails: Fernanda, Danielle, Clara, Sheila e Carla.

A toda minha família, tios, tias, primos, primas, cunhadas, cunhados e a meu amado sobrinho Edimilsinho, por nunca me deixarem desistir mesmo com a distância e por sempre confiarem em mim.

À Escola de Enfermagem da Universidade de São Paulo, pela oportunidade de aprimorar meus conhecimentos.

Às Professoras Doutoras Estela Regina Ferraz Bianchi e Ruth Natália Teresa Turrini, pelas valiosas contribuições no Exame de Qualificação e pelo apoio e carinho durante esta trajetória.

A todos os colaboradores do Hospital Universitário da Universidade de São Paulo, sobretudo, os do Serviço de Endoscopia.

A todos os amigos do Hospital Paulistano pelo apoio e amizade.

A todos vocês, muito obrigada por estarem em minha vida! 
Antonietti CC. Percepção de estresse e estilo de coping dos pacientes no período préprocedimento colonoscópico [dissertação]. São Paulo: Escola de Enfermagem, Universidade de São Paulo; 2012.

\section{RESUMO}

Introdução: A colonoscopia é um dos métodos mais completos de investigação das doenças colorretais, com vantagens por proporcionar a observação da mucosa intestinal, em tempo único e de forma direta e também por ser a técnica de maior acurácia para o diagnóstico de lesões estruturais. Salienta-se que o paciente, ao se deparar com a indicação da colonoscopia, interpreta-a como sendo um exame que provoca desconforto e desencadeia sentimentos de vulnerabilidade, vergonha, medo e ansiedade. Perante estas emoções, o procedimento poderá ser percebido como um fator estresse importante ao paciente e que requer a utilização de estratégias para o enfrentamento da situação de desafio. Objetivo: analisar a percepção de estresse e os estilos de coping em pacientes no período que antecede o procedimento colonoscópico, conforme as variáveis biossociais e clínicas. Material e método: tratase de um estudo descritivo, transversal, exploratório e de campo, com abordagem quantitativa, desenvolvido no Serviço de Endoscopia do Hospital Universitário da Universidade de São Paulo (HU-USP). Foram entrevistados 100 pacientes em período de complementação de preparo, adultos, com solicitação formal para a realização do procedimento colonoscópico. Para esta análise, foram utilizados os instrumentos Escala de Estresse Percebido (PSS - 10), o Inventário de Estratégias de Enfrentamento de Folkman e Lazarus (1985) e um roteiro de entrevista semiestruturada para caracterização da população do estudo. Resultados: o perfil biossocial da amostra foi, predominantemente, de mulheres (73\%), idade superior a 65 anos (50\%), casados ou com companheiros (90\%), com pelo menos um filho (38\%), com escolaridade superior a oito anos de estudos (33\%), que pertenciam as religiões evangélica e católica (48\% e 45\%, respectivamente), em sua maioria aposentados (48\%), com antecedentes clínicos de hipertensão arterial sistêmica (90\%) e familiar de câncer de colón (68\%); 59\% dos pacientes em período de preparo revelaram um nível médio de estresse percebido e os estilos de coping com maiores médias foram o Suporte Social $(6,43 \pm 1,54)$, Aceitação da Responsabilidade $(5,70 \pm 2,41)$ e Reavaliação Positiva $(5,64 \pm 1,41)$. As variáveis sexo, idade, estado civil, escolaridade, tipo de preparo e número de exames realizados previamente foram determinadas, como fatores preditores de estresse nessa população. As correlações estatisticamente significativas deste estudo compreenderam a associação entre o PSS-10 e as estratégias de enfrentamento Confronto, Afastamento, Suporte Social, Aceitação da Responsabilidade e Reavaliação Positiva. Entre estes preditores, houve associação do sexo feminino, da idade superior a 65 anos, dos casados ou com namorado, dos não letrados ou daqueles com $2^{\circ}$ grau completo/incompleto, do tipo de preparo ambulatorial e dos pacientes com pelo menos um exame realizado com o PSS-10 e os domínios selecionados. Conclusão: a análise da colonoscopia como fator de estresse é pouco estudada em nosso meio, assim como a associação dos processos de enfrentamento. A percepção de estresse foi maior entre os indivíduos da população da pesquisa quando comparados com a população do estudo de tradução e validação do instrumento. Quanto aos estilos de coping foram observados predomínios dos domínios com foco na emoção. Os resultados desta pesquisa permitiram o desenvolvimento de intervenções voltadas para a diminuição do estresse desses pacientes e que os estilos de enfrentamento encontrados nesta análise sejam utilizados para a melhoria da prática assistencial.

Palavra-chave: estresse psicológico, adaptação psicológica, colonoscopia, exame endoscópico. 
Antonietti CC. Perceived stress and coping style of patients in the pre-procedure colonoscopy. [dissertation]. São Paulo: Nursing School, São Paulo University; 2012.

\section{SUMMARY}

Introduction: Colonoscopy is one of the most complete methods of investigation for colorectal diseases, with several advantages. One is that it makes possible the observation of bowel mucus, directly and in a single session. Another is that it is one of the most accurate ways of diagnosing structural lesions in bowel. It is important to understand that patients who face this procedure interpret the exam as one that provokes discomfort, which leads to feelings of vulnerability, shame, fear and anxiety. In light of the emotional factors involved, the procedure may be viewed as a source of stress for the patient, and so, requires the implementation of strategies for approaching such a challenging situation. Objective: To analyze the perception of stress, according to bio-social and clinical variables, and coping styles of patients during the period preceding a colonoscopy procedure. Methods: This is a descriptive, transversal, field study with a quantitative approach developed by the Endoscopy Service of São Paulo Hospital University (HU-USP). One hundred patients in the preparatory stages were interviewed, of whom $100 \%$ were adults who had received a formal referral for the colonoscopy procedure. For the analysis, the following were employed: the Perceived Stress Scale (PSS-10), the Ways of Coping Questionare of Folkman and Lazarus (1985), as well as a semi-structured interview guide whose aim was to characterize the study population. Results: The bio-social profile of the sample population was predominantly female (73\%), 65 years or older $(50 \%)$, married or with a partner (90\%) with at least one child (38\%). The sample population also consisted of individuals with an eighth-grade or above level of education (33\%), who professed a Faith of either Catholic or Evangelical (48\% and 45\%, respectively), for the most part retired (48\%), with a history of hypertension $(90 \%)$ and a family member with colon cancer (68\%); 59\% of the patients undergoing preparations revealed a medium level of perceived stress and the coping styles most utilized by these patients were the Social Support style $(6,43 \pm 1,54)$, Acceptance of Responsibility Style $(5,70 \pm 2,41)$ and Positive Reappraisal style $(5,64 \pm 1,41)$. The variables of gender, age, marital status, schooling, type of preparation, and number of exams previously realized proved to be predictive factors of stress among this population. The statistically significant correlations within this study revealed themselves to be an association between PSS-10 and the coping strategies of Confrontive Coping, Distancing, Seeking Social Support, Acceptance of Responsibility and Positive Reappraisal. Among these predictors, an association of female, 65 years, married or with a partner, secondary schooling either complete or incomplete, with a outpatients preparation and patients with at least one procedure conducted style of PSS-10. Conclusion: The analysis of stress in the realization of colonoscopy exams is a little studied area in our field, as is the association of coping processes. The perception of stress was greater among the participants of the study, when compared with the instrument validation population. In terms of coping mechanisms, it was observed that those that focus on emotion were prevalent. The results of this study allow for a development of interventions that focus on diminishing stress in these patients. The results also permit that the coping mechanisms encountered in this analysis be utilized to better the work of care practitioners.

Keywords: psychological stress, psychological adaptation, colonoscopy, imaging exams. 


\section{LISTA DE TABELAS}

Tabela 1 - Distribuição dos pacientes em período de preparo para colonoscopia, conforme as características biossociais quanto a sexo, faixa etária, estado civil, número de filhos, religião, escolaridade e profissão. São Paulo, 2011 ......................................... 55

Tabela 2 - Distribuição dos pacientes em período de preparo para colonoscopia, conforme história clínica e de neoplasia pessoal e familiar. São Paulo, 2011

Tabela 3 - Distribuição dos pacientes em período de preparo para colonoscopia, conforme variáveis inerentes ao próprio procedimento. São Paulo, 2011

Tabela 4 - Distribuição dos pacientes em período de preparo para colonoscopia, conforme os sentimentos que os acometem. São Paulo, 2011

Tabela 5 - $\quad$ Resultados da correlação item total, do alfa de Cronbach para os dez itens da Escala de Estresse Percebido - PSS - 10. São Paulo, 2011

Tabela 6 - Resultados dos coeficientes de correlação alfa de Cronbach para o Inventário de Estratégias de Enfrentamento de Folkman e Lazarus, conforme os fatores e o número de itens. São Paulo 2011

Tabela 7 - Distribuição das pontuações mínimas, máximas, médias e desvio-padrão da Escala de Estresse Percebido - PSS - 10 dos 100 indivíduos do estudo. São Paulo - 2011

Tabela 8 - Distribuição das pontuações mínima, máxima, média e desviopadrão dos fatores de coping dos 100 indivíduos em período de preparo para a colonoscopia. São Paulo, 2011

Tabela 9 - $\quad$ Resultados do modelo de regressão linear múltiplo para a Escala de Estresse Percebido - PSS - 10, conforme as variáveis selecionadas. São Paulo - 2011

Tabela 10 - Resultados do modelo de regressão linear múltiplo para os domínios selecionados do Inventário de Estratégias de Enfrentamento de Folkman e Lazarus, conforme as variáveis selecionadas. São Paulo, 2011 
Tabela 11 - Resultados do Coeficiente de correlação para Escala de Estresse Percebido - PSS - 10 e os domínios de enfrentamento selecionados. São Paulo, 2011

Tabela 12 - Resultado da comparação das médias e desvio-padrão por agrupamento da variável sexo, conforme a Escala de Estresse Percebido - PSS - 10 e os domínios de enfrentamento selecionados. São Paulo, 2011

Tabela 13 - Resultado da comparação das médias e desvio padrão por agrupamento da variável idade, conforme a Escala de Estresse Percebido - PSS - 10 e os domínios de enfrentamento selecionados. São Paulo, 2011

Tabela 14 - Resultado da comparação das médias e desvio padrão por agrupamento da variável estado civil, conforme a Escala de Estresse Percebido - PSS - 10 e os domínios de enfrentamento selecionados. São Paulo, 2011

Tabela 15 - Resultado da comparação das médias e desvio padrão por agrupamento da variável escolaridade, conforme a Escala de Estresse Percebido - PSS - 10 e os domínios de enfrentamento selecionados. São Paulo, 2011

Tabela 16 - Resultado da comparação das médias e desvio padrão por agrupamento da variável tipo de preparo, conforme a Escala de Estresse Percebido - PSS - 10 e os domínios de enfrentamento selecionados. São Paulo, 2011

Tabela 17 - Resultado do coeficiente de regressão da variável número de exames realizados, conforme a Escala de Estresse Percebido PSS - 10 e os domínios de enfrentamento selecionados. São Paulo, 2011. 


\section{LISTA DE FIGURAS}

Figura 1 - Adaptação das diferentes fases de avaliação do evento estressor, conforme Folkman e Lazarus ........................................................... 31

Figura 2 - Histograma da dos valores de frequência e média da escala de Estresse Percebido - PSS - 10 dos pacientes em período précolonoscópico. São Paulo - 2012 ....................................................... 65 


\section{SUMÁRIO}

1 INTRODUÇÃO ....................................................................................................... 14

1.1 Aspectos relevantes do procedimento colonoscópico .................................. 16

1.2 Estresse e Estilos de Coping dos pacientes em período préprocedimento colonoscópico .................................................................. 21

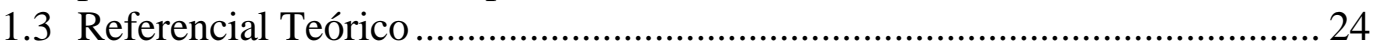

1.3.1 Base teórica da pesquisa............................................................. 24

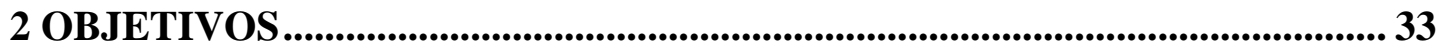

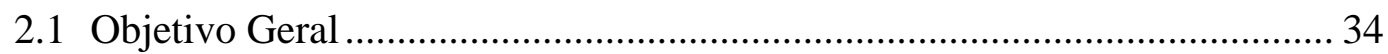

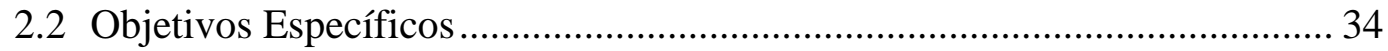

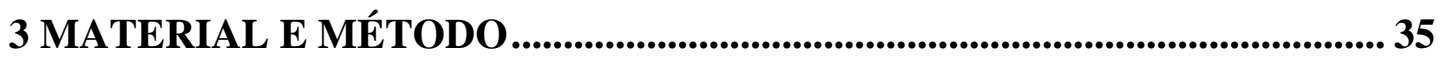

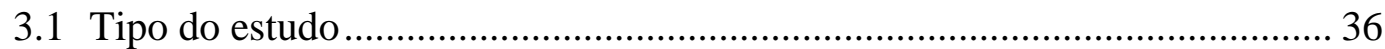

3.2 Caracterização e local do estudo ................................................................ 36

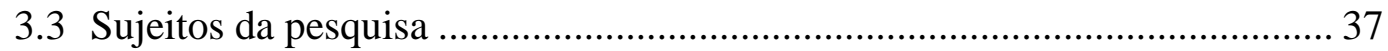

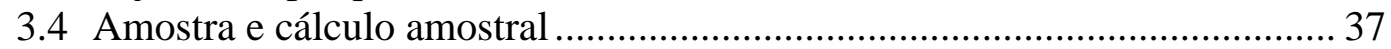

3.5 Dinâmica de atendimento e coleta dos dados.............................................. 38

3.6 Proteção dos pacientes da pesquisa ........................................................ 40

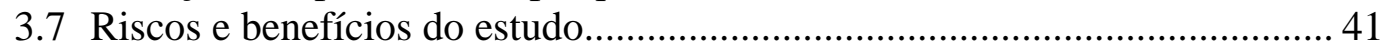

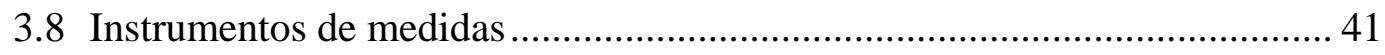

3.8.1 Caracterização biossociais, clínicas e inerentes ao procedimento .... 41

3.8.2 Escala de Estresse Percebido............................................................. 42

3.8.3 Inventário de Estratégias de Enfrentamento de Folkman e Lazarus - Ways of Coping Questionare............................................ 44

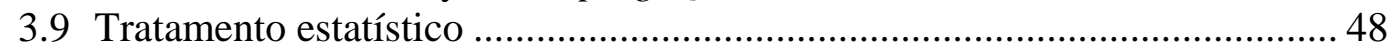

3.9.1 Agrupamento dos dados coletados ............................................... 48

3.9.2 Confiabilidade dos instrumentos da pesquisa .................................. 49

3.9.3 Apresentação e análise dos dados ..................................................... 50

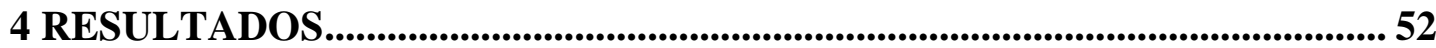

4.1 Apresentação descritiva dos dados............................................................. 54

4.1.1 Caracterização da população, conforme características

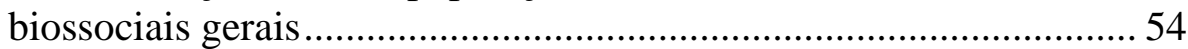

4.1.2 Caracterização da população conforme características clínicas.......... 57

4.1.3 Caracterização da população conforme as variáveis referentes ao

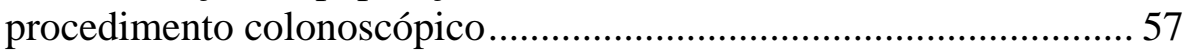

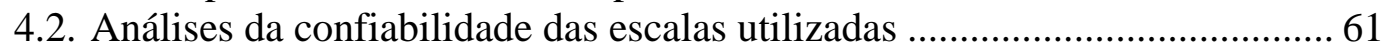

4.2.1 Escala de Estresse Percebido - PSS - 10....................................... 61

4.2.2 Inventário de Estratégias de Enfrentamento de Folkman e

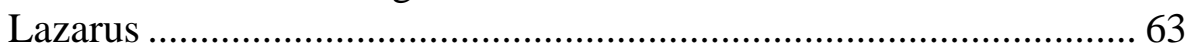

4.3 Descrição da pontuação dos instrumentos utilizados ................................... 64

4.3.1 Escala de Estresse Percebido - PSS - 10........................................... 64

4.3.2 Inventário de Estratégias de Enfrentamento de Folkman e Lazarus 
4.4 Modelo de Regressão Linear Múltiplo para a Escala de Estresse Percebido - PSS - 10 e Inventário de Estratégias de Enfrentamento de Folkman e Lazarus

4.4.1 Modelo de Regressão Linear Múltiplo para a Escala de Estresse Percebido - PSS-10.

4.4.2 Modelo de Regressão Linear Múltiplo para o Inventário de Enfrentamento de Folkman e Lazarus

4.4.3 Correlação entre a Escala de Estresse Percebido - PSS - 10 e os domínios de enfrentamento selecionados......................................... 72

4.4.4 Comparação por agrupamentos.................................................... 73

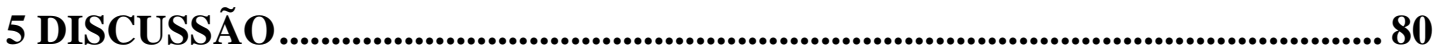

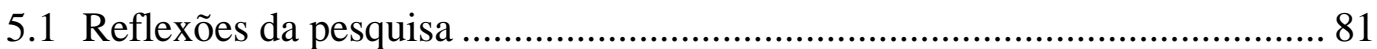

5.2 Características da população do estudo quanto aos aspectos biossociais, clínicos

5.3 Estresse Percebido, fatores preditores de estresse e Estilos de Coping para pacientes em período pré-procedimento colonoscópico

6 CONCLUSÕES 100

7 CONSIDERAÇÕES FINAIS 104

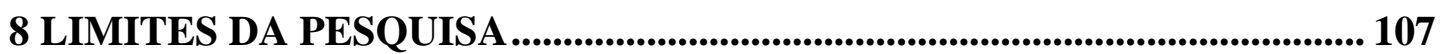

9 REFERÊNCIAS ......................................................................................... 109

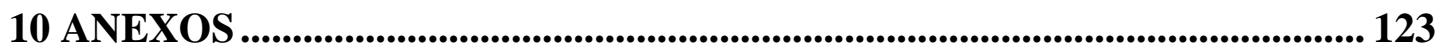

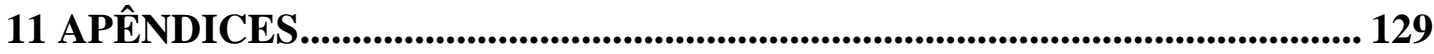


INTRODUÇÃO 
"Se nada nos salva da morte, pelo menos que o amor nos salve da vida"

Pablo Nerruda

Mesmo com poucos anos de prática profissional em Enfermagem, muitos foram os momentos em que me confrontei com afirmações dos pacientes sobre as situações conflituosas vivenciadas no período que estão prestes a receber informações diagnósticas ou quando irão se submeter a procedimentos terapêuticos, sobretudo os relacionados à Gastroenterologia.

Os principais questionamentos revelavam sensações de medo frente ao procedimento desconhecido e possível resultado, a necessidade de drogas para sedação e os fatores de risco a elas relacionadas, o desconforto frente ao longo e difícil preparo para a realização do procedimento e, no caso da Colonoscopia, o preconceito muitas vezes presente entre os pacientes por precisar realizá-la.

Essas indagações provocaram-me o levantamento de inúmeras inquietações sobre os sentimentos vivenciados por esses pacientes que, com frequência, apresentavam alterações emocionais e comportamentais importantes desencadeadas por esse método de diagnóstico e tratamento.

$\mathrm{Na}$ tentativa de compreender as alterações emocionais vivenciadas por esses pacientes esta pesquisa teve a finalidade de conhecer os fatores mais relevantes para desencadeamento das alterações emocionais e comportamentais de estresse e o estilo de coping ${ }^{1}$ utilizado pelos pacientes na fase que antecede o procedimento colonoscópico.

\footnotetext{
${ }^{1}$ Neste estudo serão utilizados dois termos para definição das estratégias utilizadas pelos pacientes: a palavra "coping" em sua versão em inglês e sem aspas por ser um termo adotado universalmente e a palavra enfrentamento. Mesmo ciente que o termo enfrentamento não expressa toda a essência da palavra "coping" na língua portuguesa.
} 


\subsection{ASPECTOS RELEVANTES DO PROCEDIMENTO COLONOSCÓPICO}

Atualmente, com o desenvolvimento dos recursos técnicos, nos quais incluem-se a informática, a cromoscopia e a magnificação da imagem, aliados aos equipamentos de vídeo e imagem, verifica-se uma grande evolução dos métodos de tratamento ou diagnósticos por imagem na prática assistencial. No entanto, a colonoscopia destaca-se na Gastroenterologia, por ser um método minimante invasivo e seguro com muitos benefícios para o maior número de pacientes ${ }^{(1)}$.

Mesmo considerando os benefícios da colonoscopia para o diagnóstico ou tratamento de doenças colorretais, estudos analisam o impacto desse procedimento na esfera emocional dos pacientes ${ }^{(1-3)}$. A ansiedade foi investigada e correlacionada com maiores necessidades de sedativos e analgésicos pelos pacientes durante a realização do procedimento e, neste contexto, destaca-se a importância exercida pela equipe de cuidado (médico e enfermagem) para diminuição da ansiedade por meio das orientações e diálogo pré-procedimento a fim de minimizar possíveis intercorrências e favorecer a realização do procedimento colonoscópico ${ }^{(2-3)}$.

A colonoscopia é um dos métodos mais completos de investigação das doenças colorretais, com vantagens sobre os demais por proporcionar a observação da mucosa intestinal, em tempo único e de forma direta e também por ser a técnica com maior acuidade para o diagnóstico de lesões estruturais $(4-5)$

Além disso, possibilita o diagnóstico prematuro de doenças, antecipando a escolha terapêutica para resultados mais satisfatórios, com melhor perspectiva de evolução ou cura da doença e por permitir ser complementado por biópsias e exames laboratoriais ${ }^{(6-9)}$.

Historicamente, a avaliação do colón já é conhecida desde os primórdios dos estudos em Gastroenterologia. Há inúmeros relatos e técnicas descritas, como no mais antigo papiro médico egípcio de "George Ebers", na Grécia antiga, que destaca os estudos de Hipócrates. Já no século passado, 
Desormeaux descreveu um instrumento rígido, com iluminação própria para examinar o reto e cólon sigmóide que, posteriormente, foi redesenhado e proporcionou melhora na sua utilização frente aos exames radioscópicos contrastados ${ }^{(10)}$.

Com o advento de equipamentos de fibras ópticas flexíveis e controláveis pelo examinador foi possível a observação de todo o colón e íleo terminal, o que revolucionou o diagnóstico e o tratamento das doenças coloproctológicas ${ }^{(9-10)}$.

Por meio dessas inovações foi possível fazer uma diferenciação na indicação do procedimento colonoscópico em duas vertentes básicas: diagnóstica e terapêutica. No procedimento diagnóstico, a indicação concentra-se na presença de hemorragia digestiva baixa, na pesquisa de sangue oculto positivo em fezes, na queixa de alteração do hábito intestinal, na dor abdominal recente, na avaliação de imagens radiológicas duvidosas ou em casos de lesões já diagnosticadas com intuito de avaliar o surgimento de novos pólipos ou tumores, no acompanhamento de doenças inflamatórias ou diverticulares e, ainda, no acompanhamento de pacientes tratados cirurgicamente para extirpação de tumores colorretais ${ }^{(10)}$.

As demais indicações correlacionam-se à prática terapêutica: polipectomias, hemostasia de lesões sangrantes, retirada de corpos estranhos, tunelização tumoral e descompressão cólica ${ }^{(10-12)}$.

O procedimento colonoscópico pode ser realizado em qualquer faixa etária, com a inclusão dos extremos de idade, contudo, observa-se uma literatura com poucos estudos que sustentem a necessidade de realização da colonoscopia em pacientes entre 11 e 20 anos, uma vez que nessa faixa etária a incidência de doenças colorretais é menos comum e a sua realização sem uma causa aparente ocasiona aumento no custo e exposição dos pacientes a riscos inerentes ao procedimento ${ }^{(13)}$.

A colonoscopia é referenciada, sobretudo, como o "padrão ouro" para o diagnóstico de patologias de cólon e reto e a primeira via de acesso para a detecção de lesões precursoras do câncer colorretal ${ }^{(10-12 ; 14-15)}$. 
A indicação do procedimento colonoscópico, como método de prevenção e detecção de neoplasias justifica-se pelo elevado número de casos novos de câncer de cólon e reto estimado para o Brasil em 2012. Espera-se número superior a 14 mil casos novos entre os homens e maior que 16 mil em mulheres. Esses valores correspondem a um risco estimado de 15 novos casos a cada 100 mil homens habitantes e 16 a cada 100 mil mulheres. Em termos de incidência, os cânceres de cólon e reto configuram-se como a terceira causa mais comum entre os homens e a segunda entre as mulheres (16). Porém, mesmo com o conhecimento desta realidade, a incorporação da colonoscopia nas políticas de prevenção de doença não é uma realidade brasileira, principalmente, nas regiões de menor recurso econômico e educacional.

Em estudo de avaliação epidemiológica e de genética molecular foi verificado que o rastreamento da doença através da colonoscopia deve seguir à seguinte classificação populacional ${ }^{(17-21)}$ :

- indivíduos de baixo risco com idade inferior a 50 anos e superior a 80 anos a colonoscopia é contra-indicada, entretanto, aqueles com idade superior a 50 anos ate 79 anos e sem outros fatores de risco para câncer colorretal, o procedimento deve ser realizado a cada dez anos;

- população de risco moderado é aquela com história familiar de câncer em um ou mais parentes de primeiro grau, história pessoal de pólipo e os indivíduos com antecedente pessoal tratados com intenção curativa, a indicação do procedimento é a cada cinco anos acima dos 40 anos ou em indivíduos abaixo de 40 anos deve ser realizada a cada dez anos;

- população de alto risco é formada por indivíduos com antecedente pessoal ou familiar de câncer, ou com diagnóstico de doença inflamatória intestinal, o procedimento deve ser realizado anualmente ou conforme o processo evolutivo da doença.

O câncer de colón quando diagnosticado em estágio inicial, estima-se uma sobrevida considerada boa com cerca de 55\% dos casos nos países desenvolvidos e $40 \%$ naqueles em desenvolvimento ${ }^{(16)}$. 
O câncer é o resultado de combinações entre fatores fisiológicos e ambientais e, para o câncer de colón, o fator de risco mais relevante é a história familiar de neoplasia de cólon e a predisposição genética para o desenvolvimento de doenças intestinais associadas também à idade avançada e dieta inadequada ${ }^{(16)}$.

Contudo, os cânceres de cólon e reto permitem detecção precoce de seus sinais e sintomas possibilitando o rastreamento e prevenção por meio de exames endoscópicos. Há dois tipos de testes realizados para o rastreamento de câncer colorretal, o primeiro, é o diagnóstico de sangue oculto nas fezes e, o segundo, por meio de equipamentos endoscópicos, sejam eles, a sigmoidoscopia flexível ou a colonoscopia; entretanto, a colonoscopia possibilita diagnóstico e remoção de lesões planas ou pólipos, diminuindo a incidência e mortalidade por esse tipo de neoplasia ${ }^{(21-22)}$.

O fator de maior associação à qualidade e acurácia do procedimento colonoscópico é o método de preparo intestinal. O método ideal deve considerar vantagens em relação à eficácia, à segurança, ao custo, à facilidade de administração e à tolerância do paciente, porém, nem sempre todas estas prerrogativas são contempladas ${ }^{(22)}$.

Dentre os produtos existentes na literatura, o Manitol $^{\circledR}$ e o Polietilenoglicol ${ }^{\circledR}$ são os mais utilizados, sendo ambos de uso seguro e efetivo, quando se necessita de um preparo do cólon com qualidade. No dia que antecede o procedimento, a não ser por alguma contraindicação, o paciente é orientado a ingerir dieta sem resíduos e a fazer uso de quatro comprimidos de Bisacodil ${ }^{\circledR(22)}$. Para complementação do preparo, no dia do exame, o paciente deverá ingerir $400 \mathrm{ml}$ de manitol ${ }^{\circledR}$ a $20 \%$ diluídos em $400 \mathrm{ml}$ de água ou suco sem resíduo ou $3.000 \mathrm{ml}$ de Polietilenoglicol ${ }^{\circledR}$ (PEG) (23). Com este preparo, frequentemente, os pacientes referem sensação de desconforto e sintomas de mal estar e fraqueza após inúmeras evacuações, o que contribuem como uma barreira negativa e a menor adesão ao procedimento colônico ${ }^{(22-23)}$. 
O preparo de cólon adequado facilita a visualização de lesões precursoras do câncer colorretal e diminui o risco de negligenciamento dessas lesões e suspensão do próprio procedimento ${ }^{(22)}$.

Os idosos podem apresentar menor tolerabilidade ao preparo colônico, sobretudo aqueles que possuem comorbidades cardiopulmonares e alterações de eletrólitos. O resultado dessas condições leva ao aumento dos efeitos adversos causados pelo preparo, bem como implica maior dificuldade técnica para realização do procedimento, entretanto, não impossibilita a realização do mesmo, somente implica em maiores cuidados durante a realização do preparo intestinal dos idosos ${ }^{(21-22)}$.

Nos últimos anos, a indicação da colonoscopia vem aumentando e, como consequência, maior incidência de complicações. Mesmo com esse aumento, a literatura é unânime ao considerar que o risco é menor quando comparado ao ganho que o procedimento traz na investigação de tumores colorretais e lesões precursoras de câncer de colón ${ }^{(8-9)}$.

Sangramento e perfuração intestinais são as complicações mais frequentes após a realização da colonoscopia seguida por polipectomia. Assim, estas devem ser realizadas de forma criteriosa e com técnica adequada. As perfurações colônicas associadas a colonoscopia são complicações mórbidas que geralmente necessitam de laparotomia de urgência ${ }^{(14-15)}$.

A hipóxia é a complicação mais frequentemente associada à sedação e pode ocorrer entre $17 \%$ e $70 \%$ dos doentes. Este evento relaciona-se com a dosagem das drogas administradas e aos fatores individuais como idade, insuficiência hepática ou pulmonar, anemia e instabilidade hemodinâmica. A criteriosa seleção de doentes, o uso da monitorização com oximetria de pulso, o emprego correto de medicação sedativa, bem como a disposição de suporte ventilatório para emergências constituem medidas eficazes na prevenção e tratamento da hipóxia ${ }^{(15,24)}$.

Atualmente, é possível a realização de procedimentos diagnósticos e terapêuticos com maior segurança. Os mais comumente realizados são 
biópsias, polipectomias, mucosectomias, tatuagem de lesões suspeitas para posterior ressecção ou revisão endoscópica, coloração de mucosa a fim de identificar limites de lesão e magnificação de superfícies e sua melhor caracterização. Pode-se assim confirmar que a colonoscopia tornou-se o método principal na busca do diagnóstico das doenças colorretais, sobretudo os tumores e suas lesões precursoras, os pólipos ${ }^{(4-5,8-10)}$.

\subsection{ESTRESSE E ESTILOS COPING DOS PACIENTES EM PERÍODO QUE ANTECEDE O PROCEDIMENTO COLONOSÓPICO}

Salienta-se que independente da necessidade, o paciente ao se deparar com a indicação do procedimento interpreta-a de diferentes formas, ou seja, um exame que causa desconforto e que desencadeia sentimentos de vulnerabilidade ou perigo, vergonha, medo e ansiedade (11). Estas características podem resultar em procedimentos mais dolorosos, com maior dificuldade técnica e risco para complicações ${ }^{(8,11-12)}$.

Com relação aos anseios sobre o procedimento, em pacientes adultos e jovens, o principal questionamento relaciona-se à dor e atitudes de maior apreensão e preocupação com o procedimento quando comparado aos indivíduos idosos. Já entre os idosos, o maior temor está em relação ao resultado do exame e à possibilidade de diagnósticos de maior gravidade ${ }^{(11)}$.

O conhecimento das complicações associadas à colonoscopia (sangramento, perfuração e alteração cardiopulmonar associadas à sedação) permite ao indivíduo um enfrentamento antecipado e possibilita o planejamento de ações com o propósito de vencer as dificuldades, mobilizar esforços de enfrentamento com o envolvimento de emoções positivas, como esperança e confiança ${ }^{(1-5,8)}$.

A possibilidade ou comprovação do diagnóstico de câncer colorretal, por meio da colonoscopia, possivelmente provoca importante impacto 
emocional, pois, representa uma caminhada dolorosa e progressiva quando não curável.

A avaliação do impacto psicológico dos pacientes que participaram de rastreamento do câncer colorretal através da colonoscopia, demonstrou que os indivíduos com risco elevado de câncer apresentaram maior preocupação na fase inicial do diagnóstico de pólipos intestinais e da polipectomia do que os demais grupos considerados sem ou de baixo risco para o surgimento de pólipos, entretanto, o monitoramento frequente proporcionou diminuição do nível de ansiedade e o desconforto dos pacientes ${ }^{(17)}$.

A atitude do paciente frente ao câncer sofre influência de fatores culturais, étnicos, sociais, econômicos, educacionais entre outros e pode, consequentemente, provocar sentimentos negativos e dificultar a elaboração das estratégias de enfrentamento. Estas estratégias quando bem utilizadas, podem contribuir e facilitar de forma mais realista e positiva para aceitação do diagnóstico e tratamento ${ }^{(18)}$.

A baixa tolerância a colonoscopia deve-se, muitas vezes, a seu processo natural que inclui fatores relacionados ao preparo do cólon, à expectativa de dor, aos sedativos e o diagnóstico desfavorável implicam em baixa adesão ao procedimento ${ }^{(12)}$.

A relação entre a quantidade de procedimentos realizados e o grau de expectativa pré-exame entre os pacientes submetidos a vários procedimentos conclui que progressivamente apresentam diminuição dos sentimentos de preocupação e estresse frente ao mesmo ${ }^{(11)}$.

Outro estudo sobre a temática revela que a ansiedade em pacientes em preparo para procedimentos não invasivos é menor, quando estes já realizaram esse exame previamente, pois há a modulação e escolha de estratégias que minimizem o seu estado emocional ${ }^{(13)}$.

Com relação à prática de sedação e analgesia durante os procedimentos endoscópicos gastrointestinais, estudo revela ser este motivo de preocupação para os pacientes, afinal, posteriormente à sedação, o indivíduo não terá controle da situação, assim como, limitará a possibilidade 
de avaliar e interagir com o ambiente e os profissionais envolvidos no cuidado ${ }^{(24)}$. Entretanto, sabe-se que a sedação na colonoscopia tem sido empregada com o objetivo de minimizar o desconforto do paciente e facilitar a realização do exame, mas não como método de diminuição da ansiedade e estresse.

Apesar do reconhecimento da importância da prática da sedação para o alívio do desconforto e ansiedade, terapias não-farmacológicas têm sido empregadas para minimizar os potenciais riscos relacionados à sedação e diminuição das quantidades de sedativos utilizados nos procedimentos. A musicoterapia destaca-se como relevante, pois, permite o relaxamento e a diminuição do estresse, já na fase anterior ou intraexame ${ }^{(25)}$.

Outras características, tais como o tempo de espera para realização do procedimento, a possibilidade do diagnóstico desfavorável, o estigma que o exame como vexatório e vergonhoso e a falta de conhecimento prévio podem elevar a ansiedade e provocar alto grau de estresse na fase que antecede o procedimento ${ }^{(11)}$. A educação do paciente tem como objetivo permitir a sua participação no processo decisório do tratamento, a diminuir a ansiedade e o estresse situacional e contribuir para que os processos de enfrentamento sejam mais efetivos ${ }^{(26)}$.

Estudo revela que a informação escrita é bem aceita, entretanto, requer o mínimo de alfabetização e motivação por parte dos pacientes ou acompanhantes em ler o material fornecido. Foi verificado, também, que a oferta de informações em vídeo como estratégia de enfrentamento permitiu aos pacientes maiores conhecimento sobre o procedimento, independente da idade, sexo ou nível educacional, com significativa redução da ansiedade e estresse $^{(26)}$.

Observou-se que pesquisas sobre a colonoscopia tenham seus focos centrados na área médica e em suas diferentes técnicas para a realização do procedimento, nos diferentes métodos de preparo de cólon e a sensação de conforto do paciente, no custo e efetividade do procedimento nas diferentes realidades sócio econômicas e na padronização de condutas de rastreamento 
do câncer colorretal ${ }^{(1-8,11-14)}$. Porém, constata-se que na literatura científica nacional, em especial, na enfermagem, nenhum estudo encontrado se concentra na área dos procedimentos diagnósticos e terapêuticos por imagem nos aspectos de estresse e enfrentamento.

Frente a esta realidade, nesta pesquisa pretende-se conhecer os aspectos que contribuem para que os pacientes tenham maior percepção de estresse frente ao procedimento, assim como, conhecer as estratégias enfrentamento mais utilizadas pelos mesmos. A partir deste conhecimento pretende-se desenvolver estudos futuros de intervenção que contribuam com as melhores práticas de assistência na Enfermagem em Gastroenterologia.

\subsection{REFERENCIAL TEÓRICO}

\subsubsection{Base teórica da pesquisa}

Como o foco desta pesquisa se concentra na análise do estresse e o estilo de enfrentamento utilizado pelos pacientes partiu-se para a busca de sustentação teórica e tomou-se como base autores cujas concepções se baseiam na interação do indivíduo e o seu ambiente e na avaliação cognitiva do acontecimento.

O termo estresse originou-se no início do século XIX, quando especialistas anglo-saxões passaram a nomeá-lo para indicar uma tensão resultante de determinada força aplicada em um corpo até seu ponto de ruptura ${ }^{(27)}$.

Para as ciências biológicas, os primeiros estudos iniciaram-se a partir da metade do mesmo século e afirmavam que o equilíbrio fisiológico do organismo modificava-se em decorrência das mudanças que ocorriam em seu meio externo, portanto, um indivíduo quando deparado com um evento 
estressor que alterasse o mecanismo de balanceamento interno poderia restabelecer os padrões de origem por meio de esforços adaptativos ${ }^{(27)}$.

O mecanismo foi definido, posteriormente, como "homeostase" indicando o esforço dos mecanismos fisiológicos corporais manterem-se em equilíbrio ${ }^{(27-29)}$.

Baseado nesta definição, o conceito de estresse foi definido como um estado que se caracteriza por uma alteração fisiológica processada no organismo em situação onde há uma reação sistêmica que desencadeie uma atividade anormal no organismo. Constitui-se, portanto, em uma reação inespecífica a qualquer alteração que exija uma adaptação frente ao evento de estresse ${ }^{(27)}$.

Observações das alterações físico-químicas do organismo permitiram denominar o estresse como uma situação manifestada por uma síndrome, a "síndrome de adaptação geral (SAG)" (27).

A expressão síndrome provém das manifestações parcialmente independentes e coordenadas entre si. A síndrome é geral, porque condiciona fenômenos generalizados de defesa. O termo adaptação indica aquisição e manutenção de estado de resistência ou equilíbrio ${ }^{(27)}$.

É importante enfatizar que esta teoria ficou conhecida como Teoria do Estresse Biológico, com modelo trifásico do estresse. A SAG consiste, portanto, em três fases: alarme ou alerta, resistência ou adaptativa e exaustão (27).

- Reação de Alarme: ou reação de alerta, corresponde ao início da resposta ao agente estressor, inconsciente ou não, há mobilização total das forças de defesa desencadeadas via sistema nervoso autônomo. Alguns sintomas característicos desta fase são: taquicardia, sudorese, cefaleia, alterações da pressão arterial, irritabilidade, fadiga. Com a cessação dos estímulos, há o retorno à homeostasia, porém, se este se mantém, dá-se início à segunda fase do processo; 
- Reação de Resistência: ansiedade, isolamento social, diminuição da potência sexual, falta ou excesso de apetite e medo são alguns dos sintomas característicos desta fase que, diferente da anterior, as reações tornam-se opostas e, consequentemente, ocorre o desaparecimento dos sintomas iniciais e a ativação do eixo hipotálamo-hipófise-suprarrenal. Caso a exposição prolongue-se, inicia-se a fase de exaustão;

- Reação de Exaustão: fase semelhante à inicial, porém, com secreção excessiva de hormônios da glândula supra-renal (mineralocorticóides e glicocorticoides), que se caracteriza por uma falha do controle homeostático com consequentes manifestações de doenças relacionadas ao estresse.

Em meados da década de 1980, outros autores trouxeram importantes contribuições para uma análise abrangente do tema estresse, incorporando a antiga teoria o papel do aparelho psíquico ${ }^{(28)}$.

Este conceito denominado "modelo interacionista ou transacional" propõe que a avaliação dos estressores pelo sujeito seja feita por um processo cognitivo, ou seja, uma avaliação subjetiva individual para uma melhor resposta ao estresse. Neste caminho, foi proposto que o estresse seja uma resposta a qualquer evento que demande do ambiente externo ou interno, e que exceda as fontes de adaptação de um indivíduo ${ }^{(28)}$.

Neste modelo, o estresse é definido como uma transação entre a pessoa e o meio, caracterizada pelo desequilíbrio entre os recursos do indivíduo e a demanda percebida. Entende-se, portanto, ser essencial a presença de dois componentes para o processo: a exigência da situação estressante e a capacidade de superação ou não do indivíduo ${ }^{(28)}$.

A existência de situações e condições dinâmicas no ambiente pode ser percebida pelo indivíduo como uma oportunidade, um limite ou uma demanda, porém o fator determinante está na percepção da condição, como estressante ou não. A capacidade individual de atender e corresponder às exigências frente ao estresse determina quantos elementos adaptadores serão utilizados ou reconhecidos ${ }^{(28)}$. 
Ainda, apoiando-se nesta concepção, admite-se estresse positivo, quando o desequilíbrio é percebido como oportunidade; e, negativo quando é observado como uma exigência ou limitação. O tipo de estresse (de demanda, oportunidade ou limitação) está associado a diferentes sintomas físicos, psicológicos ou comportamentais ${ }^{(28)}$.

Portanto, as situações são consideradas estressantes, mesmo em meio a um esforço cognitivo e comportamental, quando estas excedem ou estão no limite dos recursos individuais para lidar com as mesmas. As circunstâncias originam adaptação ou habilidades para lidar com as mesmas e são denominadas coping, estratégias ou processos de enfrentamento frente aos estressores ${ }^{(28-29)}$.

O coping é conceitualizado como "tentativas de mudanças comportamentais e cognitivas constantes para lidar com demandas externas e/ou internas específicas que são avaliadas como exigindo ou excedendo os recursos da pessoa" ${ }^{(28)}$.

As experiências estressantes devem ser analisadas como interações entre o indivíduo e o ambiente, nas quais o impacto causado é mediado pela avaliação cognitiva e pelos recursos psicológicos, sociais e culturais de que o indivíduo dispõe ${ }^{(28-32)}$.

De acordo com o modelo interacionista, na avaliação do evento ocorre o seguinte processo (ver Figura 1) ${ }^{(28-29)}$ :

- Avaliação primária: o indivíduo avalia o significado do acontecimento e a possibilidade de essa situação interferir em seu bem-estar. O processo avaliativo ocorre via sistema límbico, tálamo e hipotálamo. Os acontecimentos poderão ser classificados como irrelevantes, positivos/adequados ou ameaçadores. Os processos irrelevantes ou positivo/adequado são vistos com segurança, não apresentam ameaça e sem necessidade de esforço para o controle da situação.

- Avaliação secundária: ocorre nos centros cognitivos de avaliação e de análise do acontecimento. Neste julgamento são analisados a capacidade 
de controle e os recursos de enfrentamento disponíveis para determinada situação. Quanto maior a avaliação de risco maior será o grau de estresse.

- Reavaliação: ocorre reavaliação das ações realizadas para o controle da situação e dos estímulos estressantes. A consciência e os sistemas cerebrais avaliam as ações realizadas e, caso os resultados não sejam satisfatórios, novas estratégias serão utilizadas, com possibilidade de desenvolver os processos orgânicos e psíquicos de estresse. Para processos em que se observa sucesso na resolução, passam a não ser mais considerados como estresse.

Conforme o referencial de Folkman e Lazarus o estresse surge como uma resposta máxima ao organismo até que estratégias de enfrentamento ou adaptação atenuem o seu efeito. Considera-se este processo com relação direta ao significado do evento e dependente do contexto sócio cultural do indivíduo ${ }^{(28)}$.

De acordo com Folkman e Lazarus, os indivíduos recorrem a diferentes estratégias para o enfrentamento das situações. Estas foram agrupadas em domínios de coping e podem ser utilizadas simultaneamente conforme a exigência da situação ${ }^{(28-29)}$.

São elas: Confronto - Confrontive coping; Afastamento - Distancing; Autocontrole - Self-controlling; Suporte Social - Seeking Social Support; Aceitação de responsabilidade - Acceptance of Responsibility; Fuga e esquiva Escape-avoidance; Resolução de problemas - Planful Problem Solving; Reavaliação Positiva - Positive reappraisal ${ }^{(28-29)}$.

Estes são definidos de acordo com suas característica estratégicos, como ${ }^{(28-29)}$ :

- Confronto: incluem a visão de desafio e atenção para um aspecto da situação. Envolvem lembranças de experiências passadas e as diversas possibilidades de ações e suas conseqüências; 
- Afastamento: envolvem a negação do sentimento de medo ou de ansiedade frente a situação, o indivíduo tenta esquecer a verdade, recusando-se a acreditar em sua realidade;

- Autocontrole: são estratégias que envolvem o empenho direto do indivíduo, na tentativa de controlar a emoção advinda do problema. Os indivíduos utilizam-se da supressão dos impulsos e conscientização dos sentimentos com o intuito de não permitir a influência das emoções conflitantes;

- Suporte Social: são aquelas em que se utilizam de pessoas de seu meio social como: esposo(a), amigos(as), médicos ou colegas de trabalho na tentativa de obter cooperação e ajuda para resolver seu próprio problema;

- Aceitação da Responsabilidade: utilizadas com o objetivo de aceitar a realidade da situação. O indivíduo acredita em sua responsabilidade sobre o ocorrido e decide que nada pode ser feito para mudá-lo, submetendo-se, portanto, ao curso do fato; deixa o tempo passar, como sendo a melhor forma para contornar e aceitar a situação;

- Fuga e Esquiva: tentativa de diminuir a gravidade da situação, utilizando-se de fantasias em substituição aos pensamentos reais a respeito da situação de conflito;

- Resolução de Problema: elaboração de planos e ações alternativas com o objetivo direto de resolução da situação. O indivíduo aprende novas habilidades com o problema e tenta ajustar-se para resolvê-lo;

- Reavaliação Positiva: neste domínio, incluem-se as estratégias cognitivas para aceitação da realidade existente na situação. $O$ indivíduo tenta reestruturar o acontecimento, com o intuito de encontrar alguns aspectos que melhor favoreçam. Fala coisas a si próprio com a intenção de amenizar a gravidade existente e concentra-se nos aspectos positivos da situação, como forma de amenizar a carga do acontecimento em direção à mudança da realidade. 
Assim, as estratégias podem ser agrupadas dentro de duas dimensões básicas: coping focado no problema (função de alterar o ambiente da situação, tentativas de lidar com o impacto da situação estressante) e coping focado na emoção (regular os estados emocionais causados pelo estresse) ${ }^{(28-}$ 30).

Em geral, as formas de coping centradas na emoção ocorrem quando já houve uma avaliação de que nada pode ser feito para modificar as condições de dano, ameaça ou desafio ambientais; já as formas centradas no problema são mais utilizadas quando tais condições são avaliadas como fáceis de mudar.

As estratégias de coping focadas na emoção consistem nos processos cognitivos direcionados para tentativa de diminuição ou regulação da carga emotiva presente na situação estressante. Os recursos utilizados são: regulação afetiva, minimização, aceitação resignada, atenção seletiva e descarga emocional, afastamento como formas de manter a coragem e a autoestima $^{(28-32)}$.

Já as estratégias de coping centradas no problema são, frequentemente, direcionadas para a definição do problema e na busca de soluções alternativas com ponderação de custos e benefícios. As estratégias utilizadas são focadas na busca de informações e ações planejadas como forma de resolução e compreensão da situação ${ }^{(28-32)}$.

Deve-se salientar que as estratégias não são excludentes e nem, necessariamente, conscientes, sendo que, em muitas situações, elas podem ocorrer simultaneamente, como facilitadoras entre si ${ }^{(28-33)}$. 


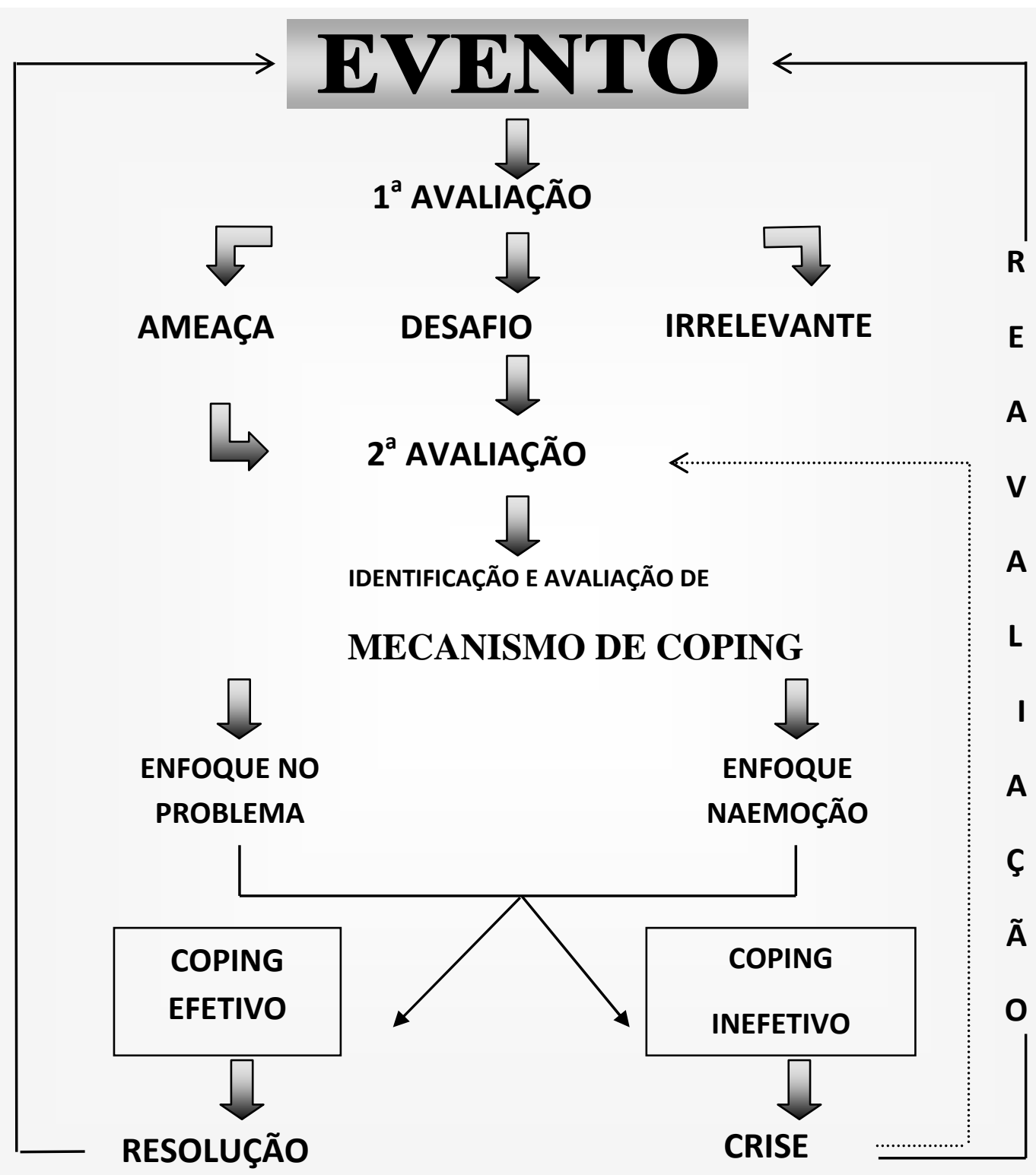

Figura 1 - Adaptação das diferentes fases de avaliação do evento estressor, conforme Folkman e Lazarus

Considera-se que múltiplas variáveis podem influir na avaliação de um determinado evento. Neste processo dinâmico, devem ser considerados os fatores individuais, como: os valores familiares e culturais, personalidade, história de vida, idade, sexo, crenças, experiências de coping (enfrentamento) e recursos disponíveis, entre outros ${ }^{(28-29)}$.

No entanto, é importante destacar que o coping depende da situação estressante específica, pois a natureza do estressor influencia a seleção das respostas de coping ${ }^{(29)}$. 
Neste referencial, vale ressaltar que os processos de coping utilizados nem sempre apresentam resultados resolutivos, no sentido de neutralizá-los ou de superar o evento, consequentemente, quando a demanda está além dos recursos individuais de enfrentamento pode, inclusive, intensificar ou criar novos estressores ${ }^{(29)}$.

Quando, eventualmente, uma situação ou uma série de situações é vivenciada de maneira negativa ou estressante, o resultado obtido poderá significar um aprendizado de insatisfação e impotência. A frequência ou a continuidade dessa situação poderá acarretar o desenvolvimento de estados de insatisfação ${ }^{(29-33)}$.

Os processos de coping não são imutáveis; podem variar no transcorrer da vida, assim como para os diferentes tipos de eventos. Estas mudanças ocorrem em razão das experiências que o indivíduo adquire nas diversas situações de vida e também pela alteração do significado do evento para o próprio indivíduo. 
OBJETIVOS 
"Eu não procuro saber as respostas, procuro compreender as perguntas."

Confúcio

Considerando o procedimento colonoscópico como importante método para o diagnóstico e tratamento de doenças, a escassez de estudos com foco no cuidado de enfermagem e, ainda, na literatura científica que nos revelam alguns métodos eficazes para o controle de estresse, mas não mostram os fatores relevantes de estresse e o estilo de enfrentamento utilizado pelos pacientes que irão se submeter ao procedimento, esta pesquisa foi desenvolvida com os seguintes objetivos:

\subsection{OBJETIVO GERAL}

- ..Analisar a percepção de estresse e os estilos de coping em pacientes no período de preparo para o procedimento colonoscópico.

\subsection{OBJETIVOS ESPECÍFICOS}

- Identificar o perfil biossocial e clínico desta amostra;

- Determinar a percepção de estresse referida pelos mesmos;

- Verificar o estilo de coping mais utilizado pelos pacientes;

- Identificar os fatores preditores de estresse mais utilizados;

- Analisar a correlação existente entre os fatores preditores de estresse, percepção de estresse referido e os estilos de coping mais utilizados. 
MATERIAL E MÉTODO 
"Sábio é aquele que conhece os limites da própria ignorância."

Socrates

\subsection{TIPO DE ESTUDO}

Trata-se de um estudo descritivo, transversal, exploratório e de campo, com abordagem quantitativa.

\subsection{CARACTERIZAÇÃO E LOCAL DO ESTUDO}

O presente estudo foi realizado no Serviço de Endoscopia do Hospital Universitário da Universidade de São Paulo.

O Hospital Universitário (HU) foi inaugurado, em 1981, 14 anos após sua idealização. É um hospital localizado na Cidade Universitária Armando de Salles Oliveira que tem como finalidadeo desenvolvimento de atividades de ensino e pesquisa na área de saúde e assistência hospitalar de média complexidade. Presta assistência como hospital comunitário para os distritos do Butantã, Jaguaré, Morumbi, Raposo Tavares, Rio Pequeno e Vila Sônia, além da comunidade universitária.

Em suas instalações, possui 258 leitos (divididos entre as unidades Clínica, Cirúrgica, Obstétrica, Pediátrica); UTI de adultos com 21 leitos; UTI Pediátrica com 16 leitos; Centro Cirúrgico com sete leitos de recuperação e nove salas cirúrgicas; Centro Obstétrico com quatro salas; Ambulatório com 57 consultórios; 17 salas de aulas entre as diversas unidades e cinco anfiteatros.

O serviço de Endoscopia conta com três salas de procedimentos endoscópicos, compostas por equipamentos de vídeo e imagem, 
monitoramento cardiorrespiratório, além de equipamentos para atendimento de emergência e três leitos para recuperação pós-procedimentos. Possui também três salas de preparo para colonoscopia e uma de retaguarda para avaliação inicial do paciente e salas para as equipes de enfermagem e médica. O setor de Endoscopia do HU realiza três exames de pacientes externos e três de pacientes internos por período.

\subsection{SUJEITOS DA PESQUISA}

Para este estudo, a população constitui-se de cem pacientes agendados para realização de procedimento colonoscópico e que se enquadraram nos seguintes critérios de seleção:

- Inclusão - adultos (acima 18 anos) que tivessem solicitação formal para realização ambulatorial do exame; com capacidade de compreensão preservada; o paciente e/ou familiar após ter assinado o Termo de Consentimento Livre e Esclarecido, antes de iniciar a coleta dos dados.

- Exclusão - estar internado para tratamento clínico ou cirúrgico, adultos com doença psiquiátrica diagnosticada; fazer uso de medicamentos psicotrópicos e que tivessem algum dano cognitivo aparente.

\subsection{AMOSTRA E CÁLCULO AMOSTRAL}

O dimensionamento amostral nesta pesquisa baseou-se na regressão linear múltipla de dez preditores com tamanho de efeito de 0,35 , confiança 
de $95 \%$ e poder de teste de $90 \%$. Deste modo, a amostra determinada foi de 100 pacientes ${ }^{(39)}$.

\subsection{DINÂMICA DE ATENDIMENTO E DA COLETA DE DADOS}

O agendamento do procedimento se dá após a consulta médica, realizada no pronto-atendimento ou ambulatório. No ato do agendamento, é entregue ao paciente, pela enfermeira do serviço de Endoscopia, um folder explicativo com informações sobre o procedimento colonoscópico e o preparo necessário para ser realizado na véspera e no dia agendado para realização do procedimento. Todas as dúvidas foram esclarecidas nesse momento.

As informações do folder destacam detalhes do preparo do cólon necessário na véspera do procedimento, em que se incluem o uso do laxativo (administração de dois comprimidos em duas etapas) e dieta líquida sem resíduos e sem restrição de quantidade.

Os pacientes que tiveram a prescrição de laxante, porém não efetuaram sua administração no dia anterior ao exame, terão seu procedimento suspenso pelo endoscopista em razão da dificuldade do preparo e limpeza do cólon. Os demais pacientes seguirão a rotina.

No dia do exame, o paciente dirige-se à secretária da unidade para que realiza a checagem da documentação e admissão ambulatorial. A seguir, é recebido pela enfermeira, que inicia a admissão e segue o protocolo da instituição. Após a entrevista inicial de enfermagem, o paciente faz a troca de vestimenta e inicia a complementação do preparo de cólon.

Esta complementação é realizada com a ingestão de 400 a 500 mililitros de Manitol $^{\circledR}$ a $20 \%$ diluídos na mesma proporção de suco de fruta solúvel sem resíduo. O paciente é orientado a tomar um copo de $200 \mathrm{ml}$ desta solução a cada 10 minutos e, associado, são oferecidos 1000 mililitros de 
água, para a adequada hidratação. Considera-se que o paciente apresenta o cólon com preparo adequado quando apresentar as evacuações líquidas de aspecto claro e sem resíduos.

O número de coletas por período foi aleatório e dependente de vários fatores, como o número de procedimentos agendados, disponibilidade do pesquisador, aceitação em participar do exame e comparecimento do paciente.

Para esta pesquisa, os dados foram coletados no dia agendado para o exame, após a admissão do paciente pelo enfermeiro responsável do Serviço e, anteriormente, ao início da complementação do preparo do cólon. (APÊNDICE I)

Nesse momento, o paciente foi informado sobre a realização da pesquisa no Serviço, o seu principal objetivo, e a garantia do sigilo de suas respostas. Posteriormente, tomou ciência do Termo de Consentimento Livre e Esclarecido, realizou sua leitura e assinatura, após concordância.

Os dados biossociais foram obtidos do prontuário ou questionados diretamente ao paciente. (APÊNDICE II)

Antes de iniciar a leitura da Escala de Estresse Percebido e do Inventário de Estratégias de Coping de Folkman e Lazarus, os participantes da pesquisa foram orientados, para que pensassem nos fatores de estresse e no estilo de coping mais utilizado, desde que tomou conhecimento da necessidade do mesmo até a coleta dos dados.

Com isto, o pesquisador iniciava o procedimento de leitura de orientação para, o preenchimento do instrumento e, a seguir, a leitura de cada item. O indivíduo deveria escolher a pontuação de cada frase que mais se adaptasse à situação relatada.

Alguns cuidados foram assegurados pelo pesquisador, para que não influenciasse na escolha das respostas, também o conteúdo dos itens ou seu significado nem a escala de respostas foram discutidos. Desse modo, os itens foram lidos pausadamente, quantas vezes fossem necessárias para facilitar 
sua compreensão e, em caso de dúvida, reiterava-se a importância da interpretação do próprio indivíduo.

Assim, após o preenchimento dos instrumentos, os sujeitos eram dispensados e agradecidos pela colaboração.

A coleta de dados iniciou-se em abril de 2011 e estendeu-se até julho do mesmo ano, sendo realizada pela própria pesquisadora.

\subsection{PROTEÇÃO DOS PACIENTES DA PESQUISA}

Inicialmente, foi realizado contato com os supervisores dos serviços de enfermagem do setor de endoscopia, com a finalidade não só de expor e esclarecer os objetivos da pesquisa, mas também para apresentação do projeto e obter informações referentes ao setor e aos procedimentos.

Após a aprovação do projeto e a fim de atender à Resolução $n^{\circ}$ 196/10/1996 (34), que visa a assegurar os direitos e deveres que dizem respeito à comunidade científica, aos sujeitos das pesquisas do estado, o projeto de pesquisa foi encaminhado ao Comitê de Ética em Pesquisa da Escola de Enfermagem da Universidade de São Paulo - CEP-EEUSP sob o número de registro ${ }^{\circ} 1011 / 2011 /$ CEP-EEUSP (ANEXO I).

Posteriormente, foi enviado ao Departamento de Enfermagem do Hospital Universitário para aprovação de viabilidade da pesquisa no serviço de endoscopia.

Após esse procedimento, foi encaminhado e aprovado pelo Comitê de Ética em Pesquisa do Hospital Universitário da Universidade de São Paulo (ANEXO II).

Em observância à mesma legislação sobre pesquisa envolvendo seres humanos, foi elaborado um Termo de Consentimento Livre e Esclarecido (APÊNDICE I), pelo qual a população do estudo foi informada de seus 
objetivos, bem como, sendo lhes garantido o anonimato, o desejo de participação ou não no estudo e seus benefícios indiretos. Os termos foram entregues em duas vias aos pacientes a fim de obter a assinatura e autorização dos mesmos para a participação no projeto. Um exemplar foi mantido em posse da pesquisadora e o outro com o paciente.

\subsection{RISCOS E BENEFÍCIOS DO ESTUDO}

O estudo não ofereceu riscos nem benefícios diretos à saúde da população estudada. Contudo, a identificação dos principais fatores preditores permitiu conhecer a percepção de estresse e as estratégias de enfrentamento (coping) utilizadas pelos mesmos (benefícios indiretos).

Como a percepção de estresse no ambiente pré-exame pode desencadear alterações emocionais, os resultados do estudo poderão contribuir para a elaboração de programas de intervenção que visem a melhoria no atendimento dessa população.

\subsection{INSTRUMENTOS DE MEDIDAS}

\subsubsection{Caracterizações biossociais, clínicas e inerentes ao procedimento}

Com intuito de atender aos objetivos da pesquisa, foram coletados os dados biossociais, os registros dos dados clínicos, bem como os instrumentos de avaliação de estresse e processos de enfrentamento (APÊNDICE II).

Os dados biossociais foram coletados do prontuário ou diretamente com o paciente que se consistiram dos seguintes itens: sexo, idade, estado civil, número de filhos, religião, escolaridade e profissão.

Nas características clínicas os pacientes poderiam ser portador das seguintes comorbidades: alteração do sistema cardiopulmonar, hipertensão 
arterial sistêmica (HAS), Diabetes Mellitus (DM), histórico pessoal de neoplasia de cólon, histórico familiar de neoplasia de cólon, presença de alergias e alterações gastrintestinais.

Para a análise dos dados relacionados ao próprio procedimento, foram selecionados os seguintes: número de exames previamente realizados, indicação do procedimento, tipo de preparo realizado, conhecimento prévio do paciente sobre o procedimento e sentimentos e preocupações vivenciados pelo mesmo desde a marcação do procedimento até sua realização.

Por meio dos dados biossociais, clínicos e relacionados ao exame foram determinados dez possíveis fatores preditores de estresse que serão, posteriormente, analisados, sendo eles: sexo (feminino e masculino), idade (20 a 39 anos; 40 a 64 anos e 65 anos ou mais), estado civil (com ou sem companheiro), escolaridade (analfabeto; primeiro grau completo ou incompleto; segundo grau completo ou incompleto; superior completo ou incompleto), indicação para a colonoscopia, tipo de preparo utilizado (ambulatorial; domiciliar), conhecimento prévio sobre o exame, número de exames realizados anteriormente $(0,1,2,3,4$ ou mais), sentimentos e preocupações correlacionados ao exame.

\subsubsection{Escala de Estresse Percebido}

Entende-se como estresse percebido a avaliação que o indivíduo faz sobre determinados eventos de vida potencialmente ameaçadores.

A Escala de Estresse de Percebido (ANEXO III) desenvolvida inicialmente por Cohen et al. ${ }^{(35)}$, e elaborada, para que o indivíduo pudesse avaliar as experiências da vida como incontrolável, imprevisível e sobrecarga no período passado de um mês. É uma escala geral, que pode ser usada em diversos grupos etários, desde adolescentes até idosos, pois não contém questões específicas do contexto. Esta ausência de especificidade do 
contexto é um fator importante na escala e, provavelmente, a razão pela qual tenha sido validada em diversas culturas ${ }^{(36-37)}$.

Inicialmente, a escala foi construída com 14 itens, seguindo o modelo Likert de cinco opções de resposta que variam de zero a 4 (0-nunca; 1-quase nuca; 2 -às vezes; 3 -quase sempre; 4-sempre).

Posteriormente, os autores revisaram as propriedades psicométricas da escala e apresentaram a versão reduzida com dez itens (PSS-10) com melhores características psicométricas em relação ao PSS-14 ${ }^{(35)}$. Para este estudo foi utilizada a versão reduzida de dez itens.

No Brasil, a PSS-14 foram traduzidas e validadas em idosos por Luft et al. ${ }^{(36)}$, posteriormente, Reis et al. fizeram a tradução e validação da PSS10 em adultos e idosos ${ }^{(37)}$.

Dos dez itens, seis são negativos $(1,2,3,6,9,10)$ e os quatro restantes $(4,5,7,8)$ positivos. Os elementos negativos destinam-se a avaliar a falta de controle e as reações afetivas negativas, enquanto os positivos medem o grau de habilidade para lidar com os estressores existentes. Para obtenção do escore final, os itens positivos têm sua pontuação somada invertida, e as demais questões negativas devem ser somadas diretamente.

A pontuação final pode variar com escore mínimo de zero e máximo de 40 pontos e quanto mais alto os escores significa maior estresse percebido pelo indivíduo.

\section{Itens negativos $-1,2,3,6,9,10$}

1. Você tem ficado triste por causa de algo que aconteceu inesperadamente?

2. Você tem se sentido incapaz de controlar as coisas importantes em sua vida?

3. Você tem se sentido nervoso e "estressado"? 
6. Você tem achado que não conseguiria lidar com todas as coisas que você tem de fazer?

9. Você tem ficado irritado porque as coisas que acontecem estão fora de controle?

10. Você tem sentido que as dificuldades acumulam-se a ponto de você acreditar que não pode superá-las?

\section{Itens positivos $-4,5,7,8$}

4. Você tem se sentido confiante em sua habilidade de resolver problemas pessoais?

5. Você tem sentido que as coisas estão acontecendo, de acordo com sua vontade?

7. Você tem conseguido controlar as irritações em sua vida?

8. Você tem sentido que as coisas estão sob seu controle?

\subsubsection{Inventário de Estratégias de Enfrentamento de Folkman e Lazarus - Ways of Coping Questionare (ANEXO IV)}

Ways of Coping Questionnaire foi construído inicialmente na década de 1970 (Ways of Coping Checklist), com base na reflexão dos sujeitos para responderem positivamente ou não 66 estratégias de enfrentamento e também para revisão de literatura pertinente à área ${ }^{(30,35)}$.

É um instrumento de medida que reflete a classificação das estratégias de coping, sendo composto na íntegra de 66 itens, abrangendo as ações e os pensamentos utilizados pelos indivíduos para lidar com demandas internas ou externas frente a uma situação específica de estresse ${ }^{(28)}$.

O instrumento foi construído e validado, seguindo os critérios metodológicos e técnicos de boa confiabilidade e aceitabilidade e a 
quantificação da carga fatorial presente em cada item. O método permite fazer o agrupamento dos itens que se relacionam entre si ${ }^{(28-29)}$. O instrumento construído compõe-se de 66 itens com resposta ordinal de quatro posições, indicando a frequência com que se usa cada estratégia: 0 - nunca usei; 1 - usei de alguma forma; 2 - usei algumas vezes; 3 - usei muitas vezes (29)

O Inventário foi traduzido e validado para a língua portuguesa, conforme os critérios técnicos aceitos para esse fim. Na fase final do estudo de validação, o instrumento foi composto de 46 itens para identificar 46 estratégias de enfrentamento agrupadas em oito diferentes fatores (35) (ANEXO IV). Neste estudo, foi utilizada a versão de 46 itens por se tratar de um Inventário reconhecido e utilizado mundialmente.

As estratégias correspondentes a cada fator são: 


\section{Confronto:}

- Descontei minha raiva em outras pessoas

- Mostrei a raiva para as pessoas que causaram o problema

- Procurei fugir das pessoas em geral

- Enfrentei como um grande desafio e fiz algo muito arriscado

- Tentei encontrar a pessoa responsável para mudar suas ideias

- De alguma forma, extravasei os meus sentimentos

\section{Afastamento:}

- Não deixei me impressionar, recusava-me a pensar muito sobre a situação

- Fiz como se nada tivesse acontecido

- Minimizei a situação recusando-me a preocupar-me seriamente com ela

- Procurei esquecer a situação desagradável

- Fiz alguma coisa que acreditava não daria resultados, mas ao menos estava fazendo alguma coisa

- Dormi mais que o normal

- Tentei não fazer nada que fosse irreversível, procurando deixar outras opções

\section{Autocontrole:}

- Procurei guardar meus sentimentos para mim mesmo(a)

- Não deixei que os outros soubessem da verdadeira situação

- Procurei não deixar que meus sentimentos interferissem muito nas outras coisas que eu estava fazendo 
- Procurei não fazer nada apressadamente ou seguir meu primeiro impulso

\section{Suporte Social:}

- Procurei um amigo ou parente para pedir conselhos

- Falei com alguém sobre como estava me sentindo

- Conversei com outra(s) pessoa(s) sobre o problema, procurando mais dados sobre a situação

- Falei com alguém que poderia fazer alguma coisa concreta sobre o problema

- Aceitei a simpatia e a compreensão das pessoas

- Procurei ajuda profissional

\section{Aceitação da Responsabilidade:}

- Prometi a mim mesmo(a), que as coisas serão diferentes da próxima vez

- Critiquei-me, repreendi-me

- Encontrei algumas soluções diferentes para o problema

- Compreendi que o problema foi provocado por mim

- Busquei nas experiências passadas uma situação similar

- Desculpei ou fiz alguma coisa para repor os danos

- Analisei mentalmente o que fazer e o que dizer

\section{Fuga e Esquiva:}

- Desejei que a situação acabasse ou que de alguma forma desaparecesse 
- Tinha fantasias de como as coisas iriam acontecer, como se encaminhariam

\section{Resolução de Problemas:}

- Eu sabia o que deveria ser feito, portanto, dobrei meus esforços para fazer, o que fosse necessário

- Fiz um plano de ação e segui-o

- Recusei recuar e batalhei pelo que eu queria

- Concentrei-me no que deveria ser feito para, em seguida, no próximo passo

\section{Reavaliação Positiva:}

- Redescobri o que é importante na vida

- Mudei alguma coisa em mim, modifiquei-me de alguma forma

- Rezei

- Saí da experiência melhor do que eu esperava

- Modifiquei aspectos da situação, para que tudo desse certo

- Inspirou-me a fazer algo criativo

- Encontrei novas crenças

- Pensei em uma pessoa que admiro e tomei-a como modelo

- Mudei ou cresci como pessoa de uma maneira positiva

Para a aferição do resultado de aplicação do Inventário foi realizada a soma dos itens de cada subgrupo e esta soma será classificada de acordo com a pontuação mínima e máxima possível. Com este resultado, pode-se concluir 
a predominância de um padrão específico de comportamento ou as estratégias mais utilizadas pelo indivíduo.

\subsection{TRATAMENTO ESTATÍSTICO}

\subsubsection{Agrupamento dos dados coletados}

O agrupamento das variáveis do estudo deu-se, após a coleta de dados, da seguinte maneira:

- Variáveis dependentes: Escala de Estresse Percebido e Escala de Estratégias de Coping de Folkman e Lazarus;

- Variáveis independentes: fatores preditores de estresse - sexo, idade, estado civil, escolaridade, indicação do procedimento, tipo de preparo realizado, conhecimento prévio, sentimentos vivenciados no período de preparo, preocupação relacionada ao procedimento e número de procedimentos já realizados.

Para os dados biossociais, clínicos relacionados à colonoscopia, à Escala de Estresse Percebido e ao Inventário de Estratégias de Enfrentamento foram feitos os seguintes agrupamentos:

1. Dados biossociais: - idade - agrupada em três categorias: de 20 a 39, de 40 a 64 e de 65 anos ou mais; - estado civil - classificado em duas categorias: com companheiro(a) ou sem companheiro(a), valorizou-se apenas a presença ou não de um companheiro(a) sem distinção do estado legal; - escolaridade - em quatro categorias: não letrado; primeiro grau incompleto ou completo, segundo grau incompleto ou completo e superior incompleto ou completo;religião: católica, evangélica e outros (Kardecistas, Protestantes e Agnósticos); - profissão: com cinco categorias classificadas em: 
área da saúde, estudantes remunerados, serviços administrativos, aposentados e do lar;

2. Dados clínicos: alterações do sistema cardiopulmonar, hipertensão arterial sistêmica, Diabetes Mellitus, história pessoal de neoplasia de cólon, história familiar de neoplasias de cólon, alergias e alterações do sistema gastrintestinal;

3. Dados relacionados à colonoscopia: - número de exames previamente realizados - 4 categorias: nenhum exame realizado, 1, 2, 4 ou mais; - indicação da colonoscopia - em 5 categorias: sangramento/anemia/alterações do hábito intestinal/dor abdominal; doença inflamatória intestinal; história familiar de câncer de cólon; controle após retirada de tumor de cólon; rastreamento de neoplasias e lesões polipóides; - tipo de preparo - ambulatorial e domiciliar; - conhecimento prévio do paciente - tinham conhecimento prévio do exame e diagnóstico; o conhecimento relacionava-se às orientações recebidas para o procedimento;

4. Escala de Estresse Percebido: foi utilizada a média do agrupamento dos dez itens da escala, denominado PSS-10;

5. Estratégias de coping: agrupados oito fatores, destes, foram selecionados cinco para serem utilizados, que foram: Confronto, Afastamento, Aceitação da Responsabilidade, Reavaliação Positiva e Suporte Social. Esta seleção baseou-se na frequência da utilização dessas estratégias entre os indivíduos e na boa confiabilidade de seus coeficientes de correlação alfa de Cronbach.

\subsubsection{Confiabilidade dos instrumentos da pesquisa}

Para verificar a confiabilidade dos instrumentos da pesquisa, optou-se por utilizar o coeficiente de correlação alfa de Cronbach, que tem a 
finalidade de avaliar a adequação e a qualidade dos instrumentos propostos (38).

Nesta pesquisa, o coeficiente foi aplicado nos itens e nos oito domínios que compõem as estratégias de coping do Instrumento de Estratégias de Enfrentamento de Folkman e Lazarus e também para os dez itens da Escala de Estresse Percebido. Admitiu-se o instrumento, como confiável para utilização e com consistência interna, quando o respectivo valor do alfa de Cronbach foi maior que 0,5.

\subsubsection{Apresentação e análise dos dados}

Todos os dados foram coletados e inseridos em um banco de dados, esse foi construído no Excel versão 2007, aplicativo do Office 10 da Microsoft Windows XP Home Edition 2010.

Para a análise estatística, utilizou-se o programa SPSS - Statistical Package for Social Science (2011), versão 7.0 e procedeu-se ao agrupamento dos dados referentes à população estudada.

Para a análise dos resultados, foram utilizados testes paramétricos e não paramétricos, levando-se em conta a natureza das distribuições dos valores, ou a variabilidade das medidas efetuadas, uma vez que os valores individuais são originários de pontos de uma mesma escala ${ }^{(39-41)}$.

$\mathrm{Na}$ análise dos dados, usou-se a distribuição de frequências, com números absolutos e percentuais para a análise e caracterização da população através das variáveis biossociais, clínicas e fatores relacionados ao procedimento.

$\mathrm{Na}$ análise de correlação e comparação de variáveis, para verificação de grupos de variáveis, foram aplicados os seguintes testes ${ }^{(39-41)}$ :

- Para a determinação da análise estatística descritiva para as escala de Estresse Percebido - PSS-10 e o Inventário de Estratégias de 
Enfrentamento de Folkman e Lazarus: foram apresentados valores mínimos e máximos, média e desvio-padrão de cada item e domínios.

- Os testes de correlação entre os fatores de coping e o estresse percebido: determinados pelo teste de correlação de Pearson.

- Para a determinação dos fatores preditores: foi realizado o teste de Regressão Múltipla.

- Para obtenção dos valores relacionados às médias dos agrupamentos realizados entre a escala de Estresse Percebido, o Inventário de Estratégias de Enfrentamento de Folkman e Lazarus e os fatores preditores de estresse percebido: testes de Regressão Linear Múltipla - ANCOVA e testes t-Student.

Adotou-se o nível de significância de 5\% para a decisão estatística em todos os testes utilizados e para os valores de alfa de Cronbach será considerado valores acima de 0,5 . 
RESULTADOS 
"O homem não morre quando deixa de viver, mas, sim, quando deixa de amar."

Charlie Chaplin

Ao buscar a melhor compreensão dos dados, conforme os objetivos propostos, a apresentação dos resultados foi dividida em quatro etapas distintas conforme a organização a seguir:

\subsection{Apresentação descritiva dos dados}

4.1.1 Caracterização da população, de acordo com as características biossociais gerais;

4.1.2 Caracterização da população, conforme as características clínicas;

4.1.3 Caracterização da população, conforme os fatores relacionados ao procedimento colonoscópico.

\subsection{Análises da confiabilidade das escalas utilizadas}

4.2.1 Escala de Estresse Percebido - PSS - 10;

4.2.2 Inventário de Estratégias de Enfrentamento de Folkman e Lazarus.

\subsection{Descrição da pontuação dos instrumentos utilizados}

4.3.1 Escala de estresse percebido - PSS-10;

4.3.2 Inventário de Estratégias de Enfrentamento de Folkman e Lazarus.

\subsection{Modelo de Regressão Linear Múltiplo para a Escala de Estresse Percebido}

- PSS-10 e o Inventário de Estratégias de Enfrentamento de Folkman e

\section{Lazarus}

4.4.1 Modelo de Regressão Linear Múltiplo para a Escala de Estresse Percebido - PSS - 10

4.4.2 Modelo de Regressão Linear Múltiplo para o Inventário de Enfrentamento de Folkman e Lazarus

4.4.3 Correlação entre a Escala de Estresse Percebido - PSS - 10 e os domínios de enfrentamento selecionados

4.4.4 Comparação por agrupamentos 


\subsection{APRESENTAÇÕES DESCRITIVAS DOS DADOS}

A seguir, os resultados apresentados referem-se aos dados coletados dos 100 indivíduos que compuseram o estudo.

\subsubsection{Caracterização da população, conforme as características biossociais gerais}

A seguir, serão apresentadas nos dados da Tabela 1 as características biossociais dos pacientes em período de preparo para colonoscopia, conforme as variáveis: sexo, idade, estado civil, filhos, religião, escolaridade e profissão.

Os dados da Tabela 1 representam a população deste estudo composta de 100 pacientes em atendimento ambulatorial no período de pré procedimento colonoscópico. Observa-se a predominância de indivíduos do sexo feminino com total de 73 mulheres (73\%) com idade variando entre 20 e 85 anos, com média de 62,3 anos, desvio padrão de 14,3 anos, distribuídas em igual número na faixa etária acima de 65 anos (50\%) e de 20 e 64 anos $(50 \%)$.

Em relação ao estado civil, os pacientes foram agrupados em duas categorias principais de interesse para análise (com companheiro/sem companheiro). Houve predominância dos que tinham companheiro (90\%), seja namorado fixo ou casados legalmente, ou não. Dos entrevistados, 95 indivíduos moravam com familiares, e os demais, sozinhos.

Referente ao número de filhos, a variação foi de, no máximo, quatro, com média de 1,33 e desvio padrão de 0,96, com a maioria de apenas um filho. A ausência de filhos foi predominante na faixa adulto-jovem (20 pacientes entre 20 e 39 anos). 
Tabela 1 - Distribuição dos pacientes em período de preparo para colonoscopia, conforme as características biossociais quanto a sexo, faixa etária, estado civil, número de filhos, religião, escolaridade e profissão. São Paulo, 2011

\begin{tabular}{|c|c|c|}
\hline CARACTERÍSTICAS BIOSSOCIAIS & $\mathbf{N}$ & $\%$ \\
\hline \multicolumn{3}{|l|}{ SEXO } \\
\hline Feminino & 73 & 73,0 \\
\hline Masculino & 27 & 27,0 \\
\hline \multicolumn{3}{|l|}{ IDADE } \\
\hline $20 \mathrm{H} 39$ anos & 9 & 9,0 \\
\hline $40 \mathrm{H} 64$ anos & 41 & 41,0 \\
\hline 65 卜 & 50 & 50,0 \\
\hline \multicolumn{3}{|l|}{ ESTADO CIVIL } \\
\hline Solteiro / Divorciado / Viúvo & 10 & 10,0 \\
\hline Casado legalmente ou não/ Com namorado & 90 & 90,0 \\
\hline \multicolumn{3}{|l|}{ ESCOLARIDADE } \\
\hline Analfabeto & 27 & 27,0 \\
\hline Primeiro grau incompleto ou completo & 12 & 12,0 \\
\hline Segundo grau incompleto ou completo & 33 & 33,0 \\
\hline Superior incompleto ou completo & 28 & 28,0 \\
\hline \multicolumn{3}{|l|}{ FILHOS } \\
\hline Nenhum & 21 & 21,0 \\
\hline 1 & 38 & 38,0 \\
\hline 2 & 29 & 29,0 \\
\hline 3 & 11 & 11,0 \\
\hline 4 & 1 & 1,0 \\
\hline \multicolumn{3}{|l|}{ RELIGIÃO } \\
\hline Católicos & 45 & 45,0 \\
\hline Evangélicos & 48 & 48,0 \\
\hline Outros (Kardecistas, Protestantes e Agnósticos) & 7 & 7,0 \\
\hline \multicolumn{3}{|l|}{ PROFISSÃO } \\
\hline $\begin{array}{l}\text { Área da Saúde (médico, enfermeiro, auxiliar e/ou técnico de } \\
\text { enfermagem e terapeuta ocupacional) }\end{array}$ & 18 & 18,0 \\
\hline Estudantes remunerados & 2 & 2,0 \\
\hline $\begin{array}{l}\text { Serviço Administrativo (secretária, administradores de } \\
\text { empresa, encarregado de setor e contador) }\end{array}$ & 18 & 18,0 \\
\hline Aposentado & 48 & 48,0 \\
\hline Do lar & 14 & 14,0 \\
\hline TOTAL & 100 & 100,0 \\
\hline
\end{tabular}


A respeito da religião e da prática religiosa, verifica-se que $45 \%$ eram católicos e 48\%, evangélicos. Entre os que pertenciam a outras religiões (7\%), três $(42,86 \%)$ kardecistas, um $(14,28 \%)$ protestante e três $(42,86 \%)$ eram agnósticos. Em relação à prática religiosa, 72\% avaliaram-se como praticantes, ao passo que $28 \%$ afirmaram que não a praticavam verdadeiramente.

Quanto à escolaridade, a média de anos estudados foi de 9,3 anos, com desvio padrão de 4,6 anos e predominância daqueles que completaram ou não o segundo grau. Verificou-se também que entre os pacientes estudados, 27 pessoas eram analfabetas funcionais.

Dentre os pacientes que informaram a profissão, $48 \%$ era aposentados (por tempo de serviço $\geq 35$ anos de contribuição fiscal), seguidos por trabalhadores da área da saúde (nove auxiliares/técnicos de enfermagem; três farmacêuticos; três médicos; dois enfermeiros; um terapeuta ocupacional) e, em igual número os que exerciam os atividades administrativas (seis secretárias; quatro administradores de empresas; três encarregados de setores; cinco contadores); dois indivíduos caracterizaram-se como estudantes remunerados e com bolsas de estudo da própria Universidade de São Paulo. 


\subsubsection{Caracterização da população conforme características clínicas}

Os dados referentes às variáveis de natureza clínica dos integrantes da pesquisa serão apresentados na Tabela 2 .

Conforme demonstra a Tabela 2, a hipertensão arterial sistêmica é a alteração clínica mais representativa, que afeta $90 \%$ dos indivíduos da amostra. Foi constatado que os pacientes hipertensos já realizam acompanhamento médico e no momento da admissão e durante a realização do procedimento, nenhuma alteração de pressão arterial foi observada.

Vale ressaltar nos resultados da amostra estudada que em 68 pacientes, o procedimento colonoscópico era realizado para rastreamento em razão da história familiar de câncer de cólon. Entre os 35 pacientes com história de neoplasia de cólon, o procedimento era realizado para controle e remoção de lesões recidivantes em período de pós-operatório tardio (30\%) e cinco para a delimitação do local cirúrgico para posterior remoção de tumor.

Tabela 2 - Distribuição dos pacientes em período de preparo para colonoscopia, conforme história clínica e de neoplasia pessoal e familiar. São Paulo, 2011

\begin{tabular}{lcc}
\hline \multicolumn{3}{c}{ História clínica e de neoplasia } \\
\multicolumn{1}{c}{ Variável } & Sim & Não \\
& $\mathbf{N ( \% )}$ & N (\%) \\
\hline Alteração do sistema cardiopulmonar & 32 & 68 \\
Hipertensão Arterial Sistêmica & 90 & 10 \\
Diabetes Mellitus & 35 & 65 \\
História pessoal de neoplasia de cólon & 35 & 65 \\
História familiar de neoplasia de cólon & 68 & 32 \\
Alergias & 0 & 100 \\
Alteração gastrintestinal & 51 & 49 \\
\hline
\end{tabular}

Entre os 51 pacientes com alterações do sistema gastrintestinal, o procedimento foi realizado para avaliação dos seguintes achados clínicos: hematoquezia (12\%); alteração do hábito intestinal (36\%); dor abdominal (17\%); doença inflamatória intestinal (21\%) e anemia inespecífica (14\%). 


\subsubsection{Caracterização da população, conforme as variáveis referentes ao procedimento colonoscópico}

Neste tópico serão apresentados nos dados das nas Tabelas 3 e 4, as variáveis inerentes ao procedimento, como: número de exames previamente realizados; justificativa do procedimento; tipo de preparo e conhecimento prévio e também os sentimentos que acometem o paciente para realização do procedimento.

Nos dados da Tabela 3, a variável número de exames realizados, tem valor mínimo de zero, ou seja, nenhum exame previamente realizado e valor máximo de quatro ou mais exames pelos quais os pacientes foram submetidos, sendo a média por paciente de 2,17 e desvio padrão de 1,45.

Portanto, verifica-se que só 15 pacientes eram inexperientes para esse tipo de procedimento cólico. Entre os motivos pelos quais os pacientes realizaram o procedimento, verifica-se que a história familiar de tumor de cólon foi uma causa predominante (68\%). 
Tabela 3 - Distribuição dos pacientes em período de preparo para colonoscopia, conforme variáveis inerentes ao próprio procedimento. São Paulo, 2011

\begin{tabular}{|c|c|c|}
\hline \multicolumn{3}{|c|}{ VARIÁVEIS INERENTES AO PROCEDIMENTO COLONOSCÓPICO } \\
\hline & $\mathbf{N}$ & $\%$ \\
\hline \multicolumn{3}{|l|}{$\mathbf{N}^{\circ}$ DE EXAMES PREVIAMENTE REALIZADOS } \\
\hline 0 & 15 & 15,0 \\
\hline 1 & 19 & 19,0 \\
\hline 2 & 33 & 33,0 \\
\hline 4 ou mais & 33 & 33,0 \\
\hline \multicolumn{3}{|l|}{ INDICAÇÃO DA COLONOSCOPIA } \\
\hline 1. Sangramento/Anemia/Alteração do hábito intestinal /Dor abdominal & 29 & 13,0 \\
\hline 2. Doença inflamatória intestinal & 21 & 20,0 \\
\hline 3. História familiar de câncer de cólon & 68 & 50,0 \\
\hline 4. Controle pós-ressecção de tumor de cólon & 20 & 10,0 \\
\hline 5. Rastreamento de neoplasias e lesões polipóides & 15 & 7,0 \\
\hline \multicolumn{3}{|l|}{ TIPO DE PREPARO } \\
\hline Ambulatorial & 93 & 93,0 \\
\hline Domiciliar & 7 & 7,0 \\
\hline \multicolumn{3}{|l|}{ CONHECIMENTO PRÉVIO DO PACIENTE } \\
\hline 1. Exame para o diagnóstico de doenças do cólon & 23 & 23,0 \\
\hline $\begin{array}{l}\text { 2. Exame para o diagnóstico de doença do cólon e as orientações sobre a } \\
\text { necessidade de preparo específico para realização do procedimento }\end{array}$ & 77 & 77,0 \\
\hline TOTAL & 100 & 100,0 \\
\hline
\end{tabular}

Nos resultados apresentados nos dados da Tabela 3, pode-se observar que o preparo dos pacientes em ambulatório foi predominante $(93 \%)$ e que o conhecimento prévio dos mesmos sobre o exame concentra-se na esfera do preparo prévio e na finalidade do procedimento (77\%). 
Pelos dados da Tabela 4, evidencia-se que os sentimentos de medo e constrangimento estavam presentes entre os pacientes $(72 \%)$ e, conforme relato estava presente desde o momento da solicitação do exame pelo médico responsável pelo cuidado.

Tabela 4 - Distribuição dos pacientes em período de preparo para colonoscopia, conforme os sentimentos que os acometem. São Paulo, 2011

\begin{tabular}{lcc}
\hline \multicolumn{1}{c}{ SENTIMENTOS REFERIDOS } & & \\
\hline & N & \% \\
\hline RELACIONADOS AO TIPO PROCEDIMENTO & 36 & 36,0 \\
Medo & 36 & 36,0 \\
Constrangimento & 18 & 18,0 \\
Ansiedade & 10 & 10,0 \\
Baixa auto-estima & & \\
RELACIONADO AO PRÓPRIO PROCEDIMENTO & 21 & 21,0 \\
$\quad$ Anestesia & 41 & 41,0 \\
Diagnóstico pós-exame & 38 & 38,0 \\
Necessidade de realizar exame & 100 & 100,0 \\
\hline TOTAL
\end{tabular}

Ainda na Tabela 4, verifica-se que as preocupações relacionadas diretamente ao procedimento referem-se à possibilidade de diagnóstico da doença, como lesões ulcerativas ou neoplásicas e a necessidade de repetição do mesmo para investigação futura ou acompanhamento evolutivo da doença. 


\subsection{ANÁLISES DE CONFIABILIDADE DAS ESCALAS UTILIZADAS}

Nos dados das Tabelas 5 e 6, são apresentados os resultados dos coeficientes de correlação de alfa de Cronbach para a Escala de Estresse Percebido e para o Inventário de Estratégias de Coping de Folkman e Lazarus. Foi considerado o valor mínimo de 0,5 para garantir a confiabilidade do instrumento.

\subsubsection{Escala de Estresse Percebido - PSS-10}

Os coeficientes de correlação alfa de Cronbach foram medidos para a escala como um todo para cada item.

Tabela 5 - Resultados da correlação item total do alfa de Cronbach para os dez itens da Escala de Estresse Percebido - PSS - 10. São Paulo, 2011

\begin{tabular}{lcc}
\hline \multicolumn{1}{c}{ ESCALA DE PSS - 10 } & & \\
\hline & $\begin{array}{c}\text { Correlação } \\
\text { item total }\end{array}$ & $\begin{array}{c}\text { Alfa de Cronbach } \\
\text { se item da escala } \\
\text { for deletado }\end{array}$ \\
\hline $\begin{array}{l}\text { PSS 1 - Você tem ficado triste por causa de algo que aconteceu } \\
\text { inesperadamente? }\end{array}$ & $-0,48$ & 0,828 \\
$\begin{array}{l}\text { PSS2 - Você tem se sentido incapaz de controlar as coisas } \\
\text { importantes em sua vida? }\end{array}$ & 0,79 & 0,358 \\
$\begin{array}{l}\text { PSS3 - Você tem se sentido nervoso e "estressado"? } \\
\text { PSS4 - Você tem se sentido confiante na sua habilidade de resolver } \\
\text { problemas pessoais? }\end{array}$ & 0,36 & 0,527 \\
$\begin{array}{l}\text { PSS5 - Você tem sentido que as coisas estão acontecendo, de } \\
\text { acordo com sua vontade? }\end{array}$ & 0,87 & 0,455 \\
$\begin{array}{l}\text { PSS6 - Você tem achado que não conseguiria lidar com todas as } \\
\text { coisas que você tem de fazer? }\end{array}$ & 0,03 & 0,434 \\
$\begin{array}{l}\text { PSS7 - Você tem conseguido controlar as irritações em sua vida? } \\
\text { PSS8 - Você tem sentido que as coisas estão sob seu controle? }\end{array}$ & 0,40 & 0,593 \\
$\begin{array}{l}\text { PSS9 - Você tem ficado irritado, porque as coisas que acontecem } \\
\text { estão fora de controle? }\end{array}$ & 0,12 & 0,549 \\
$\begin{array}{l}\text { PSS10 - Você tem sentido que as dificuldades acumulam-se a } \\
\text { ponto de você acreditar que não pode superá-las? }\end{array}$ & 0,33 & 0,547 \\
\hline
\end{tabular}


Nos dados da Tabela 5, constata-se a confiabilidade da Escala de Estresse Percebido - PSS -10 para a população do estudo, pois o valor total do coeficiente alfa de Cronbach foi de 0,583, o que indica valores aceitáveis para a análise. Estes valores sofrem variações para baixo quando se retira cada um dos itens do instrumento alternadamente, variando de valores de 0,358 (ao se deletar a Questão 3) a 0,828 para a Questão 1.

Observa-se que o item 6 apresentou correlação baixa item total, e o item 1, correlação total negativa. Portanto, percebeu-se que, caso o item 1 fosse deletado, readaptado ou reajustado para esta população, o valor do coeficiente de alfa seria de 0,828 . Mas, optou-se por não eliminá-lo. 


\subsubsection{Inventário de Estratégias de Enfrentamento de Folkman e Lazarus}

Os coeficientes de correlação do Inventário de Estratégias de Enfrentamento de Folkman e Lazarus foram medidos para a população do estudo como um todo e para os oito fatores que o compõem.

Tabela 6 - Resultados dos coeficientes de correlação alfa de Cronbach para o Inventário de Estratégias de Enfrentamento de Folkman e Lazarus, conforme os fatores e o número de itens. São Paulo - 2011

\begin{tabular}{lcc}
\hline \multicolumn{1}{c}{ INVENTÁRIO DE ESTRATÉGIAS DE ENFRENTAMENTO DE FOLKMAN E LAZARUS } \\
\hline & NÚMERO DE ITENS & ALPHA DE CRONBACH \\
\hline Confronto & 6 & $\mathbf{0 , 5 3 3}$ \\
Afastamento & 7 & $\mathbf{0 , 6 0 0}$ \\
Autocontrole & 5 & 0,323 \\
Suporte Social & 6 & $\mathbf{0 , 8 2 6}$ \\
Aceitação de Responsabilidade & 7 & $\mathbf{0 , 6 4 9}$ \\
Fuga Esquiva & 2 & $-0,377$ \\
Resolução de Problema & 4 & 0,267 \\
Reavaliação Positiva & 9 & $\mathbf{0 , 5 5 1}$ \\
\hline
\end{tabular}

Constata-se a confiabilidade do Inventário de Estratégias de Enfrentamento de Folkman e Lazarus para a população do estudo, uma vez que o valor total do coeficiente de correlação de alfa de Cronbach foi de 0,914, valor superior ao mínimo aceitável para análise.

$\mathrm{Na}$ análise dos dados da Tabela 6, observa-se que os fatores Confronto, Afastamento, Suporte Social, Aceitação da Responsabilidade e Reavaliação Positiva apresentaram coeficientes de correlação alpha de Cronbach superiores a 0,5 para esta população, o que garante a confiabilidade do Inventário para estes fatores. 


\subsection{DESCRIÇÃO DA PONTUAÇÃO DOS INSTRUMENTOS UTILIZADOS}

Neste item, será apresentada a distribuição da pontuação dos instrumentos utilizados na pesquisa.

\subsubsection{Escala de Estresse Percebido - PSS -10}

Tabela 7 - Distribuição das pontuações mínimas, máximas, médias e desvio padrão da Escala de Estresse Percebido - PSS - 10 dos 100 indivíduos do estudo. São Paulo - 2011

\begin{tabular}{lcccc}
\hline \multicolumn{5}{c}{ Distribuição da pontuação } \\
\hline & Mínimo & Máximo & Média & Desvio Padrão \\
\cline { 2 - 5 } Escore total do PSS -10 & 9,00 & 27,00 & 22,25 & 5,26 \\
\hline
\end{tabular}

Conforme os dados apresentados na Tabela 7, observa-se que a distribuição da pontuação da população estudada variou entre 9 e 27, com média de 22,25 e desvio padrão de 5,26. Deve-se considerar que o resultado da Escala de Estresse Percebido - PSS - 10 pode variar entre zero e 40 pontos. 


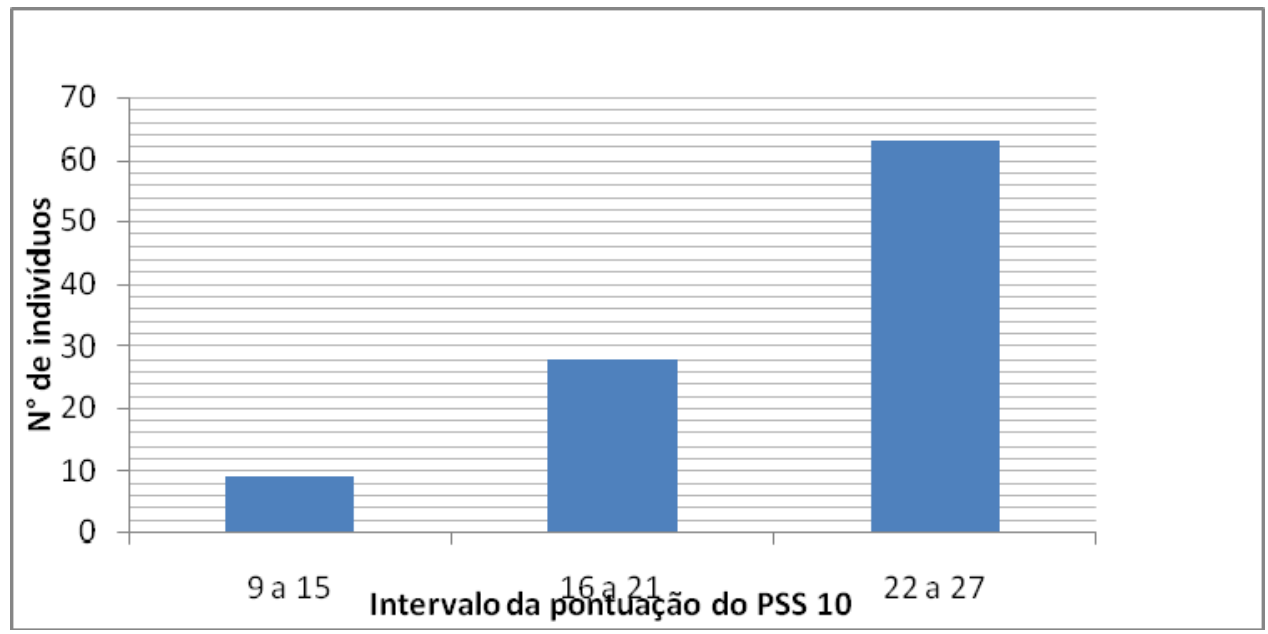

Figura 2 - Histograma da dos valores de frequência e média da escala de Estresse Percebido - PSS - 10 dos pacientes em período pré-colonoscópico. São Paulo - 2011

O Histograma, representado na Figura 2, estabelece a frequência da distribuição da pontuação apresentada pelos pacientes do estudo, por meio do gráfico do número de pacientes em período pré-colonoscópico que realizaram o exame $\mathrm{x}$ escore/pontuação total apresentada por faixa de pontuação dos pacientes na escala de PSS - 10 .

As faixas foram: nove pacientes na faixa de 9 a 15 pontos; 28 na faixa de 16 a 21 pontos e 63 com pontuação acima de 22 a 27 pontos. 


\subsubsection{Inventário de Estratégias de Enfrentamento de Folkman e Lazarus}

Para a verificação do estilo de coping mais utilizado pelos pacientes no período de preparo para colonoscopia, será apresentada a distribuição da pontuação mínima, máxima, média e desvio padrão.

O Inventário de Estratégias de Enfrentamento foi avaliado para os oito subgrupos, considerando uma variação mínima e máxima de 0 a 10, para possibilitar a comparação e equiparação das médias e desvio-padrão entre os domínios. Optou-se por essa forma de avaliação por considerar que os domínios são diferentes entre si, ou seja, apresentam distintos números de itens.

Ao utilizar o apoio dos valores das médias de cada subgrupo, pode-se referir que quanto maior a média maior será o estilo de coping ou subgrupo a ser utilizado por esses pacientes.

Pelos resultados apresentados nos dados da Tabela 8, observa-se que Fuga Esquiva $(9,22)$ foi a estratégia de coping mais utilizada pelos pacientes em período de preparo para colonoscopia, seguida de Suporte Social $(6,43)$ e Resolução de Problema (6,02). Observa-se também, que o domínio Confronto $(3,08)$ foi o menos usado pelos pacientes.

No entanto, para este estudo as estratégias Fuga Esquiva, Autocontrole e Resolução de Problema não foram consideradas por possuírem valores de coeficiente de alfa de Cronbach ( - 0,377; 0,323; 0,267 respectivamente) inferiores ao estimado para análise.

Considera-se que por possuir o valor da média mais elevada e também por apresentar um valor do coeficiente de alfa de Cronbach acima do mínimo desejável, o domínio Suporte Social foi o mais usado pelos pacientes em período de preparo para colonoscopia. 
Tabela 8 - Distribuição das pontuações mínima, máxima, média e desvio-padrão dos subgrupos de coping dos 100 indivíduos em período de preparo para colonoscopia. São Paulo, 2011

\begin{tabular}{lcccc}
\hline \multicolumn{5}{c}{ Distribuição da pontuação } \\
\hline SUGRUPOS DE COPING & Mínimo & Máximo & Média & Desvio Padrão \\
\hline Fuga e Esquiva & 6,67 & 10,0 & 9,22 & 1,24 \\
Suporte Social & 3,89 & 8,33 & 6,43 & 1,54 \\
Resolução de Problemas & 3,33 & 7,5 & 6,02 & 1,58 \\
Aceitação da Responsabilidade & 2,38 & 8,57 & 5,70 & 2,41 \\
Reavaliação Positiva & 2,59 & 7,41 & 5,64 & 1,41 \\
Autocontrole & 3,33 & 7,33 & 5,49 & 1,46 \\
Afastamento & 3,33 & 6,67 & 4,88 & 1,31 \\
Confronto & 0,00 & 4,44 & 3,08 & 1,35 \\
\hline
\end{tabular}




\subsection{MODELO DE REGRESSÃO LINEAR MÚLTIPLO PARA A ESCALA DE ESTRESSE PERCEBIDO - PSS-10 E O INVENTÁRIO DE ESTRATÉGIAS DE ENFRENTAMENTO DE FOLKMAN E LAZARUS}

Com o intuito de se conhecer as variáveis que mais se correlacionam com a percepção de estresse e com os fatores de enfrentamento apontados pela população em análise, foi aplicado o modelo de regressão linear múltiplo para os seguintes dados biossociais e os inerentes ao procedimento: sexo, idade, estado civil, escolaridade, indicação do procedimento, tipo de preparo realizado, conhecimento e preocupação relacionados ao procedimento, sentimentos vivenciados e número de procedimentos realizados

Foram consideradas as variáveis resposta ou dependentes da Escala de Estresse Percebido PSS-10 e os domínios selecionados do Inventário de Estratégia de Enfrentamento de Folkman e Lazarus, os demais itens (sexo, idade, estado civil, escolaridade, indicação do procedimento, tipo de preparo realizado, conhecimento e preocupação relacionados ao procedimento, sentimentos vivenciados e número de procedimentos realizados) variáveis explicativa ou independente (Tabelas 9 e 10).

O valor -p e o tamanho do efeito foram os coeficientes escolhidos para análise e considerados estatisticamente significativos o valor de $\mathrm{p} \leq 0,001$. 


\subsubsection{Modelo de Regressão Linear Múltiplo para a Escala de Estresse Percebido PSS-10}

Nos dados da Tabela 9, pode-se observar que as variáveis: sexo, idade, estado civil, escolaridade, tipo de preparo e número de procedimentos já realizados apresentam-se estatisticamente significativas para a Escala de Estresse Percebido PSS-10. Portanto, pode-se constatar que estas são as variáveis preditoras de estresse para os pacientes desta pesquisa.

Ainda, conforme os valores apresentados pelo tamanho do efeito das variáveis escolhidas, estima-se que o tipo de preparo $(98,2 \%)$, escolaridade $(99,1 \%)$, sexo $(88,4 \%)$, número de procedimentos realizados $(70,4 \%)$, idade $(50,4 \%)$ e estado civil $(42,1 \%)$ em ordem decrescente de valores, estão mais fortemente associados com o fenômeno de análise, ou seja, a percepção de estresse

Tabela 9 - Resultados do modelo de regressão linear múltiplo para a Escala de Estresse Percebido - PSS - 10, conforme as variáveis selecionadas. São Paulo - 2011

\begin{tabular}{lcc}
\hline Variáveis independentes & Valor $-\mathbf{p}$ & Tamanho de efeito \\
\hline Sexo & $<\mathbf{0 , 0 0 1}$ & $\mathbf{0 , 8 8 4}$ \\
Idade & $<\mathbf{0 , 0 0 1}$ & $\mathbf{0 , 5 0 4}$ \\
Estado Civil & $<\mathbf{0 , 0 0 1}$ & $\mathbf{0 , 4 2 1}$ \\
Escolaridade & $<\mathbf{0 , 0 0 1}$ & $\mathbf{0 , 9 9 1}$ \\
Indicação do procedimento & 0,135 & 0,086 \\
Tipo de preparo realizado & $<\mathbf{0 , 0 0 1}$ & $\mathbf{0 , 9 8 2}$ \\
Conhecimento prévio do procedimento & 0,360 & 0,041 \\
Sentimentos vivenciados no período do preparo & 0,183 & 0,061 \\
Preocupação relacionada ao procedimento & 0,471 & 0,032 \\
$\mathrm{~N}^{\circ}$ de procedimentos já realizados & $<\mathbf{0 , 0 0 1}$ & $\mathbf{0 , 7 0 4}$ \\
\hline
\end{tabular}




\subsubsection{Modelo de Regressão Linear Múltiplo para o Inventário de Enfrentamento de Folkman e Lazarus}

Os domínios Confronto, Afastamento, Suporte Social, Aceitação da Responsabilidade e Reavaliação Positiva foram selecionados para a análise em associação com as variáveis independentes.

Conforme os resultados apresentados nos dados da Tabela 10, a maioria das variáveis independentes selecionadas apresentou resultados estatisticamente significativos com os domínios de enfrentamento selecionados. Mas, as variáveis sexo e o tipo de preparo não apresentaram resultado estatisticamente significativo para o domínio Suporte Social da mesma forma que a variável idade para Confronto.

Ao analisar o tamanho do efeito das variáveis selecionadas observa-se que a escolaridade $(97,1 \%)$, tipo de preparo $(84,5 \%)$, número de procedimentos realizados $(78,8 \%)$, sexo $(77,8 \%)$ e idade $(61,0 \%)$ estão mais fortemente associada ao domínio Reavaliação Positiva. Apenas a variável tipo de preparo foi associada com o domínio Suporte Social. 
Tabela 10 - Resultados do modelo de regressão linear múltiplo para os domínios selecionados do Inventário de Estratégias de Enfrentamento de Folkman e Lazarus, conforme as variáveis selecionadas. São Paulo, 2011

\begin{tabular}{|c|c|c|c|}
\hline Variáveis Independentes & Variáveis Dependentes & Valor $-\mathbf{p}$ & Tamanho de efeito \\
\hline \multirow{5}{*}{ Sexo } & Confronto & $<0.001$ & 0,225 \\
\hline & Afastamento & $<0.001$ & 0,116 \\
\hline & Suporte Social & 0,395 & 0,008 \\
\hline & Aceitação da Responsabilidade & $<0.001$ & 0,433 \\
\hline & Reavaliação Positiva & $<0.001$ & 0,779 \\
\hline \multirow{5}{*}{ Idade } & Confronto & 0,008 & 0,103 \\
\hline & Afastamento & $<0.001$ & 0,321 \\
\hline & Suporte Social & $<0.001$ & 0,226 \\
\hline & Aceitação da Responsabilidade & $<0.001$ & 0,589 \\
\hline & Reavaliação Positiva & $<0.001$ & 0,610 \\
\hline \multirow{5}{*}{ Escolaridade } & Confronto & $<0.001$ & 0,913 \\
\hline & Afastamento & $<0.001$ & 0,872 \\
\hline & Suporte Social & $<0.001$ & 0,706 \\
\hline & Aceitação de Responsabilidade & $<0.001$ & 0,899 \\
\hline & Reavaliação Positiva & $<0.001$ & 0,971 \\
\hline \multirow{5}{*}{ Tipo de Preparo } & Confronto & $<0.001$ & 0,130 \\
\hline & Afastamento & $<0.001$ & 0,213 \\
\hline & Suporte Social & 0,008 & 0,077 \\
\hline & Aceitação da Responsabilidade & $<0.001$ & 0,265 \\
\hline & Reavaliação Positiva & $<0.001$ & 0,845 \\
\hline \multirow{5}{*}{ Estado Civil } & Confronto & $<0.001$ & 0,357 \\
\hline & Afastamento & $<0.001$ & 0,494 \\
\hline & Suporte Social & $<0.001$ & 0,554 \\
\hline & Aceitação da Responsabilidade & $<0.001$ & 0,321 \\
\hline & Reavaliação Positiva & $<0.001$ & 0,182 \\
\hline \multirow{5}{*}{$\begin{array}{l}\text { Número de procedimentos } \\
\text { realizados }\end{array}$} & Confronto & $<0.001$ & 0,630 \\
\hline & Afastamento & $<0.001$ & 0,291 \\
\hline & Suporte Social & $<0.001$ & 0,355 \\
\hline & Aceitação da Responsabilidade & $<0.001$ & 0,611 \\
\hline & Reavaliação Positiva & $<0.001$ & 0,788 \\
\hline
\end{tabular}




\subsubsection{Correlação entre a Escala de Estresse Percebido PSS-10 e os domínios de enfrentamento selecionados}

Os dados da Tabela 11 mostram o grau de correlação existente entre as duas variáveis: Percepção de Estresse e Estratégias de Enfrentamento.

Tabela 11 - Resultados do Coeficiente de Correlação para Escala de Estresse Percebido - PSS - 10 e os domínios de enfrentamento selecionados. São Paulo, 2011

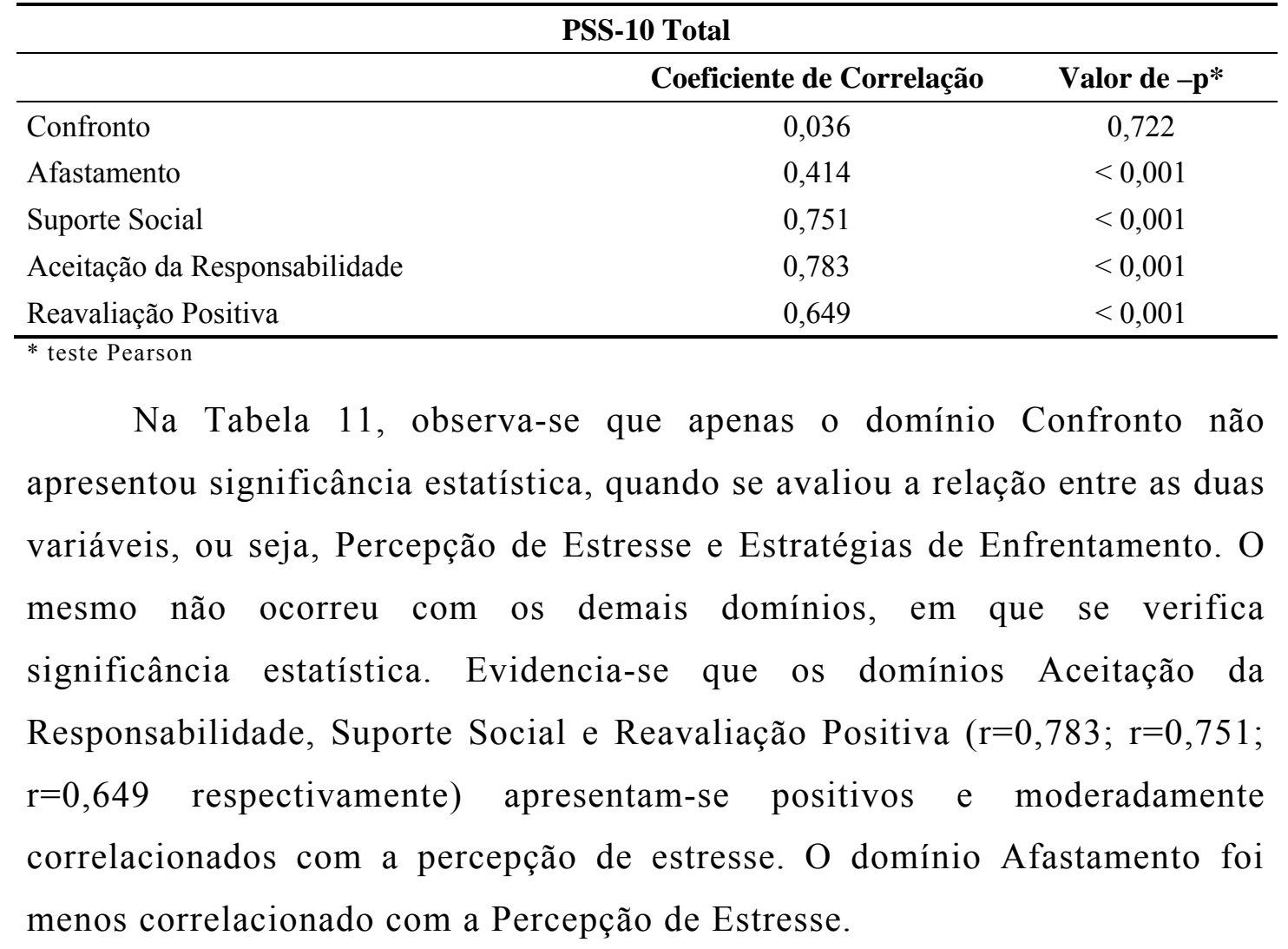




\subsubsection{Comparação por agrupamentos}

$\mathrm{Na}$ sequência de apresentação dos resultados, serão apresentadas as médias por agrupamento das variáveis preditoras de estresse, conforme Escala de Estresse Percebido e os domínios selecionados do Inventário de Enfrentamento de Folkman e Lazarus.

Os resultados serão apresentados pelos valores da média, desvio padrão e valor $-\mathrm{p}$.

Tabela 12 - Resultado da comparação das médias e desvio padrão por agrupamento da variável sexo, conforme a Escala de Estresse Percebido - PSS - 10 e os domínios de enfrentamento selecionados. São Paulo, 2011

\begin{tabular}{lccccc}
\hline \multirow{2}{*}{ INSTRUMENTOS } & \multicolumn{4}{c}{ SEXO } & \\
\cline { 2 - 5 } & \multicolumn{2}{c}{$\begin{array}{c}\text { Feminino } \\
(\mathbf{n}=\mathbf{7 3})\end{array}$} & \multicolumn{2}{c}{$\begin{array}{c}\text { Masculino } \\
(\mathbf{n}=\mathbf{2 7})\end{array}$} & \\
\cline { 2 - 5 } & Média & Desvio Padrão & Média & Desvio Padrão & Valor-p* \\
\hline PSS-10 Total & 24,77 & 2,92 & 15,44 & 3,96 & $<0,001$ \\
Confronto & 3,33 & 1,29 & 2,38 & 1,24 & $<0,001$ \\
Afastamento & 5,12 & 1,45 & 4,21 & 0,25 & $<0,001$ \\
Suporte Social & 6,89 & 1,48 & 5,16 & 0,78 & 0,395 \\
Aceitação da Responsabilidade & 6,59 & 2,16 & 3,26 & 0,82 & $<0,001$ \\
Reavaliação Positiva & 6,14 & 1,31 & 4,27 & 0,40 & $<0,001$ \\
\hline * & & & & &
\end{tabular}

Pelos dados da Tabela 12, observa-se que no sexo feminino as médias para a Escala de Estresse Percebido e os domínios Confronto, Afastamento, Suporte Social, Aceitação da Responsabilidade e Reavaliação Positiva apresentaram médias maiores, quando comparadas com o sexo masculino. Estas diferenças foram estatisticamente significativas para todos os domínios, com exceção do domínio Suporte Social. 
Nos dados da Tabela 13, observa-se que os intervalos de idade entre 20 e 29 anos e 65 anos ou mais apresentaram os valores de médias superiores tanto para a Escala de Estresse Percebido como para os domínios Confronto, Afastamento, Suporte Social, Aceitação da Responsabilidade e Reavaliação Positiva.

Entretanto, após a análise de regressão múltipla e para identificar os pares de variáveis que diferem entre si, foi realizado o teste de Post Hoc.

Tabela 13 - Resultado da comparação das médias e desvio padrão por agrupamento da variável idade, conforme a Escala de Estresse Percebido - PSS - 10 e os domínios de enfrentamento selecionados. São Paulo, 2011

\begin{tabular}{|c|c|c|c|c|c|c|c|}
\hline \multirow{3}{*}{ INSTRUMENTOS } & \multicolumn{6}{|c|}{ IDADE } & \multirow[b]{3}{*}{ Valor-p* } \\
\hline & \multicolumn{2}{|c|}{$\begin{array}{c}20 \text { a } 39 \text { anos } \\
(n=9)\end{array}$} & \multicolumn{2}{|c|}{$\begin{array}{c}40 \text { a } 64 \text { anos } \\
(n=41)\end{array}$} & \multicolumn{2}{|c|}{$\begin{array}{c}65 \text { anos ou mais } \\
(n=50)\end{array}$} & \\
\hline & Média & $\begin{array}{l}\text { Desvio } \\
\text { Padrão }\end{array}$ & Média & $\begin{array}{l}\text { Desvio } \\
\text { Padrão } \\
\end{array}$ & Média & $\begin{array}{l}\text { Desvio } \\
\text { Padrão } \\
\end{array}$ & \\
\hline PSS Total & 23,89 & 3,48 & 19,12 & 5,62 & 24,52 & 3,75 & $<0,001$ \\
\hline Confronto & 4,19 & 0,74 & 2,19 & 1,15 & 3,60 & 1,14 & 0,08 \\
\hline Afastamento & 5,76 & 1,37 & 3,99 & 0,62 & 5,44 & 1,30 & $<0,001$ \\
\hline Suporte Social & 7,16 & 1,93 & 5,56 & 0,91 & 7,00 & 1,55 & $<0,001$ \\
\hline $\begin{array}{l}\text { Aceitação da } \\
\text { Responsabilidade }\end{array}$ & 6,50 & 3,09 & 4,00 & 1,50 & 6,93 & 2,05 & $<0,001$ \\
\hline Reavaliação Positiva & 6,21 & 1,86 & 4,61 & 0,90 & 6,38 & 1,12 & $<0,001$ \\
\hline
\end{tabular}

Para se obter esta diferenciação, foram realizadas as comparações entre os três grupos da variável por faixa etária: os indivíduos entre 20 e 39 anos com aqueles entre 40 e 64 anos (1); os de 20 e 39 anos com os de 65 anos ou mais (2) e aqueles entre 40 e 64 anos com os de 65 anos ou mais (3). Estes foram comparados com a Escala de Estresse Percebido e os cinco domínios de enfrentamento selecionados.

Para a Escala de Estresse Percebido, ficou demonstrado que a comparação das médias das faixas entre 20 e 39 anos e 65 anos ou mais 
apresentou médias semelhantes entre si e foram estatisticamente significativas e diferenciaram-se da faixa entre 40 e 64 anos.

Portanto, os pacientes com 20 e 39 anos e 65 anos ou mais apresentaram percepção de estresse maior que os indivíduos na faixa 40 e 64 anos.

Para o enfrentamento, os domínios Afastamento, Suporte Social, Aceitação da Responsabilidade e Reavaliação Positiva foram estatisticamente significativos.

Observa-se na Tabela 14 que os pacientes que referiram viver com o companheiro, ou seja, os casados legalmente ou não ou que possuíam namorados ou parceiros fixos apresentaram os valores de médias superiores tanto para a Escala de Estresse Percebido como aos domínios Confronto, Afastamento, Suporte Social, Aceitação da Responsabilidade e Reavaliação Positiva.

Estas diferenças foram estatisticamente significativas.

Tabela 14 - Resultado da comparação das médias e desvio-padrão por agrupamento da variável estado civil, conforme a Escala de Estresse Percebido PSS - 10 e os domínios de enfrentamento selecionados. São Paulo, 2011

\begin{tabular}{lccccc}
\hline \multirow{2}{*}{ INSTRUMENTOS } & \multicolumn{4}{c}{ ESTADO CIVIL } & \\
\cline { 2 - 4 } & \multicolumn{2}{c}{$\begin{array}{c}\text { Solteiro / Divorciado / } \\
\text { Viúvo (n = 10) }\end{array}$} & $\begin{array}{c}\text { Casamento legal ou não / } \\
\text { com namorado (n = 90) }\end{array}$ & \\
\cline { 2 - 4 } & Média & $\begin{array}{c}\text { Desvio- } \\
\text { Padrão }\end{array}$ & Média & $\begin{array}{c}\text { Desvio- } \\
\text { Padrão }\end{array}$ & \multirow{2}{*}{ Valor-p* } \\
\hline PSS-10 Total & 18,70 & 3,16 & 22,64 & 5,30 & $<0,001$ \\
Confronto & 2,66 & 1,25 & 3,12 & 1,35 & $<0,001$ \\
Afastamento & 3,61 & 0,46 & 5,02 & 1,29 & $<0,001$ \\
Suporte Social & 5,61 & 1,21 & 6,51 & 1,54 & $<0,001$ \\
Aceitação da Responsabilidade & 3,71 & 1,72 & 5,91 & 2,38 & $<0,001$ \\
Reavaliação Positiva & 4,33 & 1,29 & 5,79 & 1,35 & $<0,001$ \\
\hline * teste t- Student & & & & &
\end{tabular}


Na comparação das médias entre os domínios, o Suporte Social obteve maior pontuação (média $=6,51$; valor $-\mathrm{p}<0,001$ ). 
Quanto à escolaridade, observa-se nos dados da Tabela 15 que os valores das médias dos não letrados e aqueles com Segundo grau completo/incompleto foram semelhantes e mais elevados quando comparados com os pacientes com primeiro grau completo/incompleto e aqueles com nível Superior completo/incompleto para a Escala de Estresse Percebido.

Tabela 15 - Resultado da comparação das médias e desvio padrão por agrupamento da variável escolaridade, conforme a Escala de Estresse Percebido PSS - 10 e os domínios de enfrentamento selecionados. São Paulo, 2011

\begin{tabular}{|c|c|c|c|c|c|c|c|c|c|}
\hline \multirow{3}{*}{ INSTRUMENTOS } & \multicolumn{8}{|c|}{ ESCOLARIDADE } & \multirow[b]{3}{*}{ Valor-p* } \\
\hline & \multicolumn{2}{|c|}{$\begin{array}{c}\text { Analfabeto } \\
(n=27)\end{array}$} & \multicolumn{2}{|c|}{$\begin{array}{c}\text { Primeiro grau } \\
\text { incompleto ou } \\
\text { completo } \\
(n=12)\end{array}$} & \multicolumn{2}{|c|}{$\begin{array}{l}\text { Segundo grau } \\
\text { incompleto ou } \\
\text { completo } \\
(n=33)\end{array}$} & \multicolumn{2}{|c|}{$\begin{array}{c}\text { Superior } \\
\text { incompleto ou } \\
\text { completo } \\
(\mathbf{n}=\mathbf{2 8})\end{array}$} & \\
\hline & Média & $\begin{array}{l}\text { Desvio } \\
\text { Padrão }\end{array}$ & Média & $\begin{array}{l}\text { Desvio } \\
\text { Padrão }\end{array}$ & Média & $\begin{array}{l}\text { Desvio } \\
\text { Padrão }\end{array}$ & Média & $\begin{array}{l}\text { Desvio } \\
\text { Padrão }\end{array}$ & \\
\hline PSS Total & 26,04 & 1,01 & 17,33 & 1,15 & 26,00 & 3,33 & 16,29 & 4,55 & $<0,001$ \\
\hline Confronto & 1,89 & 0,46 & 3,51 & 1,36 & 4,44 & 1,23 & 2,42 & 1,20 & $<0,001$ \\
\hline Afastamento & 3,82 & 0,48 & 3,96 & 0,46 & 6,66 & 1,66 & 4,18 & 0,29 & $<0,001$ \\
\hline Suporte Social & 6,11 & 0,00 & 4,62 & 1,09 & 8,33 & 1,25 & 5,25 & 0,87 & $<0,001$ \\
\hline $\begin{array}{l}\text { Aceitação da } \\
\text { Responsabilidade }\end{array}$ & 5,96 & 0,24 & 3,49 & 1,64 & 8,57 & 2,01 & 2,99 & 0,46 & $<0,001$ \\
\hline Reavaliação Positiva & 5,55 & 0,00 & 4,81 & 0,54 & 7,40 & 1,46 & 4,00 & 0,52 & $<0,001$ \\
\hline
\end{tabular}

Nos resultados apresentados pelos valores das médias dos domínios de enfrentamento, observou-se que aqueles com Segundo Grau completo/ incompleto apresentaram valores mais elevados quando comparados com os demais domínios selecionados. No entanto, para se identificar os pares de variáveis que diferem entre si foi realizado o teste de Post Hoc com seis combinações diferentes dois a dois.

As combinações dois a dois foram os não letrados com os pacientes com Primeiro Grau completo/incompleto; os pacientes não letrados com os que possuíam Segundo Grau completo/incompleto; os não letrados com os que tinham nível Superior completo/incompleto; os pacientes com Primeiro Grau completo/incompleto com aqueles com que possuíam Segundo Grau 
completo/incompleto; aqueles com Primeiro Grau completo/incompleto com os que possuíam nível superior completo/incompleto e, por último, foi comparado os indivíduos com Segundo Grau completo/incompleto com aqueles que possuíam nível Superior completo/incompleto.

O teste de Post hoc demonstrou que todas as comparações para a Escala de Estresse Percebido e os cinco domínios de enfrentamento apresentaram significância estatística.

Para os estilos de coping, os pacientes não letrados utilizam mais o subgrupo Suporte Social e os com Segundo Grau incompleto ou completo utilizam-se do fator Aceitação da Responsabilidade.

Tabela 16 - Resultado da comparação das médias e desvio padrão por agrupamento da variável tipo de preparo, segundo a Escala de Estresse Percebido PSS - 10 e os domínios de enfrentamento selecionados. São Paulo, 2011

\begin{tabular}{|c|c|c|c|c|c|}
\hline \multirow{3}{*}{ INSTRUMENTOS } & \multicolumn{4}{|c|}{ TIPO DE PREPARO } & \multirow[b]{3}{*}{ Valor-p* } \\
\hline & \multicolumn{2}{|c|}{$\begin{array}{c}\text { Ambulatorial } \\
(\mathrm{n}=93)\end{array}$} & \multicolumn{2}{|c|}{$\begin{array}{c}\text { Domiciliar } \\
(n=7)\end{array}$} & \\
\hline & Média & $\begin{array}{l}\text { Desvio } \\
\text { Padrão }\end{array}$ & Média & $\begin{array}{l}\text { Desvio } \\
\text { Padrão } \\
\end{array}$ & \\
\hline PSS-10 Total & 23,25 & 3,92 & 9,00 & 0,00 & $<0,001$ \\
\hline Confronto & 2,97 & 1,34 & 4,44 & 0,00 & $<0,001$ \\
\hline Afastamento & 4,92 & 1,34 & 4,28 & 0,00 & $<0,001$ \\
\hline Suporte Social & 6,61 & 1,41 & 3,88 & 0,00 & 0,008 \\
\hline $\begin{array}{l}\text { Aceitação da } \\
\text { Responsabilidade }\end{array}$ & 5,94 & 2,31 & 2,38 & 0,00 & $<0,001$ \\
\hline Reavaliação Positiva & 5,73 & 1,42 & 4,44 & 0,00 & $<0,001$ \\
\hline
\end{tabular}

Nos dados da Tabela 16, observou-se que os pacientes que realizaram preparo ambulatorial, ou seja, iniciaram o preparo no domicílio e realizaram a complementação no ambulatório, obtiveram médias mais elevadas para a Escala de Estresse Percebido quando comparados com os com preparo somente domiciliar. Esta diferença de pontuação apresentou resultados estatisticamente significativos. 
Na comparação dos domínios de enfrentamento selecionados, observase que os domínios Afastamento, Suporte Social, Aceitação da Responsabilidade e Reavaliação Positiva apresentaram médias de pontuação mais elevadas para o preparo ambulatorial quando comparados com o preparo no domicílio.

O domínio Suporte Social não apresentou significância estatística quando comparado entre os seis domínios selecionados.

A associação avaliada pela Tabela 17 afirma que o estresse e os cinco subgrupos de estilos de coping foram significantes em razão do valor $-p$ $<0,001$, portanto, quanto maior o número de exames menor será o estresse percebido pelo paciente. O subgrupo Confronto foi o estilo de coping mais utilizado por essa classe de pacientes.

Tabela 17 - Resultado do coeficiente de regressão da variável número de exames realizados, conforme a Escala de Estresse Percebido - PSS - 10 e os domínios de enfrentamento selecionados. São Paulo, 2011

\begin{tabular}{|c|c|c|c|}
\hline \multirow{2}{*}{ INSTRUMENTOS } & \multicolumn{2}{|c|}{$\begin{array}{c}\text { NÚMERO DE EXAMES } \\
\text { REALIZADOS }\end{array}$} & \multirow[b]{2}{*}{ Valor $-\mathbf{p}^{*}$} \\
\hline & $\begin{array}{l}B \text { - coeficiente de } \\
\text { regressão }\end{array}$ & Erro padrão & \\
\hline PSS-10 Total & $-0,98$ & 0,073 & $<0.001$ \\
\hline Confronto & $-1,05$ & 0,085 & $<0,001$ \\
\hline Afastamento & $-0,35$ & 0,059 & $<0,001$ \\
\hline Suporte Social & 0,60 & 0,085 & $<0,001$ \\
\hline Aceitação da Responsabilidade & 1,09 & 0,092 & $<0,001$ \\
\hline Reavaliação Positiva & 0,50 & 0,028 & $<0,001$ \\
\hline
\end{tabular}

Os dados da Tabela 17 apresentaram o teste de regressão linear para a variável numérica, não agrupada, número de exames realizados, a fim de determinar a sua correlação com os instrumentos, ou seja, determinar a variação do impacto do número de exames realizados para o aumento ou diminuição da pontuação dos instrumentos utilizados. 
Para a correlação com a Escala de Estresse Percebido, PSS-10, o coeficiente de regressão é negativo, portanto, a cada exame realizado a pontuação do estresse percebido determinado pelo individuo diminui, em média, em 0,98 pontos.

Entretanto, para os domínios de coping observa-se que a cada exame realizado os domínios Confronto a Afastamento são menos utilizados pelos pacientes, por outro lado, os domínios Aceitação da Responsabilidade, Suporte Social e Reavaliação Positiva são mais utilizados, com valores de $p$ estatisticamente significativos. 
"Quando você pensa que sabe todas as respostas, vem a vida e muda todas as perguntas."

Luís Fernando Verissímo

Neste capítulo será apresentada a discussão dos resultados encontrados na presente pesquisa quanto aos dados biossociais e clínicos, o estresse percebido, estilos de coping mais utilizados e as associações encontradas entre as variáveis selecionadas dos 100 pacientes que formaram a população do estudo.

\subsection{REFLEXÕES DA PESQUISA}

Desde 1960, verifica-se grande avanço tecnológico na observação do aparelho digestivo, graças ao advento dos endoscópios flexíveis, o que permitiu diversas produções científicas, principalmente, aquelas relacionadas à técnica de realização do procedimento, o preparo do paciente para a realização do procedimento e as intervenções diagnóstica e terapêutica das doenças colônicas ${ }^{(1,8,42)}$.

A colonoscopia mostrou-se como o método mais eficaz para o rastreamento de doenças colorretais frente aos demais testes diagnósticos, como a pesquisa de sangue oculto e sigmoidoscopia flexível, pois demonstra mais sensibilidade e especificidade que as demais para a detecção lesões, como pólipos e neoplasias ${ }^{(43)}$.

A colonoscopia é um procedimento onde o paciente tem uma participação importante, tanto no que se refere a um preparo intestinal adequado e efetivo quanto para a realização de um procedimento seguro e sem intercorrências. A percepção do exame colonoscópico como estressante 
pode aumentar a ansiedade, o desconforto e a sensação dolorosa o que acarreta frequente recusa para a realização do procedimento ${ }^{(44-45)}$.

Entretanto, pouco se estuda sobre as emoções vividas pelo paciente frente ao procedimento e suas implicações na estrutura psíquica. Os estudos que se propõem a este enfoque tratam, principalmente, das intervenções adotadas para diminuir o estresse e, neste contexto, as pesquisas se concentram nas técnicas de relaxamento, tendo a música como método para diminuir a ansiedade antes e durante a realização do procedimento; na orientação do paciente com manuais ou vídeos educativos; na comparação de drogas e métodos não invasivos que melhor se adéqua para diminuição da ansiedade, medo, dor e que contribuem para uma melhor aceitação do paciente do procedimento proposto e, na descrição da relação entre estresse e alterações gastrointestinais e suas implicações patofisiológicas, clínica e no tratamento ${ }^{(46-49)}$.

Para a análise destas variáveis, estresse e enfrentamento, optou-se por utilizar a Escala de Estresse Percebido e o Inventário de Estratégias de Enfrentamento de Folkman e Lazarus, como método para se atingir os objetivos do estudo, por serem instrumentos amplamente utilizados e pelos critérios metodológicos adotados de adaptação para a língua portuguesa, preconizados para este fim.

Os instrumentos foram testados e validados em diferentes populações com resultados de boa confiabilidade em sua utilização. Além disso, na literatura nacional, observa-se reduzido número de instrumentos traduzidos e validados destinados para avaliação de estresse e processos de enfrentamento. Desse modo, os instrumentos aqui escolhidos são frequentemente utilizados por diferentes autores, o que assegura sua fidedignidade quando se deseja avaliar os construtos aqui utilizados e permite a comparação de resultados.

Para avaliar a adequação e a qualidade dos instrumentos foi calculado o coeficiente de correlação de alfa de Cronbach em ambos. Com isto, observa-se que na Escala de Estresse Percebido, o valor do coeficiente de 
correlação foi de 0,583 (alfa de Cronbach), valor que se manteve pouco acima do estipulado nesta pesquisa, de 0,5 .

Diferentemente da literatura estrangeira que apresenta resultados com valores mais elevados e, ao se questionar o motivo que poderia ter influenciado para um resultado de baixo valor de alfa na pesquisa atual, acredita-se que o instrumento esteja corretamente medindo o construto de estresse, porém, talvez seja necessária uma revisão da tradução para o português que torne os itens mais adequados para a população dessa pesquisa $(50-52)$

Ainda, ao se analisar os valores dos coeficientes de correlação de cada item do PSS-10, observou-se que apenas o item 1 do instrumento ("Você tem ficado triste por causa de algo que aconteceu inesperadamente?") se mostrou com valor item-total negativo, ou seja, caso o mesmo fosse retirado da escala o valor de alfa passaria a ser de 0,828 , valor este semelhante ao encontrado em outros estudos cujos valores variaram entre 0,72 e $0,83^{(50,52-53)}$. Possivelmente, os indivíduos estudados não entenderam ou avaliaram esse item como representativo para a percepção de estresse, pois o procedimento colonoscópico é agendado via ambulatorial com um determinado tempo de espera para a realização do mesmo não sendo um acontecimento inesperado como questionado no item, influenciando assim o valor de alfa.

Entretanto, a fim de manter o instrumento em sua forma original, sua unidimensionalidade e permitir a comparação com outros estudos, optou-se por manter o item 1 nessa pesquisa.

Já para o Inventário de Estratégias de Enfrentamento de Folkman e Lazarus, o valor total de alfa de Cronbach foi de 0,914 , considerado este satisfatório para a análise. Ao se avaliar seus oito domínios separadamente, observa-se que nem todos apresentaram resultados satisfatórios e foram incluídos para análise nesta pesquisa, somente aqueles que apresentaram coeficientes acima 0,5, sendo eles, os domínios, Confronto, Afastamento, Suporte Social, Aceitação da Responsabilidade e Reavaliação Positivo, tendo 
sido desprezados os demais. Com este procedimento garantiu-se a adequação do inventário para a investigação desejada.

Portanto, acredita-se que o delineamento dessa pesquisa foi adequado, evitando-se assim erros metodológicos que pudessem comprometer a fidedignidade dos resultados obtidos.

\subsection{CARACTERÍSTICAS DA POPULAÇÃO DO ESTUDO QUANTO AOS ASPECTOS BIOSSOCIAIS E CLÍNICOS}

Quanto às características biossociais, observa-se predomínio de pacientes do sexo feminino na população investigada com $73 \%$ dos casos. Possivelmente, este resultado deve-se ao fato de que importantes afecções intestinais indicativas para a colonoscopia, como constipação, síndrome do

cólon irritável e doença de Crohn são mais frequentes entre as mulheres ${ }^{(54-}$ 57)

Apesar dos fatores acima citados, torna-se difícil entender o motivo para tal diferença proporcional entre os sexos, neste estudo, porém acreditase que mesmo com o desconhecimento do exame e independentemente da classe socioeconômica, as mulheres têm como tradição maior auto-cuidado, pois essa prática está mais incorporada a seus hábitos de saúde para a prevenção de doenças.

Em estudo sobre a adesão dos indivíduos para a realização do procedimento colonoscópico pós-polipectomia foi observado que as mulheres possuem maior aceitação e aderem melhor ao programa de acompanhamento endoscópico como método preventivo ${ }^{(58)}$.

Além disto, a maior adesão das mulheres para compor a amostra do estudo pode ser justificada pela maior disponibilidade das mesmas para serem entrevistadas a qualquer momento da fase de preparo para o 
procedimento, fato que não foi observado entre os homens, pois, recusavamse a participar caso já tivessem iniciado a complementação do preparo do cólon.

Obteve-se também, nesta pesquisa, uma média de idade superior a 62 anos possivelmente devido às características fisiológicas relacionadas ao avanço da idade. Idosos apresentam maior propensão ao câncer e a outras patologias do cólon, como, alterações da mucosa intestinal devido ao sedentarismo associados a aposentadoria, efeito e interações medicamentosas, redução da ingestão de fibras e líquidos e alterações hormonais, que os jovens, o que ocasiona aumento da prevalência de constipação, neoplasias de cólon e doenças diverticulares, causas essas indicativas de colonoscopia ${ }^{(16,59-60)}$.

Entretanto, dentre os sinais e sintomas apresentados, há o risco mais elevado de morbidade e mortalidade por câncer de cólon entre os idosos, porém sabe-se que medidas preventivas adequadas a essa população podem retardar ou evitar o aparecimento e disseminação de lesões neoplásicas ${ }^{(61-62)}$.

Em estudo realizado com a população asiática, indivíduos com idade entre 50 e 75 anos são caracterizados de médio risco para o desenvolvimento de neoplasia de cólon e devem realizar o rastreamento anual ou bianual para sangue oculto em fezes e colonoscopia a cada dez anos ${ }^{(63)}$. A colonoscopia pode ser realizada satisfatoriamente em mais de $97 \%$ dos pacientes idosos, incluindo os de 80 anos ou mais, com taxas de complicações baixas, conforme estudo norte-americano, devendo ser o método preferencial para a investigação e rastreamento de câncer e doenças do cólon ${ }^{(64-65)}$.

Quanto à escolaridade, 61\% dos entrevistados tinham mais de oito anos de estudo e $27 \%$ eram não letrados. De acordo com estudo brasileiro, em 2005 a taxa de não letrados para pessoas com idade igual ou superior a 15 anos era de 10,8 \% no país, sendo nas áreas urbanas da região Sudeste 6,2 \%. E, em 2010, as taxas de adultos com mais de oito anos aumentaram progressivamente com $63 \%$ na região sudeste ${ }^{(66)}$. 
Esses dados representam adequadamente a população atendida pelo HU-USP: população da região atendida, principalmente a de baixa renda e funcionários do HU-USP e da Universidade (os atendidos são, na sua maioria, de baixa escolaridade ou cursos técnicos).

Dos pacientes, 90\% referiram ter um companheiro, e, 95\% moravam com familiares. O suporte emocional proporcionado pelo companheiro contribui para melhor adesão a tratamentos de saúde, percepção de controle, senso de estabilidade e bem estar emocional ${ }^{(67-69)}$. Para os indivíduos entrevistados, a presença do companheiro durante o período de preparo para a colonoscopia mostrou-se um fator de impacto para auxiliá-los na contagem do tempo para ingerir o laxativo, na hidratação corporal e para minimização da ansiedade.

Neste estudo a crença religiosa foi incluída como variável, pois os indivíduos podem recorrer como uma estratégia de enfrentamento, pois, muitas vezes, necessitam de fontes de apoio para enfrentar as diversas situações de vida dentre as quais a doença.

A hipertensão arterial sistêmica (HAS) foi a patologia de maior frequência na população do estudo. Trata-se de uma doença cardiovascular de alta prevalência, acomete mais de $60 \%$ da população com 60 anos ou mais, com envolvimento daqueles de etnia negra e do sexo feminino. Acompanhando esse expressivo número, encontram-se a alta prevalência de fatores de risco e comorbidades, que, agregados à mesma, tornam essa condição clínica associado com o envelhecimento, responsável por tão elevada taxa de eventos cardíacos e cerebrovasculares ${ }^{(70)}$.

Entretanto, os antecedentes familiares e pessoais de câncer de colón, variáveis clínicas estas relacionadas diretamente ao procedimento, foram duas importantes características utilizadas. A colonoscopia, para a maioria dos pacientes estudados, foi utilizada como método de rastreamento ou acompanhamento de neoplasias ou demais lesões colônicas.

Os indivíduos com histórico familiar de pólipos ou câncer de cólon, mas sem qualquer suscetibilidade genética, tem um risco aumentado de 
desenvolver câncer de cólon comparado aos sem histórico ${ }^{(71)}$. Em uma metaanálise de estudos de coorte, o risco relativo de pacientes desenvolverem câncer de cólon devido um parente de primeiro grau diagnosticado positivamente para a lesão foi estimado em 2,24, e aumentou para 3,97, se, dois parentes de primeiro grau foram afetados ${ }^{(72)}$.

Para os indivíduos sem histórico de câncer de cólon e com idade inferior a 50 anos o aproveitamento da colonoscopia é relativamente baixo em comparação com os pacientes com histórico familiar. Em estudo randomizada, a eficácia da colonoscopia como método de minimização de incidência e mortalidade de pacientes com histórico familiar de neoplasia de cólon foi determinada como elevada frente aos demais individuos da pesquisa $^{(73-74)}$.

Entretanto, para entender a necessidade do rastreamento desses pacientes é necessário compreender o câncer colorretal. No Brasil, o câncer de colón configura-se como problema de saúde pública de dimensão nacional, pois, o câncer de cólon e reto em homens é o segundo mais frequente na região Sudeste e terceiro nas regiões Sul e Centro-oeste; já para as mulheres, é o segundo mais frequente nas regiões Sudeste e Sul ${ }^{(16,75-76)}$.

A localização mais frequente de neoplasias primárias do intestino grosso é o terço distal do cólon transverso e cólon descendente. Entre os fatores relacionados ao desenvolvimento do câncer de cólon, encontram-se, principalmente, a idade (sendo a maioria dos casos diagnosticada após os 60 anos), dietas inadequadas, história de parentes de primeiro grau com adenomas diagnosticados antes dos 60 anos de idade, história pessoal pregressa de adenomas ou câncer de mama, ovário ou endométrio, e, portadores de colite ulcerativa crônica ou Doença de Crohn também apresentam risco aumentado de desenvolverem câncer do intestino ${ }^{(77)}$.

O câncer do cólon tem a particularidade de exibir lesão precursora conhecida que é o pólipo adenomatoso e o tempo estimado para aparecimento do adenoma é superior a 10 anos, período este suficientemente longo para permitir sua identificação, ressecção e, portanto, prevenção do câncer. A alta 
incidência do câncer de colón e a diferença nos resultados do tratamento, de acordo com o estádio da doença, justificam os esforços para detecção precoce e de seu rastreamento em população considerada de risco para a doença ${ }^{(75,77-81)}$.

Por rastreamento entende-se a aplicação de provas simples, de fácil execução em grande massa populacional, com o objetivo de selecionar indivíduos que, ainda que assintomáticos, devem submeter-se a métodos mais específicos e de maior complexidade para a possível detecção de adenomas e de câncer precoce, seu objetivo não é diagnosticar, mas sim diminuir a mortalidade por câncer na população alvo ${ }^{(78-79)}$.

Como resultado de avaliações epidemiológicas e de genética molecular, o rastreamento deve ser realizado de acordo com a estimativa de risco para a neoplasia que o indivíduo apresenta: pacientes com idade superior a 50 anos, sem outros fatores de risco geralmente integram a População de Baixo Risco deve-se considerar pesquisa de sangue oculto em fezes a cada dois anos e a cada cinco anos sigmoidectomia flexível; pacientes com história familiar em um ou mais parentes de primeiro grau, história pessoal de pólipo maior do que um centímetro ou múltiplos pólipos de qualquer tamanho e os indivíduos com antecedente pessoal tratado com intenção curativa são classificados como de Risco Moderado deve ser considerado colonoscopia a cada cinco anos a partir dos 50 anos ou menos de dez anos para os pacientes mais jovens; e os indivíduos com história familiar hereditário na forma de PAF (polipose adenomatosa familiar) ou HNPCC (câncer colorretal hereditário sem polipose), ou com diagnóstico de doença inflamatória intestinal na forma da pancolite ou colite esquerda geralmente são de Alto Risco para desenvolver de câncer e para seu rastreamento devese realizar colonoscopia a cada um ou dois anos para familiares com hereditariedade comprovada para o câncer com inicio aos 25 anos ou cinco anos antes da primeira idade de diagnóstico do familiar ${ }^{(80-83)}$.

Em estudo atual realizou-se a avaliação da prevalência de risco familiar e sua associação com a ocorrência de lesões, observou-se que 
parentes de primeiro grau têm maior risco de desenvolver câncer de cólon, associado a fatores como idade avançada e o maior número de familiares com câncer de cólon e, também, que a colonoscopia ${ }^{(84)}$.

Com relação ao histórico pessoal de câncer de cólon, estudo revela que há evidências significativas sobre a associação entre a presença de pólipos com hábitos alimentares inadequados e de vida considerados de risco, como tabagismo e etilismo ${ }^{(85)}$.

Apesar da importância da colonoscopia para esta classe de pacientes que possuem histórico familiar e pessoal de câncer de cólon são reconhecidas as dificuldades inerentes à realidade brasileira relacionadas às condições socioeconômicas desfavoráveis, desconhecimento da população sobre este tipo de câncer, falta de acesso ao sistema de saúde e insuficiente disponibilidade diagnóstica. Esta realidade é responsável pelo atraso do diagnóstico e o tratamento de lesões, em geral em estádios avançados, que são mais complexos e demandam internações prolongadas ${ }^{(78,80-82,86)}$.

Além do histórico de câncer, os pacientes apresentaram outras alterações gastrintestinais, que acarretaram na indicação da colonoscopia, alterações do hábito intestinal, acompanhamento de doenças inflamatórias intestinais, dor abdominal a esclarecer, sangramento retal e anemia constituíram as causas mais comuns para a realização do exame.

Esses dados se correlacionam com a literatura, que denotam a colonoscopia como um excelente método de diagnóstico e tratamento para as doenças do cólon em pacientes adultos, pois contribuem com alta incidência de diagnósticos, embora nem sempre relacionados aos sintomas apresentados $(1,8)$.

No tocante aos fatores relacionados à colonoscopia, os pacientes foram analisados conforme a quantidade de exames realizados previamente, os motivos para a realização do procedimento, tipo de preparo realizado, conhecimento prévio, sentimentos e preocupações relacionados ao exame. 
Verificou-se que quanto ao tipo de preparo para a colonoscopia, 97\% dos pacientes realizaram o preparo domiciliar com complementação no Serviço de Endoscopia do Hospital Universitário.

Lembrando que o método de preparo ideal deve apresentar vantagens em relação à eficácia, à segurança, ao custo, à facilidade de administração e à tolerância do paciente, contudo ainda não está disponível uma substância que apresente todas estas qualidades, e, que a complementação do preparo pode ocasionar uma variedade de efeitos adversos pelas medicações utilizadas, como por exemplo, desidratação, dor abdominal intensa e diarréia prolongada. Sobretudo, apesar da alta sensibilidade do procedimento, o mesmo pode ser inefetivo para diagnósticos, caso haja a impossibilidade de visualização do ceco devido preparo inadequado, com presença de resíduos no cólon, favorecendo resultados errôneos ou inconclusivos $(1,8,87)$.

A colonoscopia com complementação de preparo realizado ambulatorialmente foi considerada como melhor escolha pela instituição, pois há a possibilidade de acompanhar o paciente durante a complementação do preparo, verificando a sua efetividade e diminuindo riscos de intercorrências ou reações adversas durante a complementação.

Nesta discussão, a análise das características biossociais, clínicas e referente à colonoscopia dos pacientes ficaram restritas aos aspectos mais relevantes e significativos, de modo que pudessem ser analisados, posteriormente, em associação com o estresse percebido e os processos de enfrentamento mais utilizados.

Outras diversas variáveis, tais como número de filhos, religião, profissão, conhecimento prévio do exame, sentimentos e preocupações referentes ao procedimento, também foram analisadas, juntamente com o estresse percebido e os processos de enfrentamento mais utilizados, porém optou-se por não incluí-las na análise do estudo, pois não se constatou significância estatística em nenhuma destas. 


\subsection{ESTRESSE PERCEBIDO, FATORES PREDITORES DE ESTRESSE E ESTRATÉGIAS DE COPING PARA PACIENTES EM PERÍODO PRÉ- PROCEDIMENTO COLONOSCÓPICO}

Após a análise da caracterização desta população irá se discutir os resultados das manifestações do estresse percebido e estratégias de enfrentamento mais utilizadas e sua relação com os fatores preditores de estresse na amostra selecionada.

Pretendeu-se, nesta pesquisa, comparar a literatura nacional e internacional sobre o estresse percebido com a percepção de estresse dos pacientes em período de preparo para a colonoscopia, avaliada através da Escala de Estresse Percebido - PSS - 10 e caracterizada por média de 22,25 pontos. Após a comparação realizada, pelo Teste $\mathrm{t}$ de Student, entre os resultados das médias encontrados na pesquisa atual $(22,25)$ com os resultados das médias encontrados na pesquisa de tradução e validação para a língua portuguesa da Escala de Estresse Percebido $(15,13)$ permite observar que há uma diferença estatisticamente significativa entre ambos os valores e pode-se afirmar que os pacientes da pesquisa atual possuem maior percepção de estresse ${ }^{(36)}$.

Esta diferença de médias entre ambas, possivelmente, se deve ao fato de que na amostra de validação, idosos participantes de grupos de estudo, não estavam vivenciando, no momento da coleta de dados, um evento específico de estresse como os pacientes desse estudo, que estão prestes a iniciar um preparo de cólon, muitas vezes, demorado e incomodo cujo resultado poderá ser determinante na condução de suas vidas.

Outra comparação realizada, com teste t de Student, entre a pesquisa atual com pacientes diabéticos, também verificou significância estatística entre os valores dos resultados das médias de ambas, sendo eles de 22,25 e 21,34, respectivamente, o que denota uma diferença muito pequena entre ambos. Essa semelhança justifica-se, provavelmente, pois os pacientes em ambas pesquisas estão, na sua maioria, em tratamento de doenças crônico- 
degenerativas ou estão em fase de acompanhamento e avaliação de sintomas e doenças, o que pode gerar sensação de insegurança e medo, fatores este de estresse para estes indivíduos ${ }^{(88)}$.

$\mathrm{Na}$ análise das variáveis preditores de estresse, sexo, idade, estado civil, escolaridade, tipo de preparo e número de exames, foi verificado significância estatisticamente significativas.

Com relação ao sexo, as mulheres, nesta pesquisa, apresentaram maior percepção de estresse que os homens. Verifica-se que este resultado vem ao encontro com outros estudos em que mostram que as mulheres apresentam maior percepção de estresse do que os homens. As mulheres do estudo atual referiram medo de diagnóstico desfavorável (câncer) que para elas tem um significado de mudança do estilo e do contexto de vida, pois, por serem em sua maioria já aposentada, o cuidado doméstico e familiar fica sob sua responsabilidade.

$\mathrm{Na}$ comparação do nível de estresse e de depressão em pacientes em tratamento de diálise verificou-se que o sexo feminino, mesmo em menor número, apresenta a maior média de estresse. Outro estudo que valida a escala de PSS na Europa, demonstrou que as mulheres apresentaram escores significativamente mais elevados. A diferença entre os gêneros e maior percepção de estresse entre as mulheres emergiu também quando examinada a relação entre o estresse percebido e comportamentos alimentares ${ }^{(89-91)}$.

Fatores culturais, ambientais, hormonais e genéticos podem estar associados a essa maior percepção feminina. Embora homens e mulheres pareçam ser igualmente afetados pelo estresse ambiental e cultural, as mulheres têm sido sobrecarregadas pela multiplicidade de papéis sociais e familiares que atualmente assumem, estando mais vulneráveis a doenças emocionais e também sofrem influência dos hormônios femininos.

Há indícios que o sexo feminino apresenta maior sensibilidade emotiva do que os homens, aspecto especialmente vinculado a seus papéis familiares e conjugais ${ }^{(91-94)}$. As maiores fontes de estresse apontadas, em estudo prospectivo, pelas participantes, mulheres com câncer, estavam 
ligadas a relações familiares e a problemas nessa área da vida. Os problemas familiares relatados foram compreendidos como fontes prolongadas de estresse, cujo enfrentamento exige esforços contínuos e repetidos no cotidiano, aumentando seu potencial "estressogênico" (94).

A influência dos hormônios femininos é considerada a principal característica e que determina a diferença de percepção do evento como estressor entre os gêneros, principalmente, durante a segunda fase do ciclo menstrual, gestação e menopausa da mulher ${ }^{\left({ }^{94)}\right.}$. Neste estudo, contudo, não foi controlada essa influência nas participantes o que pode acarretar em limitações para essa comparação.

Outra característica está na diferenciação das áreas cerebrais estimuladas para ativação do eixo central do estresse entre os gêneros. Para os homens, a ativação do eixo está relacionada com o córtex pré-frontal influenciando resposta de enfrentamento ao estresse mais racional; já para as mulheres, há a estimulação do sistema límbico, área essa que controla e regula as emoções e que possivelmente dará origem à construção de estratégias de enfrentamento mais emotivas frente ao evento ${ }^{(95)}$.

$\mathrm{Na}$ relação do estresse e estratégias de enfrentamento, as mulheres apresentaram médias de pontuação maiores e com significância estatística para as estratégias Confronto, Afastamento, Aceitação da Responsabilidade e Reavaliação Positiva com exceção do Suporte Social. Acredita-se que por apresentarem maior estresse utilizam também de maneira mais intensa as estratégias de enfrentamento na tentativa de diminuir a carga emocional do evento. Vale destacar que todas as estratégias pelas mulheres utilizadas estão embasadas em atitudes emocionais com o intuito de aceitar ou amenizar a realidade da situação que poderá vivenciar.

Para o sexo feminino, a frustração e a incerteza podem ser comparadas a uma falha na sua responsabilidade de se auto-proteger e cuidar da sua família ${ }^{(96-97)}$. Aliado com a auto-proteção, o sentimento de culpa foi um dos aspectos mais presentes nos relatos de pacientes e pode-se supor que a 
presença deste sentimento acarrete uma sobrecarga emocional adicional ao que a doença ou incerteza já ocasiona.

Posteriormente, ao se analisar o estressor idade pode-se concluir que os indivíduos entre 20 e 39 anos e os idosos, com 65 anos ou mais, apresentaram maior percepção de estresse do que os indivíduos na faixa etária entre 40 e 64 anos. Nesta pesquisa acredita-se que os mais jovens estão mais preocupados com as características do procedimento, ou seja, sedação, medo de sentir dor, o desconforto da complementação do preparo, sentem-se inseguros e envergonhados pelas características inerentes do procedimento e pela via de acesso para sua realização, além disso, para muitos é primeiro procedimento que se submetem.

De modo diferente, os idosos referem preocupação com o resultado do diagnóstico e pelo impacto que poderá acarretar na continuidade da vida. A possibilidade do resultado desfavorável, como a presença do câncer, sucinta sentimentos de medo relacionados com o tratamento e os recursos disponíveis para provimento do próprio cuidado e de seus familiares.

Em especial, o idoso brasileiro experimenta diariamente dificuldades, sendo a burocracia da aposentadoria, a dificuldade financeira, problemas com o atendimento à saúde, morte de amigos e familiares e a discriminação social tornam o idoso cada vez mais susceptível ao estresse e à depressão ${ }^{(36,98)}$. Neste sentido, os idosos deste estudo vivenciam, muitas vezes, doenças já existentes que em associação com as dificuldades acima referida, necessitam de ajustamento para condução de vida com melhor qualidade possível. Neste contexto a família exerce uma função importante no suporte para sua manutenção e equilíbrio emocional.

As redes sociais formadas por familiares e amigos significativos diminui o efeito do estresse nos indivíduos mais velhos. Estas redes oferecem suporte na forma de afeto e assistência. A ausência de parentes, especificamente mais próximos, está associada com agravamento de doenças e mortalidade entre idosos ${ }^{(99)}$. 
Mesmo considerando a importância do Suporte Social para os idosos, os adultos jovens também utilizaram o Suporte Social como forma de enfrentamento. Outro aspecto importante é a utilização do Afastamento por este grupo de indivíduos jovens. Neste contexto de negação dos sentimentos de medo advindos de uma situação de ameaça faz com que outras estratégias possam surgir, sendo estas, muitas vezes, associadas a comportamentos poucos saudáveis.

Já na avaliação do fator estado civil ressaltou-se, neste estudo, que há uma maior percepção de estresse dos pacientes que possuíam um companheiro (esposo(a), namorado(a)).

Os dados revelam que nem sempre a presença de um vínculo afetivo minimiza o estresse, uma vez que o resultado da colonoscopia pode alterar toda uma rotina de vida do paciente e influenciar na sua relação hierárquica e financeira frente à família. Na comparação desse estressor com os estilos de coping observou-se que os mesmos utilizaram todos os estilos selecionados, sendo o Suporte Social aparece com maior média de pontuação.

Sabe-se que rede social, seja através dos familiares e amigos, ou a busca de pessoas para o esclarecimento de dúvidas, contribui que este estilo seja frequentemente utilizado. A presença de suporte psicossocial e de rede social propicia melhor qualidade de vida para os pacientes.

Consequentemente duas vertentes podem ser analisadas, o Suporte Social como fator positivo no auxilio da redução do estresse ou negativo frente ao mesmo. Para a primeira, observa-se uma associação positiva entre saúde mental e o apoio social, esse último funcionando como mediador do estresse e modificando seu efeito. O indivíduo que conta com alto nível de apoio social enfrenta mais positivamente às situações estressantes se comparado a outros que não dispõem deste recurso ${ }^{(100)}$.

Porém, ao analisar a segunda vertente, a negativa, percebe-se que o Suporte Social também pode causar percepção de falta de autonomia e dificuldade para retribuir a ajuda recebida. Estudos mostram que esta percepção é um fator e pode acarretar insatisfação, estresse, e depressão, que 
normalmente está também associada com um sentimento de ser uma carga para pessoas da rede de apoio. Cabe destacar que as consequências negativas são mais prevalentes em sociedades como a ocidental na qual a produtividade é um valor importante ${ }^{(99,101)}$.

Neste estudo, a escolaridade foi apresentada como fator preditor importante de estresse percebido, sendo que os indivíduos não letrados $(27 \%$ da população) e pacientes que iniciaram pelo menos o segundo grau (33\%) corroboraram para os níveis mais altos de percepção de estresse.

Outros três estudos também caracterizaram que quanto menor o grau de escolaridade do individuo maior a sua percepção de estresse frente aos inúmeros fatores a ele associados ${ }^{(36,50-51)}$. Acredita-se que a escolaridade tenha se caracterizado como estressor devido a todas as informações serem repassadas por meio de folders explicativos, além de uma orientação verbal repassada rapidamente pelas enfermeiras responsáveis no momento do agendamento do exame e, caso algum item não tenha sido totalmente esclarecido, a baixa escolaridade pode influenciar no entendimento incompleto ou incorreto e contribuir para um preparo inadequado e possível suspensão do procedimento.

A escolaridade apresentou-se como um forte preditor em outro estudo onde também se verifica que houve o predomínio de enfrentamento focalizado na emoção, neste caso o Suporte Social, por pessoas com menor escolaridade menor, permitindo supor que dificuldades relativas à condição socioeconômica somar-se-iam às dificuldades da condição de saúde resultando em um número maior de estressores, com repercussão negativa sobre o bem-estar psicológico e sobre a apreciação da qualidade de vida ${ }^{(102)}$.

Aspectos socioeconômicos podem estar aqui implicados: eventualmente em função de maior preconceito junto a segmentos menos escolarizados da população poderiam estar com mais dificuldade de receber apoio emocional. Pode-se presumir, ainda, que níveis mais altos de escolaridade estariam favorecendo as habilidades sociais e de comunicação, 
levando a condições facilitadoras da busca e da satisfação com o suporte emocional recebido.

Nesta pesquisa houve o predomínio de preparo tipo ambulatorial (93\%) com o preparo iniciado em domicílio, com o uso de laxativos e dieta leve, e realizam a sua complementação para a colonoscopia no Serviço de Endoscopia do HU. Esse fato em si já poderia ocasionar um aumento do estresse percebido, entretanto, adiciona-se a essa questão a necessidade de realizar evacuações em um ambiente totalmente diferente e com a presença de outros pacientes em uma mesmo local.

$\mathrm{Na}$ tentativa de melhor se adaptarem à situação de estresse citada, a estratégia que obteve maior média da pontuação foi Aceitação da Responsabilidade. Pode-se entender que com esta estratégia o indivíduo assume a responsabilidade pela dieta no dia anterior ao preparo hospitalar e na ingestão dos medicamentos laxativos para auxiliar no processo de limpeza colônica.

As dificuldades relacionadas ao preparo intestinal podem interferir na tolerância da situação e propiciar desconforto e impacto emocional negativo nos pacientes. Sabe-se da importância que esses fatores sejam minimizados através de estratégias adequadas orientação, por meio de vídeos ou folders explicativos e uso de intervenções, como a musicoterapia e acompanhamento da enfermagem durante o preparo complementar de colón para aumentar a probabilidade de um preparo completo, bem sucedido e com menor impacto emocional ${ }^{(103-104)}$.

Além de aumentar os riscos processuais e custos da colonoscopia, um preparo intestinal inadequado aumenta o risco e dificulta a visualização de pólipos e na busca por lesões indicativas de câncer. Portanto, melhorar a tolerância do paciente e de conformidade com preparo intestinal pode aumentar a probabilidade de um procedimento completo e bem sucedido e com menores indices de percepção de estresse pelos pacientes. 
O constrangimento provocado pelas inúmeras evacuações, sua urgência e o enfraquecimento físico que provoca é um fator que, muitas vezes, dificulta a adesão do procedimento pelos pacientes.

Os exames endoscópicos são considerados procedimentos invasivos, desconfortáveis e estressantes. A colonoscopia, em virtude da necessidade de laxantes para o preparo do cólon, de sua complexidade técnica e do constrangimento devido à maior exposição, causa ansiedade, preocupação e exposição do indivíduo ao preconceito. No entanto, a colonoscopia é, atualmente, o procedimento de escolha para investigação de enfermidades do intestino grosso de elevada acurácia e possibilidade de realização de procedimentos terapêuticos, mas requer elevada colaboração e tolerância dos pacientes. A tolerância pode ser interpretada de várias maneiras, como aceitação, nível de satisfação e conforto durante o exame, ou disposição para repetir o procedimento.

A última avaliação a ser efetuada é a correlação entre o número de exames realizados previamente pelos pacientes, o estresse percebido e a estratégia de enfrentamento mais utilizada. Nesta análise verifica-se que quanto maior o número de procedimentos realizados menor será o estresse percebido pelo paciente. Possivelmente neste processo de repetição de exames, o indivíduo conhece o preparo, os fatores de risco envolvidos e o fator surpresa com o resultado se torna mais controlado.

Ainda, na medida em que os pacientes se submetem ao procedimento de rotina, diminui o risco das lesões pré-malignas (pólipos) se tornarem lesões tumorais de maior comprometimento.

A fim de minimizar o estresse desses pacientes houve o fornecimento de informações e/ou orientações antes do procedimento colonoscópico, proporcionando ao paciente um mecanismo de participação das decisões sobre o tratamento e redução de ansiedade. O oferecimento de informações irá maximizar o conhecimento e minimizar a ansiedade.

Há diferentes formas de oferecer informações, a mais utilizada é a orientação escrita reconhecida pela sua importância, porém, restringe-se a 
uma classe populacional, pois requer minimimamento uma alfabetização básica, bem como a motivação para ler o material fornecido.

Nesta associação de estresse percebido, número de procedimentos realizados e estilo de enfrentamento, observa-se que Aceitação da Responsabilidade foi mais pontuado e se justifica pelo entendimento do indivíduo tem sobre na adesão ao tratamento, principalmente para o controle de lesões polipóides e de novas lesões tumorais ou para o rastreamento de neoplasias e doenças intestinais crônicas.

Quanto a Aceitação de Responsabilidade, o indivíduo aceita a realidade e engaja-se no processo de lidar com a situação estressante. Muitas vezes o paciente se sente responsável por desencadear a situação estressante e neste sentido, enfrenta sentimentos de autocrítica e repreensão. Porém, esses sentimentos podem ter um efeito motivador, estimulando-o a enfrentar seus problemas de maneira diferente, com intuito de permanecer o controle sobre a doença e autonomia para o cuidado ${ }^{(29)}$. 
CONCLUSÕES 
"Por mais longa que seja a caminhada o mais importante é dar o primeiro passo."

Vinicius De Moraes

Com os achados desta pesquisa pode-se concluir que:

$\checkmark$ O perfil biossocial da amostra foi, predominantemente, de mulheres (73\%), com idade superior a 65 anos (50\%), casados ou com companheiros (90\%), com pelo menos um filho (38\%), a escolaridade foi de indivíduos com segundo grau completo ou incompleto (33\%), de religião Evangélica (48\%), em sua maioria aposentados (48\%).

$\checkmark$ A maioria apresentou história clínica de hipertensão (90\%) e histórico familiar de câncer de colón (68\%).

$\checkmark$ A maioria (66\%) já tinha realizado um ou mais exames com preparo ambulatorial (93\%) e tinham conhecimento do exame como método diagnóstico de doença e sobre a necessidade de preparo específico $(77 \%)$.

$\checkmark$ Os pacientes referiram medo e constrangimento do exame (72\%), principalmente relacionado ao diagnóstico pós-procedimento $(41 \%)$.

$\checkmark$ Os valores da média da pontuação da Escala de Estresse Percebido nesta amostra foi de 22,25 pontos, com variação de 9 a 15 pontos ( 9 pacientes); 16 a 21 pontos (28 pacientes) e 22 a 27 (63 pacientes).

$\checkmark$ Houve predominância dos domínios Suporte Social, Aceitação da Responsabilidade, Reavaliação Positiva, Afastamento e Confronto.

$\checkmark$ Sexo, idade, estado civil, escolaridade, tipo de preparo realizado e número de exames realizados foram determinados como fatores preditores de estresse; 
As correlações estatisticamente significativas compreenderam:

$\checkmark$ A correlação entre a Escala de Estresse Percebido e as estratégias de enfrentamento foram significantes para os domínios Afastamento, Suporte Social, Aceitação da Responsabilidade e Reavaliação Positiva;

$\mathrm{Na}$ comparação entre os sexos houve predominância da média de pontuação da Escala de Estresse Percebido para o sexo feminino com significância estatística. Da mesma forma houve predominância de médias de pontuação para o sexo feminino em todos domínios. Foi observada significância estatística para todos os domínios com exceção do Suporte Social.

Na comparação entre as faixas etárias houve predominância da média de pontuação da Escala de Estresse Percebido para as faixas entre 20 e 39 anos e 65 anos ou mais com significância estatística. Na comparação entre as faixas houve predominância das médias de pontuação dos domínios Afastamento e Suporte Social para indivíduos de 20 a 39 anos e Aceitação de responsabilidade e Avaliação positiva para os indivíduos com 65 anos ou mais e este resultado apresentou significância estatística.

Na comparação entre os indivíduos sem companheiros com aqueles casados ou com namorado houve predominância da média de pontuação da Escala de Estresse Percebido para aqueles com companheiro e esta diferença apresentou significância estatística. $\mathrm{Na}$ comparação entre as duas variáveis houve predomínio da média de pontuação para os domínios Confronto, Afastamento, Suporte Social, Aceitação da Responsabilidade e Reavaliação Positiva para os indivíduos casados legalmente ou não e com namorado e este resultado apresentou significância estatística. 
$\mathrm{Na}$ comparação entre os graus de escolaridade houve predominância da média de pontuação da Escala de Estresse Percebido dos indivíduos não letrados e aqueles com segundo grau completo/incompleto e esta diferença apresentou significância estatística. $\mathrm{Na}$ comparação entre a escolaridade houve predomínio da média de pontuação para os domínios Confronto, Afastamento, Suporte Social, Aceitação da Responsabilidade e Reavaliação Positiva para os indivíduos com segundo grau completo/incompleto e este resultado apresentou significância estatística.

$\checkmark \mathrm{Na}$ comparação entre os tipos de preparo houve predominância da média de pontuação da Escala de Estresse Percebido dos indivíduos com preparo ambulatorial e esta diferença apresentou significância estatística. $\mathrm{Na}$ comparação entre o tipo de preparo houve predomínio da média de pontuação para os domínios Confronto, Afastamento, Aceitação da Responsabilidade e Reavaliação Positiva para os indivíduos com preparo ambulatorial e este resultado apresentou significância estatística.

$\mathrm{Na}$ comparação entre o número de exames realizados foi observado que quanto maior o número de exames menor a percepção de estresse dos indivíduos. Nesta mesma comparação com os domínios de enfrentamento foi observado que quanto maior o número de exames realizados menor a utilização dos domínios Confronto e Afastamento e maior a utilização dos domínios Aceitação da Responsabilidade, Suporte Social e Reavaliação Positiva. 
CONSIDERAÇÕES FINAIS 
"Dê a quem você ama: asas para voar, raízes para voltar e motivos para ficar."

$\underline{\text { Dalai Lama }}$

Estudar estresse e os estilos de coping como processo interativo entre pacientes que estão em período de preparo para exames diagnósticos e terapêuticos revelou muitas dificuldades para obtenção de dados correlativos na literatura mundial, mas os resultados desta pesquisa demonstraram-se significativos.

Quanto aos resultados obtidos, vale ressaltar que a coleta de dados, nesta pesquisa, foi realizada no momento prévio ao início da complementação do preparo para a colonoscopia o que pode ter afetado ou influenciado na percepção de estresse do paciente. Neste momento, possivelmente altos níveis de estresse psicológico puderam ser observados, o que, por este motivo, levou muitos pacientes a negaram sua participação, pois, tinham medo de atrasar o preparo ou que qualquer dado apresentado na coleta de dados pudesse alterar a conduta com relação ao exame.

Também foi possível verificar que os estilos de coping focados na emoção foram predominantes e podem estar associados a características pessoais, seja por fatores biossociais, clínicos ou correlacionados ao exame.

Para concluir, não se poderia deixar de enfatizar a importância não só da inclusão dos conceitos de estresse e coping nos cursos de graduação de enfermagem, como também na avaliação de saúde dos pacientes em preparo para exames diagnósticos.

O cuidado dos pacientes nesta situação deve ser revisto como uma atividade que merece preparo técnico e científico de seus profissionais. A consciência da importância da avaliação do estresse pela equipe de saúde nas diferentes esferas da assistência pode contribuir positivamente para conhecer as alterações emocionais e para que se desenvolvam intervenções que 
contribuam para uma melhor adaptação do indivíduo frente a situações de desafio e melhore a qualidade do cuidado.

Os resultados deste estudo merecem reflexões que visem o esclarecimento do estresse e das estratégias de enfrentamento como um processo dinâmico e que faz parte da vida de cada indivíduo nas diferentes situações, permitindo assim, autoconhecimento, avaliação e reavaliação dos estressores pelos pacientes no processo de preparo para a colonoscopia, para que estes possam enfrentá-los com segurança e efetividade. 


\section{LIMITES DA PESQUISA}


"Não é o que você faz, mas quanto amor você dedica no que faz é o que realmente importa." Madre Teresa De Calcutá

Os limites da pesquisa serão apresentados segundo dificuldades encontradas com relação a:

\section{$\checkmark$ POUCOS ARTIGOS CORRELACIONADOS ENCONTRADOS}

Os estudos com foco sobre o tema são incipientes e, futuramente pretende-se continuar buscando novos conhecimentos nesta linha de pesquisa, os quais poderão possibilitar mudanças nas intervenções para minimizar o estresse percebido pelo paciente e auxiliar no desenvolvimento de estratégias de enfrentamento efetivas.

Um ponto que deve ser destacado é a inexistência de estudos brasileiros sobre estresse percebido e estilos de coping em pacientes em período pré-procedimento colonoscópico, o que, de certa forma, dificultou a comparação de resultados.

\section{$\checkmark \quad$ ESCALA DE ESTRESSE PERCEBIDO - PSS-10}

A escala PSS -10, possivelmente ainda não esteja adequada para ser usada com toda a população brasileira, pelo menos não para a população desse estudo. Esse fato pode ser verificado através da observação dos valores de alfa de Cronbach do item $\mathrm{n}^{\circ} 01$ que apresentou valores inversos, aos demais itens da escala, indicando que o mesmo possivelmente necessita ser readaptado ou reajustado para a língua portuguesa. Sugere-se a realização de mais estudo clínicos de validação do instrumento para a comparação dos resultados apresentados. 
$\checkmark$ CARACTERÍSTICAS DA POPULAÇÃO

$\checkmark$ PREDITOR SEXO - MAIOR RECUSA DE HOMENS

$\checkmark$ PREDITOR TIPO DE PREPARO 


\section{REFERÊNCIAS}


"A vida é uma peça de teatro que não permite ensaios. Por isso cante, chore, ria e viva intensamente antes que a cortina se feche e a peça termine sem aplausos.”

Charlie Chaplin

1. Nahas SC, Alves PRA, Araújo SEA. Emprego da colonoscopia como método diagnóstico e terapêutico das doenças do intestino grosso. Resultados observados em 1.715 exames. Rev Hosp Clin Fac Med S Paulo 1998; 53:11721.

2. Morgan J, Roufeil L, Kaushik S, Bassett M. Influence of coping style and pre colonoscopy information on pain and anxiety of colonoscopy. Gastrointest Endosc 1998; 48(8):119-127.

3. Jones MP, Ebert CC, Sloan T, Spanier J, Bansal A, Howden CA, Vanagunas AD. Patient anxiety and elective gastrointestinal endoscopy. J Clin Gastroenterol 2004; 38(1):35-40.

4. Habra-Gama A, Bringel RWA, Nahas SC, Araújo SEA, Souza Jr AH, Calache JE, Alves PA. Bowel preparation for colonoscopy: comparison of mannitol and sodium phosphate - Results of a prospective randomized study. Rev Hosp Clin Fac Med São Paulo 1999; 54(6):187-192.

5. Silva EJ, Câmara MAR, Gaidão E, Almeida EC. Colonoscopia: Análise crítica de sua indicação. Rev bras Coloproct 2003; 23(2): 77-81.

6. Freitas MC, Mendes MMR. Condição crônica: análise do conceito no contexto da saúde do adulto. Rev Latino-Am. Enfermagem 2007; 15(4): 5907. 
7. Serafim TS, Costa ALS. Sintomas somáticos de depressão em pacientes portadores de Retocolite Ulcerativa Idiopática. Acta Paul Enferm 2009; 22(3): 295-300.

8. Nahas SC, Marques CFS, Araújo SA, Aisaka AA, Nahas CSR, Pinto RA, Kiss DR. Colonoscopia como método diagnóstico e terapêutico das moléstias do intestino grosso: análise de 2.567 exames. Arq Gastroenterol. $2005 ; 42(2): 77-82$.

9. Thuller FPBM et al. Quantos exames são necessários para adquirir aptidão em colonoscopia?. Arq. Gastroenterol 2004; 41(4): 211-4.

10. Quilici FA. Colonoscopia. In: Magalhães AF, Cordeiro FT, Quilici FA, et al. Endoscopia Digestiva. Editora Revinter - RJ; 2004.

11. Brandt LJ. Patients' attitudes and apprehensions about endoscopy: how to calm troubled waters. Am J Gastroenterol 2001; 96(2): 280-4.

12. Condon A, Graff L, Elliot L, Ilnyckyj A. Acceptance of colonoscopy requires more than test tolerance. Can J Gastroenterol 2008; 22(1): 41-7.

13. Medeiros VCC. Paciente cirúrgico: a influência da ansiedade nas estratégias de enfrentamento utilizadas no período pré-operatório. Escola de Enfermagem - USP 2002.

14. Brenner AS; Lima VZ; Valarini SBM; Valarini R; César AMP. Colonoscopia em pacientes não pediátricos abaixo de 20 anos de idade traz pouca contribuição nos resultados. Rev bras Coloproct 2007; 27(4): 412-16.

15. Radaelli F, Meucci G, Sgroi G, Minoli G, Italian Association of Hospital Gastroenterologists (AIGO). Technical performance of colonoscopy: the key role of sedation/analgesia and other quality indicators. Am J Gastroenterol 2008; 103: 1122-30. 
16. Ministério da Saúde (Brasil), Instituto Nacional do Câncer. Estimativa 2012 - incidência de câncer no Brasil. Rio de Janeiro: Instituto Nacional do Câncer 2011.

17. Miles A, Atkin WS, Kralj-Hans I, Wardle J. The psychological impact of being offered surveillance colonoscopy following attendance at colorectal screening using flexible sigmoidoscopy. J Med Screen 2009; 16: 124-30.

18. Lorencetti A, Simonetti JP. As estratégias de enfrentamento de pacientes durante o tratamento de radioterapia. Rev Latino-Am. Enfermagem $2005 ; 13(6): 944-50$.

19. Habr-Gama A. Câncer coloretal: a importância de sua prevenção. Arq Gastroenterol 2005; 42(1): 2-3

20. Lyra HF, Bonardi MA, Schiochet VJC, et al. Importância da colonoscopia no rastreamento de pólipos e câncer colorretal em pacientes portadores de pólipos retais. Rev bras Coloproct 2005; 25(3): 226-34.

21. Mandel JS. Screening for colorectal cancer. Gastroenterol Clin North Am 2008; 37(1): 97-115.

22. Lichtenstein GR, Cohen LB, Uribarri J. Review article: Bowel preparation for colonoscopy--the importance of adequate hydration. Aliment Pharmacol Ther 2007; 26(5): 633-41.

23. Brambilla E, dal Ponte MA, Manzini M, Fellini RT, Buffon VR, May RS. Preparo de cólon para colonoscopia com polietilenoglicol versus sulfato de magnésio em pacientes acima de 70 anos de idade. Rev bras Coloproct $2008 ; 28(2): 204-9$.

24. Ivano FH, Romeiro PC, Matias JE, Baretta GA, Kay AK, Sasaki CA, Nakamoto R, Tambara EM. Estudo comparativo de eficácia e segurança entre 
propofol e midazolam durante sedação para colonoscopia. Rev Col Bras Cir $2010 ; 37(1): 10-6$.

25. Tam WWS, Wong ELY, Twinn SF. Effect of music on procedure time and sedation during colonoscopy: A meta-analysis. World J Gastroenterol 2008; 14(34): 5336-43.

26. Bytzer P, Lindeberg B. Impact of a precolonoscopy information video on patient satisfaction and anxiety - a randomized trial. Endoscopy 2007; 39: $710-14$

27. Seyle H. Stress: a tensão da vida. Ibrasa - SP 1959.

28. Lazarus RS, Folkman S. Stress, appraisal, and coping. New York: Springer 1984.

29. Savoia MG, Santana, PR, Mejias, NP. Adaptação do inventário estratégias de coping de Fokman e Lazarus para o português. Psicol USP 1996; $7(1 / 2): 183-201$.

30. Souza J.N, Chaves E.C, Caramelli P. Coping em idosos com doença de Alzheimer. Rev Latino-Am Enfermagem 2007; 15(1):93-99.

31. Antoniazzi AS, Dell'Aglio DD, Bandeira DR. O conceito de coping: uma revisão teórica. Estudos de Psicologia 1998; 3(2): 273-94.

32. Ribeiro J, Santos C. Estudo conservador de adaptação do Ways of Coping Questionnaire: a uma amostra e contexto portugueses. Aná. Psicológica 2001; 19(4): 491-50.

33. Costa ALS. Processos de enfrentamento de estresse e sintomas depressivos em pacientes portadores de retocolite ulcerativa idiopática [tese 
de doutorado]. São Paulo: Universidade de São Paulo, Escola de Enfermagem 2003.

34. Brasil. Resolução 196/96. Inciso VII do artigo $1^{\circ}$ do Decreto $\mathrm{n}^{\circ}$ 99.438, de 7 de agosto de 1990 .

35. Cohen S, Karmack T, Mermelsteinm R. A global measure of perceived stress. J Health Soc Behav 1983;24(4):385-96.

36. Luft CB, Sanches SO, Mazo GZ, Andrade A. Versão brasileira da Escala de Estresse Percebido: tradução e validação para idosos. Rev Saúde Pública 2007; 41(4): 606-15.

37. Reis RS, Hino AAF, Añez CRR. Perceived Stress Scale: reliability and validity study in Brazil. J Health Psychol 2010; 15(1): 107-14.

38. Cronbach LJ. Coefficient alpha and the internal structure of tests. Psychometrika 1951; 16: 297-334.

39. Neter J, Kutner MH, Nachtsheim CJ, Li W. Applied Linear Statistical Models. McGraw-Hill/Irwin 2004; 5: 1373.

40. LoBiondo-Wood G, Haber J. Pesquisa em Enfermagem.Guanabara Koogan 2001; 4.

41. Polit DF, Beck CT, Hungler BP. Fundamentos de Pesquisa em Enfermagem. São Paulo: Artmed 2004; 4.

42. Santos CHM, Cury MS; Saad FT. Principais achados de colonoscopias realizadas em caráter de urgência e eletivas. Rev Bras Coloproct 2009; 29(1): 083-087.

43. Walsh JME, Terdiman JP. Colorectal cancer screening - scientific review. JAMA 2003; 289(10): 1288-1290. 
44. Bechtold ML, Puli SR, Othman MO, Bartalos CR, Marshall JB, Roy PK. Effect of music on patients undergoing colonoscopy: a meta-analysis of randomized controlled trials. Dig Dis Sci 2009; 54:19-24.

45. Bytzer P, Lindeberg B. Impact of a precolonoscopy information video on patient satisfaction and anxiety. Endoscopy 2007; 39: 710-714.

46. Condon A, Graff L, Elliot L, Ilnyckyj A. Acceptance of colonoscopy requires more than test tolerance. Can J Gastroenterol 2008;22(1):41-47.

47. Tam WWS, Wong ELY, Twinn SF. Effect of music on procedure time and sedation during colonoscopy: A meta-analysis. World J Gastroenterol 2008; 14(34): 5336-5343.

48. Pearson S, Maddern GJ, Hewett P. Interacting effects of preoperative information and patient choice in adaptation to colonoscopy. Dis Colon Rectum 2005; 48(11):2047-54.

49. Monfared MH, Talaie R, Zojaji H, Dadashzadeh N, Derakhshan F, Zali MR. Impact of sedation use on patient anxiety and satisfaction during Colonoscopy. Gastroenterology and Hepatology From Bed to Bench 2008; $1(2): 65-69$.

50. Lee EY, Mun MS, Lee SH, Cho HSM. Perceived stress and gastrointestinal symptoms in nursing students in Korea: a cross-sectional survey. BMC Nursing 2011;10:22.

51. Leung DYP, Tai-hing L, Chan SSC. Three versions of Perceived Stress Scale: validation in a sample of Chinese cardiac patients who smoke. BMC Public Health 2010; 10:513. 
52. Wang Z, Chen J, Boyd JE, Zhang H, Jia X, et al. Pyschometric properties of the Chinese version of perceived stress scale in policeman. PLOS ONE 2011; (6):12.

53. Luft CDB, Sanches SO, Mazo GZ, Andrade A. Versão brasileira da Escala de Estresse Percebido: tradução e validação para idosos. Rev Saúde Pública 2007; 41(4): 606-615.

54. Oliveira SCM, Pinto-Neto AM, Conde DM, et al. Prevalência e fatores associados à constipação intestinal em mulheres na pós-menopausa. Arq Gastroenterol 2005; 42(1):24-29.

55. Gallegos-Orozco JF, Foxx-Orenstein AE, Sterler SM, Stoa JM. Chronic constipation in the elderly. Am J Gastroenterol 2012; 107:18-25.

56. Victoria CR, Sassak LY, Nunes HRC. Incidence and prevalence rates of inflammatory bowel diseases, in midwestern of São Paulo State, Brazil. Arq Gastroenterol 2009;46(1):20-25.

57. Dong WP, Oh YLMD, Sung GS, et al. The differences in prevalence and sociodemographic characteristics of irritable bowel syndrome according to Rome II and Rome III. J Neurogastroenterol Motil 2010; 16(2): 186-193.

58. Brambilia E, Dal Ponte MA, Buffon VR, Fellini RT, Dal Bosco A, May RS. Aderência ao controle colonoscópico nos pacientes submetidos à ressecção endoscópica de adenomas. Rev bras Coloproct 2006; 26(3): 249252.

59. Malheiros APR, Teixeira MG, Habr-Gama A, Alacantara PSM. Resultados do tratamento cirúrgico do câncer colo-retal em doentes de idade até 64 anos e de 65 anos ou mais. Rev bras Coloproct 2005; 25(2):128-136. 
60. Ferriolli E, Moriguti JC. Envelhecimento do aparelho digestório. In: Freitas EV, et al. Tratado de geriatria e gerontologia. Guanabara Koogan 2002; 376-379.

61. Almeida FFN, Araújo SEA, Santos FPS, Franco CJ, Santos VR, Nahas SC, Habr-Gama A. Colorectal cancer screening. Rev Hosp Clin Fac Med S Paulo 2000; 55(1):35-42.

62. Borum ML. Colorectal cancer screening. Primary Care 2001; 28:66174.

63. So WKW, et al. Colorectal cancer screening behaviour and associated factors among Chinese aged 50 and above in Hong Kong e A populationbased survey. European Journal of Oncology Nursing 2011; 287-291.

64. Arora A, Singh P. Colonoscopy in patients 80 years of age and older is safe, with high success rate and diagnostic yield. Gastrointest Endosc 2004; 60(3):408-13.

65. Karajeh MA, Sanders DS, Hurlstone DP. Colonoscopy in elderly people is a safe procedure with a high diagnostic yield: a prospective comparative study of 2000 patients. Endoscopy 2006; 38 (3): 226-230.

66. Instituto Brasileiro de Pesquisa e Estatística. Ministério da Educação. Rio de Janeiro (Brasil): IBGE; 2011.

67. Chor D, et al. Medidas de rede e apoio social no estudo pró-saúde: pré-testes e estudo piloto. Cadernos de Saúde Pública 2001; 17(4): 87-896.

68. Nicolussi AC, Sawada NO. Fatores que influenciam a qualidade de vida de pacientes com câncer de cólon e reto. Acta Paul Enferm 2010;23(1): 125-30. 
69. Aragão EIS, Vieira SS, Alves MGG, Santos AF. Suporte Social e Estresse: uma revisão de literatura. Psicologia em foco 2009: 2(1).

70. Borelli FAO, Souza MG, Passarelli O, Pimenta E, Gonzaga C, Cordeiro A, Lotaif L, Amodeo C. Hipertensão arterial no idoso: importância em se tratar. Rev Bras Hipertens 2008; 15(4):236-239.

71. Arditi C, Peytremann-Bridevaux I, Burnand B, Eckardt VF, Bytzer P, Agréus L, Dubois RW, Vader JP, Froehlich F, Pittet V, Schusselé Filliettaz S, Juillerat P, Gonvers JJ; EPAGE II Study Group. Appropriateness of colonoscopy in Europe (EPAGE II): Screening for colorectal cancer. Endoscopy 2009; 41: 200-208.

72. Butterworth AS, Higgins JPT, Pharoah P. Relative and absolute risk of colorectal cancer for individuals with a family history: a meta-analysis. Eur J Cancer 2006; 42: 216-227.

73. Johns LE, Houlston RS. A systematic review and meta-analysis of familial colorectal cancer risk. Am J Gastroenterol 2001; 96: 2992-3003.

74. Cottet V, Pariente A, Nalet B, Lafon J, Milan C, Olschwang S, Bonaiti-Pellié C, Faivre J, Bonithon-Kopp C; ANGH Group. Colonoscopic screening of first-degree relatives of patients with large adenomas: increased risk of colorectal tumors. Gastroenterology 2007; 133(4): 1086-1092.

75. Pignone M, Rich M, Teutsch S, Berg AO, Lohr KN. Screening for colorectal cancer in adults at average risk: a summary of the evidence for the U.S. Preventive Services Task Force. Ann Intern Med 2002; 137:132-41.

76. Brasil. Ministério da Saúde. Fundação Nacional de Saúde. Centro Nacional de Epidemiologia. Sistema de Informações sobre Mortalidade (SIM). Disponível em: http://www.datasus.gov.br. 
77. Brasil. Ministério da Saúde. Secretaria de Assistência à Saúde. Instituto Nacional de Câncer. Falando sobre câncer do intestino / Instituto Nacional de Câncer, Sociedade Brasileira de Coloproctologia, Colégio Brasileiro de Cirurgiões, Associação Brasileira de Colite Ulcerativa e Doença de Crohn, Colégio Brasileiro de Cirurgia Digestiva, Sociedade Brasileira de Endoscopia Digestiva, Sociedade Brasileira de Cancerologia, Sociedade Brasileira de Oncologia Clínica. INCA 2003.

78. Adachi M, Ryan P, Collopy B, Fink R, Mackay J, Woods R, Okinaga K, Muto T, Moriaka Y. Adenoma-carcinoma sequence of the large bowel. Aust N Z J Surg 1991;61:409-14.

79. Winawer S, Fletcher R, Rex D, Bond J, Burt R, Ferrucci J, Ganiats T, Levin T, Woolf S, Johnson D, Kirk L, Litin S, Simmang C, Gastrointestinal Consortium Panel. Colorectal cancer screening and surveillance: clinical guidelines and rationale - Update based on new evidence. Gastroenterolgy $2003 ; 124: 544-60$.

80. Perez RO, Proscurshim I, Julião GPS, Picolo M, Gama-Rodrigues J, Habr-Gama A. Screening of colorectal cancer in a brazilian town preliminary results. Arq Bras Cir Dig 2008; 21(1):12-5.

81. Young J, Jass JR. The case for a genetic predisposition to serrated neoplasia in the colorectum: hypothesis and review of the literature. Cancer Epidemiol Biomarkers Prev 2006; 15(10):1778-84.

82. Burt R, Jass JR. Hyperplastic polyposis. In: Hamilton SR, Aaltonen LA, editors. Pathology and genetics of tumours of the digestive system. Lyon: IARC Press 2000; 135-6.

83. Australian Cancer Network Colorectal Cancer Guidelines Revision Committee: Guidelines for the Prevention, Early Detection and Management 
of Colorectal Cancer. Sydney: The Cancer Council Australia and Australian Cancer Network 2005.

84. Castiglione G, Visioli CB, Zappa M, Grazzini G, Mallardi B, Mantellini P. Familial risk of colorectal cancer in subjects attending an organized screening programme. Dig Liver Dis 2012; 44(1):80-83.

85. Sam $M$ et al. Lifestyle and dietary risk factors for colorectal hyperplastic and adenomatous polyps. Cancer Epidemiol Biomarkers Prev. 2012; 21(3):563.

86. U.S. Preventive Services Task Force. Screening for colorectal cancer: recommendation and rationale. Ann Intern Med 2002;137:129-31.

87. Manzione CR. Oral bowel preparation with bisacodil and $10 \%$ lactulose solution for elective colonoscopy. Rev Bras Coloproct 2000:20(2): 91-94.

88. Lessmann JC, Guerreiro DM, Silva V, Nassar JM. Relações entre estresse e hábitos de saúde em mulheres com diabetes mellitus tipo 2. Universidade Federal de Santa Catarina 2011.

89. Sims R, Gordona S, Garcia W, Clarka E, Monyea D, Callenderb C, Campbella A. Perceived stress and eating behaviors in a community-based sample of African Americans. Eat Behav 2008; 9(2): 137-142.

90. Andreou E, Alexopoulos EC, Lionis C, Varvogli L, Vargogli L, Gnardellis C, Chrousos GP, Darviri C. Perceived Stress Scale: reliability and validity study in Greece. Int J Environ Res Public Health 2011; 8(8):32873298 .

91. Padulla SAT, Burneiko RCVM, Bortolatto CR, Maeda FL, Morimoto J, et al. Tempo de hemodiálise relacionado ao nível de estresse e depressão 
em pacientes do Instituto do Rim da Santa Casa de Misericórdia de Prudente. Revista Eletrônica de Fisioterapia da FCT/UNESP 2009;1(1).

92. Calais SL, Andrade LMB, Lipp MEN. Stress entre calouros e veteranos de jornalismo. Estudos de Psicologia 2007; 24: 69-77.

93. Neuber LMB, Neme CMB, Rodrigues JRP, Pessoa EC, Kamiya CP, Vespoli HML, Uemura. Aspectos psicossociais e afetivo-conjugais em mulheres com e sem câncer da mama. Revista Brasileira de Mastologia 2007; $17: 156-162$.

94. Neme CMB, Lipp MEN. Estresse psicológico e enfrentamento em mulheres com e sem câncer. Psicologia: Teoria e Pesquis 2010; 26(3): 475483.

95. Wang JJ, Snyder M, Kaas M. Stress, Ioneliness and depression in Taiwanese rural community-dwelling elders. Int J Nurs Stud 2001; $38(3): 339-47$.

96. Faria AMDB, Cardoso CL. Aspectos psicossociais de acompanhantes cuidadores de crianças com câncer: stress e enfrentamento. Estudos de Psicologia 2010; 27(1):13-20.

97. Menezes CNB, Passareli PM, Drude FS, Santos MA, Valle ERM. Câncer infantil: organização familiar e doença. Revista Mal Estar e Subjetividade 2007; 7(1):191-201.

98. Porcu M, Scantamburlo VM, Albrecht NR, Silva SP, Vallim FL, Araujo CR, et al. Estudo comparativo sobre a prevalência de sintomas depressivos em idosos hospitalizados, institucionalizados e residentes na comunidade. Acta Scientiarum 2002; 24(3):713-717. 
99. Ramos MP. Apoio social e saúde entre idosos. Sociologias, Porto Alegre 2002; 4(7):156-175.

100. Aragão EIS, Vieira SS, Alves AMG, Santos AF. Suporte Social e Estresse: uma revisão de literatura. Psicologia em foco 2009; 2(1).

101. Cicirelli VG. Family support in relation to health problems of the elderly. In T.H. Brubaker (ed.), Family relationships in later life. Newbury Park 2001; 212-228.

102. Seidl EMF, Zannon CMLC, Tróccoli BT. Pessoas vivendo com HIV/AIDS: Enfrentamento, suporte social e qualidade de vida. Psicologia: Reflexão e Crítica 2005; 18(2):188-195.

103. Morgan J, Roufeil L, Kaushik S, Bassett M. Influence of coping style and precolonoscopy information on pain and anxiety of colonoscopy. Gastrointest Endosc 1998; 48(2):119-27.

104. Lichtenstein GR, Cohen LB, Uribarri J. Review article: bowel preparation for colonoscopy - the importance of adequate hydration. Aliment Pharmacol Ther 2007; 26(5):633-641. 
ANEXOS 
"Nunca nada grandioso no mundo foi feito sem uma grande dose de paixão." Georg Wilhelm Friedrich Hegel

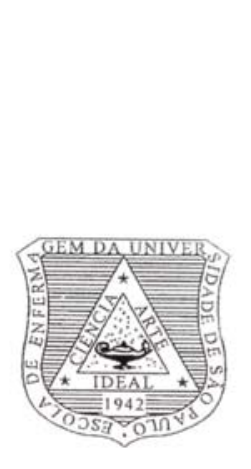

\author{
ANEXO I \\ UNIVERSIDADE DE SÄO PAULO \\ ESCOLA DE ENFERMAGEM \\ Av. Dr. Enéas de Carvalho Aguiar, 419 - CEP 05403-000 \\ Tel.: (011) 3061-7548/8858 - Fax: (011) 3061-7548 - \\ Săo Paulo - SP - Brasi \\ e-mail: edipesq@usp.br
}

São Paulo, 08 de abril de 2011.

Ilm. ${ }^{a} \mathrm{Sr}{ }^{\mathrm{a}}$

Prof. ${ }^{\mathrm{a}}$ Dr. ${ }^{\mathrm{a}}$ Ana Lucia Siqueira Costa

Ref:: Processo $n^{\circ}$ 1011/2011/CEP-EEUSP

Prezada Senhora,

Em atenção à solicitação referente à análise do projeto "Estresse e estilo de coping dos pacientes em período de pré-procedimento colonoscópico", informamos que o mesmo foi considerado aprovado pelo Comitê de Ética em Pesquisa da Escola de Enfermagem da Universidade de São Paulo (CEP/EEUSP).

Analisado sob o aspecto ético-legal, atende às exigências da Resolução $\mathrm{n}^{\circ}$ 196/96 do Conselho Nacional de Saúde.

Esclarecemos que após o término da pesquisa, os resultados obtidos deverão ser encaminhados ao CEP/EEUSP, para serem anexados ao processo.

Atenciosamente,

Prof. ${ }^{a}$ Dr. ${ }^{a}$ Célia Maria Sivalli Campos

Coordenadora do Comitê de Ética em Pesquisa da

Escola de Enfermagem da Universidade de São Paulo 


\title{
ANEXO II
}

\section{प1}

São Paulo, 17 de fevereiro de 2011.

\author{
À Câmara de Pesquisa da Comissão de Ensino e Pesquisa e \\ Ao Comitê de Ética em Pesquisa \\ Hospital Universitário da Universidade de São Paulo
}

Senhores Coordenadores,

O projeto de pesquisa "Estresse e estilo de coping dos pacientes em período de pré procedimento colonoscópico", cujo investigador principal é a Profa. Aná Lúcia Siqueira Costa, a ser realizado nas dependências do Hospital Universitário da USP (HUUSP), foi considerado exeqüivel pela Divisão de Enfermagem de Pacientes Externos (Mestrado - aluna: Camila Cristine Antonietti).

Como o investigador principal não pertence ao Hospital Universitário a responsável pelo projeto será a Enfa. Rejane Siqueira Neto.

Declaro que esta Diretoria e o responsável pelo projeto têm conhecimento dos procedimentos da Universidade de Säo Paulo no que se refere à excelência científica exigida, às caracteristicas da revisão anônima por pares e aos termos da Resolução 196/96 do Conselho Nacional de Saúde e suas Resoluções complementares.

Nestes termos, estaremos sempre à disposição da Câmara de Pesquisa e do Comitê de Ética em Pesquisa para dirimir qualquer dúvida que surja no decorrer da análise do presente projeto.

Atenciosamente,

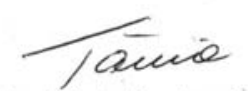

Enfa. Dra. Tânia Regina Sancinetti Diretor de Divisão

Departamento de Enfermagem COREN SP 12.672 
ANEXO III

\section{UNIVERSIDADE DE SÃO PAULO}

ESCOLA DE ENFERMAGEM

\section{PROGRAMA DE PÓS-GRADUAÇÃO - MESTRADO EM ENFERMAGEM}

Cada questão deste instrumento é referente a seus pensamentos e sentimentos, desde o dia em que foi feita a solicitação do procedimento colonoscópico. Em cada questão, por favor, indique com um $\mathrm{X}$ qual a frequência do sentimento ou pensamento.

$0=$ Nunca $1=$ Quase nunca $2=$ Às vezes $3=$ Quase sempre $\quad 4=$ Sempre

Após a data do agendamento do procedimento colonoscópico, com que frequência...

\begin{tabular}{|l|l|l|l|l|l|}
\hline 1. Você tem ficado triste por causa de algo que aconteceu inesperadamente? & 0 & 1 & 2 & 3 & 4 \\
\hline 2. Você tem se sentido incapaz de controlar as coisas importantes em sua vida? & 0 & 1 & 2 & 3 & 4 \\
\hline 3. Você tem se sentido nervoso e "estressado"? & 0 & 1 & 2 & 3 & 4 \\
\hline $\begin{array}{l}\text { 4. Você tem se sentido confiante em sua habilidade de resolver problemas } \\
\text { pessoais? }\end{array}$ & 0 & 1 & 2 & 3 & 4 \\
\hline $\begin{array}{l}\text { 5. Você tem sentido que as coisas estão acontecendo de acordo com a sua } \\
\text { vontade? }\end{array}$ & 0 & 1 & 2 & 3 & 4 \\
\hline $\begin{array}{l}\text { 6. Você tem achado que não conseguiria lidar com todas as coisas que você tem } \\
\text { de fazer? }\end{array}$ & 0 & 1 & 2 & 3 & 4 \\
\hline $\begin{array}{l}\text { 7. Você tem conseguido controlar as irritações em sua vida? } \\
\text { 8. Você tem sentido que as coisas estão sob seu controle? }\end{array}$ & 0 & 1 & 2 & 3 & 4 \\
\hline $\begin{array}{l}\text { 9. Você tem ficado irritado porque as coisas que acontecem estão fora de } \\
\text { controle? }\end{array}$ & 0 & 1 & 2 & 3 & 4 \\
\hline $\begin{array}{l}\text { 10. Você tem sentido que as dificuldades acumulam-se a ponto de você } \\
\text { acreditar que não pode superá-las? }\end{array}$ & 0 & 1 & 2 & 3 & 4 \\
\hline
\end{tabular}




\author{
ANEXO IV \\ UNIVERSIDADE DE SÃO PAULO \\ ESCOLA DE ENFERMAGEM \\ PROGRAMA DE PÓS-GRADUAÇÃO - MESTRADO EM ENFERMAGEM
}

\title{
QUESTIONÁRIO DE ESTRATÉGIAS DE COPING
}

A seguir vai encontrar um conjunto de afirmações que se referem a várias estratégias utilizadas para lidar com situação de estresse referente ao procedimento colonoscópico. Assinale a frequência com que utilizou cada uma das estratégias indicadas, de acordo com a seguinte escala:

\section{0 - Nunca usei 1 - Usei de alguma forma 2 - Usei algumas vezes 3 - Usei muitas vezes}

\begin{tabular}{|c|c|c|c|c|}
\hline $\begin{array}{l}\text { 1. Concentrei-me apenas na situação e no que deveria ser feito, para em seguida, } \\
\text { pensar no próximo passo para resolver o problema. }\end{array}$ & 0 & 1 & 2 & 3 \\
\hline $\begin{array}{l}\text { 2. Fiz alguma coisa em que eu acreditava, mesmo que não pudesse dar resultados, mas } \\
\text { ao menos eu estava tentando fazer alguma coisa. }\end{array}$ & 0 & 1 & 2 & 3 \\
\hline 3. Tentei encontrar a pessoa responsável pelo problema para mudar a sua opinião. & 0 & 1 & 2 & 3 \\
\hline $\begin{array}{l}\text { 4. Conversei com outras pessoas sobre o problema, procurando mais esclarecimentos } \\
\text { sobre a situação. }\end{array}$ & 0 & 1 & 2 & 3 \\
\hline 5. Critiquei-me e repreendi-me. & 0 & 1 & 2 & 3 \\
\hline $\begin{array}{l}\text { 6. Tentei não fazer nada que fosse definitivo para resolver o problema, e procurei mais } \\
\text { informações sobre ela. }\end{array}$ & 0 & 1 & 2 & 3 \\
\hline 7. Agi como se nada tivesse acontecido. & 0 & 1 & 2 & 3 \\
\hline 8. Procurei guardar os meus sentimentos para mim mesmo. & 0 & 1 & 2 & 3 \\
\hline 9. Tentei olhar para os pontos mais favoráveis do problema. & 0 & 1 & 2 & 3 \\
\hline 10. Dormi mais do que normal. & 0 & 1 & 2 & 3 \\
\hline 11. Mostrei a raiva que sentia para as pessoas que causaram o problema. & 0 & 1 & 2 & 3 \\
\hline 12. Aceitei a simpatia e a compreensão das pessoas. & 0 & 1 & 2 & 3 \\
\hline 13. A situação levou-me a fazer algo positivo. & 0 & 1 & 2 & 3 \\
\hline 14. Procurei esquecer a situação desagradável que estava acontecendo. & 0 & 1 & 2 & 3 \\
\hline 15. Procurei ajuda profissional. & 0 & 1 & 2 & 3 \\
\hline 16. Mudei ou cresci como pessoa de uma maneira positiva. & 0 & 1 & 2 & 3 \\
\hline 17. Desculpei ou fiz alguma coisa para compensar os danos. & 0 & 1 & 2 & 3 \\
\hline
\end{tabular}




\begin{tabular}{|c|c|c|c|c|}
\hline 18. Fiz um plano de ação para resolver o problema e consegui. & 0 & 1 & 2 & 3 \\
\hline 19. De alguma forma extravasei meus sentimentos. & 0 & 1 & 2 & 3 \\
\hline 20. Compreendi que o problema foi provocado por mim. & 0 & 1 & 2 & 3 \\
\hline 21. Saí da experiência melhor do que eu esperava. & 0 & 1 & 2 & 3 \\
\hline 22. Falei com alguém que poderia fazer alguma coisa concreta sobre o problema. & 0 & 1 & 2 & 3 \\
\hline 23. Enfrentei o problema como um grande desafio e fiz algo muito arriscado & 0 & 1 & 2 & 3 \\
\hline 24. Procurei não fazer nada apressadamente ou seguir meu primeiro impulso. & 0 & 1 & 2 & 3 \\
\hline 25. Encontrei novas crenças. & 0 & 1 & 2 & 3 \\
\hline 26. Redescobri o que é importante na vida. & 0 & 1 & 2 & 3 \\
\hline 27. Modifiquei aspectos da situação para que tudo desse certo no final. & 0 & 1 & 2 & 3 \\
\hline 28. Procurei fugir das pessoas em geral. & 0 & 1 & 2 & 3 \\
\hline 29. Não deixei me impressionar, me recusava a pensar muito sobre a situação. & 0 & 1 & 2 & 3 \\
\hline 30. Procurei um amigo ou parente para pedir conselhos. & 0 & 1 & 2 & 3 \\
\hline 31. Não deixei que os outros soubessem da verdadeira situação. & 0 & 1 & 2 & 3 \\
\hline 32. Minimizei a situação me recusando a preocupar-me seriamente com ela. & 0 & 1 & 2 & 3 \\
\hline 33. Falei com alguém sobre como estava me sentindo. & 0 & 1 & 2 & 3 \\
\hline 34. Recusei recuar e batalhei pelo que eu queria. & 0 & 1 & 2 & 3 \\
\hline 35. Descontei minha raiva em outra pessoa. & 0 & 1 & 2 & 3 \\
\hline 36. Busquei nas experiências passadas uma situação similar. & 0 & 1 & 2 & 3 \\
\hline $\begin{array}{l}\text { 37. Eu sabia o que deveria ser feito, portanto, dobrei meus esforços para fazer o que } \\
\text { fosse necessário. }\end{array}$ & 0 & 1 & 2 & 3 \\
\hline 38. Prometi que as coisas serão diferentes na próxima vez. & 0 & 1 & 2 & 3 \\
\hline 39. Encontrei algumas soluções diferentes para o problema. & 0 & 1 & 2 & 3 \\
\hline $\begin{array}{l}\text { 40. Procurei não deixar que meus sentimentos interferissem muito nas outras coisas } \\
\text { que eu estava fazendo. }\end{array}$ & 0 & 1 & 2 & 3 \\
\hline 41. Mudei alguma coisa em mim, modifiquei-me de alguma forma. & 0 & 1 & 2 & 3 \\
\hline 42. Desejei que a situação acabasse ou que de alguma forma desaparecesse. & 0 & 1 & 2 & 3 \\
\hline 43. Tinha fantasias de como as coisas iriam acontecer, como se encaminhariam. & 0 & 1 & 2 & 3 \\
\hline 44. Rezei. & 0 & 1 & 2 & 3 \\
\hline 45. Analisei mentalmente o que fazer e o que dizer. & 0 & 1 & 2 & 3 \\
\hline $\begin{array}{l}\text { 46. Pensei em uma pessoa que admiro e em como ela resolveria a situação e a tomei } \\
\text { como modelo. }\end{array}$ & 0 & 1 & 2 & 3 \\
\hline
\end{tabular}




\section{APÊNDICES}


"Mude seus pensamentos e você mudará seu mundo" Norman Vincent

\section{APÊNDICE I \\ UNIVERSIDADE DE SÃO PAULO \\ ESCOLA DE ENFERMAGEM}

\section{Termo de Consentimento livre e esclarecido para a pesquisa}

Título do Projeto: "Percepção de estresse e o estilo de coping dos pacientes em período pré procedimento colonoscópico"

Pesquisador Responsável: Profa. Dra. Ana Lúcia Siqueira Costa

Co-autora: Mestranda Camila Cristine Antonietti

Instituição/Departamento: Universidade de São Paulo - Escola de Enfermagem

Local da coleta de dados: Hospital Universitário de São Paulo.

Prezado(a) Senhor(a):

- Você está sendo convidado(a) a responder às perguntas deste formulário de forma totalmente voluntária.

- Antes de concordar em participar desta pesquisa e responder este formulário, é muito importante que você compreenda as informações e instruções contidas neste documento.

- Os pesquisadores deverão responder todas as suas dúvidas antes que você decida participar da pesquisa.

- Você poderá ter acesso, a qualquer momento, às informações sobre procedimentos, riscos e benefícios relacionados à pesquisa, inclusive para esclarecimentos de eventuais dúvidas.

- Você tem o direito de desistir de participar da pesquisa a qualquer momento, caso surja algum desconforto ou desinteresse ao longo da sua participação, sem que haja nenhum prejuízo durante o período de seu tratamento na Instituição.

- Nada será cobrado pela sua participação, assim como, não haverá remuneração financeira caso decida pela sua participação. 
Objetivo do estudo: Identificar os estressores e mecanismos de enfrentamento ao estresse entre os pacientes em pré-exame de colonoscopia no Serviço de Endoscopia do Hospital Universitário.

Procedimentos: Após a sua autorização, a sua participação nesta pesquisa consistirá nas respostas de alguns questionários para avaliar a sua percepção de estresse e mecanismos de enfrentamento utilizados para o alívio do estresse, bem como realizar a coleta de dados sóciodemográficos e clínicos. Os questionários serão respondidos após a consulta de enfermagem e anteriormente ao início do preparo para o procedimento colonoscópico. Os questionários serão respondidos no período máximo de uma hora e todas as informações obtidas serão analisadas em conjunto com as de outros voluntários, não sendo divulgada a identificação do paciente sob nenhuma hipótese. Os dados serão analisados e divulgados em eventos de caráter científico e em publicações da área da saúde.

Benefícios. Esta pesquisa permitirá conhecer o impacto do estresse e as estratégias utilizadas pelos pacientes para lidar com o estresse. Sendo o estresse nessas ocasiões um fator desencadeante de alterações na saúde, os resultados deste estudo permitirão propor programas de intervenção que visem à qualidade de vida desses pacientes.

Riscos. O preenchimento deste formulário não representará nenhum risco.

Sigilo. As informações fornecidas por você serão confidenciais e de conhecimento apenas dos pesquisadores responsáveis. Os sujeitos da pesquisa não serão identificados em momento algum, mesmo quando os resultados desta pesquisa forem divulgados em qualquer forma.

O senhor(a) tem o direito de ser mantido atualizado sobre os resultados parciais da pesquisa que sejam de conhecimento dos pesquisadores e, caso seja constatada alterações importante dos resultados, o senhor(a) será encaminhado para atendimento no HU/USP, segundo o critério de assistência do mesmo (hospital de atendimento secundário) e me comprometo a encaminhá-lo a esse serviço para atendimento especializado.

Garantimos ao senhor(a) acesso, em qualquer etapa do estudo, aos profissionais responsáveis pela pesquisa para esclarecimentos de eventuais dúvidas. O principal pesquisador é a Dra. Ana Lucia Siqueira Costa que poderá ser encontrada na Av. Dr. Enéas de Carvalho Aguiar, n. 419, Cerqueira César, CEP 05403-000 Tel.: (11) 3061.7544 - Fax: 3061.7546 - São Paulo - SP, e co-autora é a Mestranda Camila Cristine Antonietti, que 
poderá ser encontrada no mesmo endereço mencionado anteriormente, e, no email: cantonietti@usp.br.

Se você tiver alguma consideração ou dúvida sobre a ética da pesquisa, entre em contato com o Comitê de Ética em Pesquisa do Hospital Universitário (CEP- HU) no mesmo endereço Av. Prof. Lineu Prestes, 2565 - Cidade Universitária - CEP: 05508-000 - São Paulo - SP - Telefone: 3091-9457 - Fax: 3091-9452 - email: cep@hu.usp.br

Este termo será preenchido em duas vias, sendo que uma ficará sobre os seus cuidados e outra com a pesquisadora responsável.

Declaro que, após convenientemente esclarecido pelo pesquisador e ter entendido o que me foi explicado, consinto em participar do presente Projeto de Pesquisa.

São Paulo, de 2011.

Assinatura do sujeito pesquisado ou Responsável Legal

Nome do pesquisado:

$\mathrm{N}^{\circ}$ do RG:

Data de nascimento:

Endereço e telefone para contatos posteriores:

Assinatura do pesquisador Escola de Enfermagem - USP 
APÊNDICE II

UNIVERSIDADE DE SÃO PAULO

ESCOLA DE ENFERMAGEM

PROGRAMA DE PÓS-GRADUAÇÃO - MESTRADO EM ENFERMAGEM

ROTEIRO PARA ENTREVISTA - LEVANTAMENTO BIOSSOCIAIS DE DADOS DOS PACIENTES ATENDIDOS NA UNIDADE DE ENDOSCOPIA FORMULÁRIO N ${ }^{\mathrm{O}}$

Nome do paciente:

Número de registro do SAME:

DADOS DE IDENTIFICAÇÃO

\begin{tabular}{|c|c|c|}
\hline Gênero: & ( ) feminino & ( ) masculino \\
\hline Estado civil & $\begin{array}{l}\text { ( ) solteiro } \\
\text { ( ) divorciado } \\
(\quad) \text { amasiado }\end{array}$ & $\begin{array}{l}\text { ( ) casado } \\
\text { ( ) viúva/o }\end{array}$ \\
\hline Idade: & anos & \\
\hline Tem filhos? & ( ) sim. Quantos? & ( ) não \\
\hline \multicolumn{3}{|l|}{ Até que ano estudou? } \\
\hline \multicolumn{3}{|l|}{ Qual a sua profissão? } \\
\hline \multicolumn{3}{|l|}{ Qual a sua religião? } \\
\hline \multicolumn{3}{|c|}{ DADOS CLÍNICOS } \\
\hline Histórico pessoal & $\begin{array}{l}\text { ( ) doenças cardio- } \\
\text { pulmonares/ quais: } \\
\text { ( ) alteração sistema } \\
\text { circulatório. quais: } \\
\text { ( ) hipertensão } \\
\text { ( ) diabetes } \\
\text { ( ) alterações gastro- } \\
\text { intestinais/quais: }\end{array}$ & $\begin{array}{l}\text { ( ) histórico de neoplasias } \\
\text { pessoais ou familiar } \\
\text { presença de alergia } \\
\text { medicações em uso: }\end{array}$ \\
\hline
\end{tabular}




\begin{tabular}{|l|l|l|}
\hline Quantas vezes você fez esse exame? & $\begin{array}{l}\text { ( ) } 1 \\
\text { ( ) } 3\end{array}$ & $\begin{array}{l}\text { ( ) } 2 \\
\text { ( ) } 4 \text { ou mais }\end{array}$ \\
\hline $\begin{array}{l}\text { Qual o principal motivo da realização } \\
\text { da colonoscopia? }\end{array}$ & $\begin{array}{l}\text { ( ) sangramento retal } \\
\text { ( ) anemia } \\
\text { ( ) alteração do hábito } \\
\text { intestinal } \\
\text { ( ) doença inflamatória } \\
\text { intestinal } \\
\text { ( ) diarréia } \\
\text { ( ) emagrecimento } \\
\text { ( ) histórico familiar de } \\
\text { câncer de intestino } \\
\text { ( ) biópsias/ remoção de } \\
\text { pólipos } \\
\text { ( ) obstrução intestinal }\end{array}$ & $\begin{array}{l}\text { ( ) rotina pós-operatória de } \\
\text { ( ) dor abdominal } \\
\text { ( ) rastreamento de } \\
\text { neoplasias } \\
\text { ( ) fistula reto-vaginal } \\
\text { ( ) massa abdominal }\end{array}$ \\
( ) exame de prevenção \\
( ) outros:
\end{tabular}

